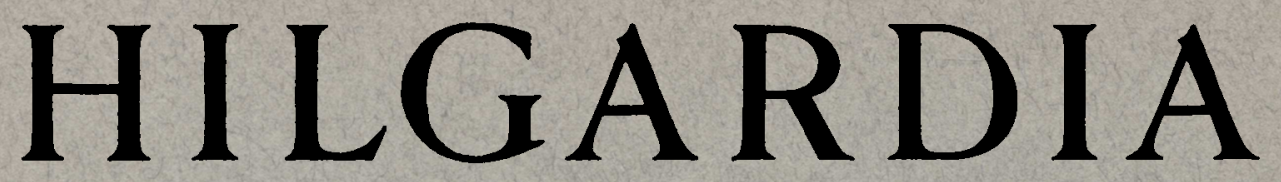

A Journal of Agricultural Science Published by the California Agricultural Experiment Station

CONTENTS

\title{
OUTLINE OF AMPELOGRAPHY FOR THE VINIFERA GRAPES IN CALIFORNIA
}

FREDERIC T. BIOLETTI 


\title{
$\begin{array}{llllllllll}H & \text { I } & \text { L } & G & A & R & D & \text { I } & \text { A }\end{array}$
}

A Journal of Agricultural Science Published by

the California Agricultural Experiment Station

\begin{tabular}{lll}
\hline VoL. 11 & JUNE, 1938 & No. 6 \\
\hline
\end{tabular}

\section{OUTLINE OF AMPELOGRAPHY FOR THE VINIFERA GRAPES IN CALIFORNIA ${ }^{1}$}

\author{
FREDERIC T. BIOLETTI ${ }^{2}$
}

\section{INTRODUCTION}

THE WORD "AMPELOGRAPHY" by its derivation from ampelos-vine-and graphe-writing-means the description of vines. In actual modern usage it is usually confined to what may be called the horticultural description of grapes. It differs both in purpose and material from botanical description. The taxonomic botanist deals with species, each consisting of a group of like plants which are more similar to one another than to the members of any other species; the horticultural ampelographist deals principally with variations among seedlings of the same species.

The species of the botanist is a group of like individuals, usually seedlings; the variety of the ampelographist is a single individual-the clone - or the totality of all the plants derived by vegetative propagation from a single seedling ${ }^{3}$ and constituted therefore simply of parts of the same individual. The variations of the seedlings of a species in nature are comparatively rare and tend to disappear in competition with the type most suited to the environment. Under culture, any of these variations which are found desirable by man are propagated and preserved and in time may become very numerous.

In their Ampelographie, Viala and Vermorel ${ }^{4}$ list 24,000 names and synonyms of grapes representing about 5,000 varieties, derived principally from one species, Vitis vinifera. Hedrick in his Grapes of New

${ }^{1}$ Received for publication April 6, 1937.

${ }^{2}$ Professor of Viticulture, Emeritus.

"Or in rare cases from a "bud sport" or mutation.

4 Viala, P., and V. Vermorel. Ampelographie. 7 vols. 3,146 p. Masson et Cie, Paris, France. 1901-1910. 
York $^{5}$ lists 1,200 varieties, mostly hybrids of $V$. labrusca and $V$. vinifera; and Ravaz in his Vignes americaines ${ }^{6}$ lists several hundred, mostly grafting stocks obtained by the hybridizing of several American species. Undoubtedly many hundreds, if not thousands, of vinifera varieties of Anatolia, Syria, Armenia, the Caucasia, Persia, Turkestan, Afghanistan, North Africa, and other regions are not included and would probably increase the number of named and cultivated varieties of vinifera to well over 6,000 .

Purposes of Ampelography. - The classification of vine varieties has two more-or-less distinct objects, which are confused by some ampelographists. One is to group the varieties naturally, that is, in accordance with origin or genetic relationship, and the other is to group them in such a way that the classification will have a practical use in the identification of varieties. The first is the object of the botanist, the second that of the horticulturist.

Since these objects differ, if they are to be attained, the methods must differ also. In defining and limiting a group of individuals which he calls a species, the botanist notes only the special characters which each and all of these individuals possess in common, and carefully excludes all the variations between individuals which he considers to indicate mere varieties within the same species group. Now as these varieties constitute the main interest of the horticultural ampelographist, the variations which distinguish them and which the systematic botanist neglects in the characterization of the species, are his main preoccupation. The result is, or should be, that the ampelographical description of a grape variety emphasizes and is confined to exactly those characters which for the purpose of the taxonomist are of minor importance.

Horticultural ampelography consists of the description of varieties of vines (Euvitis and Muscadinia). Its purposes are:

1. To give information regarding the characters, uses, and requirements of the various varieties.

2. To aid in the identification of these varieties.

To accomplish these purposes, the varieties must first be described fully, then classified in accordance with the descriptions in such a way that a key can be constructed which will lead to the description by which a variety is to be identified and its characters known. (See table 1 and p. 233.)

Classifications.-Many writers have given attention to the description

${ }^{5}$ Hedrick, U. P. Grapes of New York. New York State Dept. of Agr. Fifteenth Annual Rept. Vol. 3, Part II. 564 p. 1908.

${ }^{8}$ Ravaz, L. Vignes americaines. 376 p. C. Coulet et fils. Montpellier, France. 1902. 
and classification of vine varieties, from Magon the Carthagenian about 250 B.C., and Columella in the first century A.D., to Odart, Pulliat, and Viala and Vermorel in France, Goethe in Germany, and Rovasenda and Molon in Italy in modern times, to mention but a few of the best known. During the last hundred years, dozens of classifications have been proposed which are well reviewed by G. Molon in his Ampelografia.

Some of these classifications are called "natural," notably that of Simon Clemente de Rojas y Clemente, ${ }^{8}$ and divide the grapes into orders, tribes, families, and varieties, to each of which is given a Latin name. These classifications are based on the methods of the taxonomic botanist but fail to unite varieties according to descent or relationship, about which little is known, or to unite them into groups of horticulturally similar individuals; and they are of little use as keys for the identification of varieties.

The most useful classifications are frankly artificial, having for their sole object the identification of varieties by leading to the correct name and description. For this purpose the chief indications used are the gross characters of the fruit-berries and cluster-and of the leaves and growing shoots and of the mature vine with its canes, trunk, and roots.

To use characters taken from all of these various parts of the vine would require examination of the trunk and canes in winter, the shoots in spring, the leaves in summer, and the fruit in autumn. This would increase the difficulty and decrease the utility of the system. Characters, all of which can be seen at the same time, are essential for many of the chief uses of a horticultural classification. The only part of the vine which generally supplies a sufficient number of distinguishing characters is the mature fruit, and this is the basis of most of the modern systems of classification as far as they are used for the construction of a key. This key is intended to lead to the full description, where these and numerous other characters are used to distinguish each variety from the other varieties in the same class.

The principal purposes of a horticultural description are two-foldfirst, to determine the correct name of a variety; and second, to indicate its value for a particular use. No description alone can accomplish either of these purposes completely. All it can do in most cases is to narrow the choice by elimination so that by comparison and experience a correct conclusion may be reached.

This is because every character that can be used in describing a vine

${ }^{7}$ Molon, G. Ampelografia. 1243 p. Milan, Italy. 1906.

${ }^{8}$ Rojas y Clemente, Simon Clemente de. Ensayo sobre las variedades de la vid commun que vegetan en Andalucia. Madrid, Spain. 1879. 
fluctuates considerably, is influenced by environmental conditions, and overlaps. For an extreme example : an Emperor grape is nearly black in the north-coast region, red in the southern San Joaquin Valley, and almost without color in the Coachella Valley. In the same way, size, form, texture, flavor, and even relative time of ripening vary with conditions sufficiently to overlap minor, though often very important, differences in these respects.

In describing a variety or using a description, these facts should be recognized.This does not mean, however, that the description of a variety is impossible or useless. It simply means that every character fluctuates about a mode, which may be considered the property of the normal grape or leaf or whatever part is described.

The mode is, however, sometimes less valuable for the characterization of a variety than the perfect form, when this can be found and recognized. The berry will vary in form according to its nourishment. If stunted by competition with the other berries of too large a crop, it will not reach its perfect form. The color will vary greatly with the temperature and the amount of sunshine it receives. For the purposes of classification, the deepest color attained by the variety may be considered perfect or normal for that variety though it may not be the most desirable, as with the Emperor and the Flame Muscat.

The leaf will likewise vary in form according to the kind of nourishment it receives. If growing on a sucker with a high nitrogen-to-carbohydrate ratio, it will be more deeply lobed than is usual. If supplied with a low nitrogen-to-carbohydrate ratio, the sinuses between the lobes may be much reduced. (See fig. 1.)

The characteristic form is that recognized as most common where the variety is best known. With observations and experience, this characteristic form may usually be distinguished. For example, the shape of the normal or perfect berry of the Flame Tokay (Ahmeur-bou-Ahmeur) is very distinct, being that of a hemisphere at the stalk end and of a half barrel at the lower. Yet spherical, oval, and somewhat elongated Tokay berries may often be found on the same cluster. By examining a sufficient number of berries on well-developed clusters, however, it is not hard to determine the normal or characteristic form of the berry of this variety. (See figs. $2, K$, and $3, K$.)

All systems of classifying vines commence by dividing them into large groups on the basis of some character which differs for each group. Each of these large groups is then subdivided into smaller groups on the basis of some other varying character, and these smaller groups on the basis of another varying character and so on. However far this subdivision 
can be carried practically, the end result will be a number of groups each consisting of a number of varieties. The number of varieties in a final group may be small but is usually fairly large. The individuals of each final group are then differentiated by means of as complete a description of each individual as is practically possible or necessary.

The first division into groups can be used for the construction of a key by which a variety that is being studied can be traced to its place in

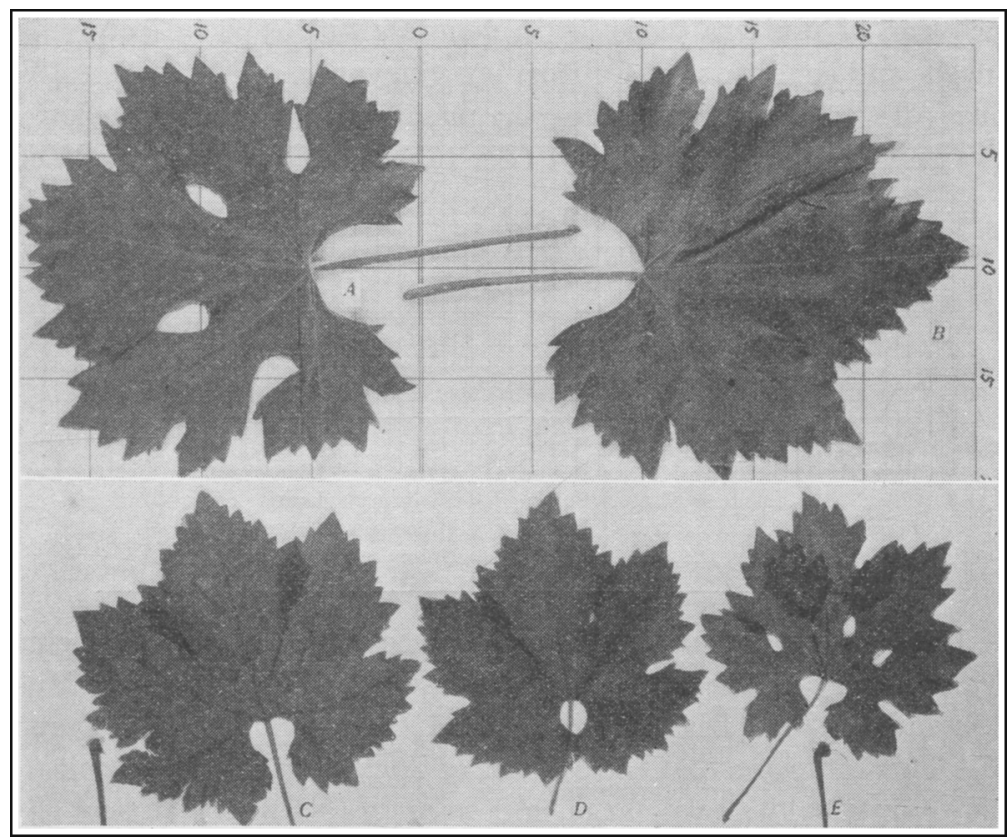

Fig. 1.-Fluctuations in leaf outline on the same vine: $A$ and $B$, Burgrave, $A$ being the usual form; $C-E$, Zinfandel, $D$ being the usual form.

the system. A comparison of its characters with the full description of its associates in this place is then used to determine its name and group. For large final groups a supplementary key is often useful.

Too much should not be expected of this process. It is almost useless in the hands of a beginner or of one unfamiliar with a large number of varieties. To one whose experience with vines has made him familiar with their differences and who can distinguish with confidence a considerable number of varieties, it is very useful in bringing him to a probably correct decision as to the identification of a variety which is new to him. Certainty of identification of an unfamiliar variety can be attained in most cases, however, even by the expert, only by actual comparison of the 
variety with a specimen whose genuineness is guaranteed by its origin. Good colored illustrations of the variety are a great help but cannot give the certainty of living specimens.

\section{A PROPOSED CLASSIFICATION OF VINIFERA VARIETIES}

A complete ampelography even of a single species is beyond the scope of this sketch. All that is attempted here, therefore, is to discuss what seems the best practical classification, for use as a key, and for the horticultural description of vinifera varieties in general, with especial reference to the needs and conditions of Californian vineyards.

$K e y$. - The characters used for the primary classification, or key, are all drawn from the mature berry. (See table 1.) The scheme outlined in

TABLE 1

Key for Grape Varieties Based on Gross Characters OF THE BERRY

\begin{tabular}{|c|c|c|c|c|}
\hline Character & 1 & 2 & 3 & $\begin{array}{c}\text { Number } \\
\text { of } \\
\text { groups }\end{array}$ \\
\hline Color....... & White & Red & Black & 3 \\
\hline Form $\ldots, \ldots, \ldots, \ldots, \ldots$ & Round & Oval & Elongate & 9 \\
\hline Size $\ldots \ldots \ldots \ldots$ & Small & Medium & Large & 27 \\
\hline Period........ & Early & Midseason & Late & 81 \\
\hline Flavor $\ldots \ldots \ldots \ldots \ldots \ldots \ldots$ & Neutral & Aromatic & Muscat & 243 \\
\hline
\end{tabular}

table 1 makes it possible to indicate the place of a variety in the primary classification by means of a number of five digits, for example, Muscat of Alexandria 12323, Black Corinth 31111, Gros Colman 31331, Emperor 32331. This indicates that the Muscat of Alexandria is to be looked for in the group of white, oval, large, midseason grapes with a Muscat flavor. This would be almost sufficient to locate it exactly without further description. The digits following Black Corinth indicate that it is a black, round, small, early grape of neutral flavor. In this group it would find many associates, but reference to the fuller description would quickly reveal its correct name by its very small size and its seedlessness. Similarly the Gros Colman would be traced to the group of black, round, large, late grapes of neutral flavor, where it would be found in company with Black Morocco, Gros Maroc, and many others, from some of which, other characters, including those of the leaves, would be necessary to distinguish it.

The next example shows a difficulty with this system and, indeed, with any proposed system of classifying grapes. The first digit indicates that the Emperor is black, ${ }^{9}$ which is true in certain soils and climates. In other

"See discussion of color terms, p. 234. 
conditions and in most localities where it is grown commercially in California, however, it is dull red. This can be indicated by an alternate number in parenthesis-Emperor 3(2)2331. This might lead to two color groups, in either of which it should be found.

Complete Description.-The fuller description of a variety to which the key leads should give more precise information regarding the berry characters and also of any other characters of the fruit, especially those in which it is peculiar. These will include some or all of the following:

Skin: Texture, bloom, astringency

Pulp: Texture, color, special flavor

Seeds: Presence, number, size, shape, texture, astringency

Cluster: Size, form, density

Stem: Size, form, texture

Pedicel: Size, brush, torus, adherence

A still fuller description is in many cases necessary, covering characters of the vegetative parts of the vine. The most useful are :

Leaves: Size, form, color, texture, indument (hairiness)

Shoots: Color and indument, vigor and succulence

Tendrils: Size, branching

Canes: Length, thickness, texture, color, internodes

Buds : Size, prominence, form, color, indument

General characters of the vine: Vigor, size, bark of trunk, habit, ${ }^{10}$ soil adaptation, susceptibility to disease, productivity

\section{DISCUSSION OF CHARACTERS}

All the characters which can be used in describing or classifying vines are continuous in their variation, not discrete. That is to say, whatever definite terms are used to describe the variations of a character will not apply exactly to all cases. It is always possible that cases will occur where the variation of the character falls between two adjacent terms. For example, if berries are divided by size into small, medium, and large, however these terms are defined, it will in many cases be difficult to decide whether the berries of a certain variety are small or medium, or of another variety, medium or large. Two intermediate classes, smallmedium and large-medium, may be made, but the difficulty, though lessened, still remains. There will be found cases in which it is uncertain whether the berries should be called large or large-medium, and so forth. This difficulty occurs with form, color, period of ripening, and all other characters that can be used.

Any descriptive term in a biological classification therefore indicates

${ }^{10}$ The direction of growth-port (carriage) of the French ampelographists. 
not an absolute or discrete character but a region or approximate position in a continuous series.

There is much difference of opinion and practice among ampelographers as to how many divisions or terms should be made for each character. Lucas in 1874 divided all grapes into five color classes-green, yellow, gray, red, and blue; the Commission of Ampelography in 1875 reduced these classes to two-colored and white. Comte Odart in 1848 classified grapes according to the amount of heat necessary to ripen the fruit, making seven groups; Lucas in 1874 reduced these groups to three-early, medium, and late.

The most convenient and useful method seems to be to use in the primary classification for a general key a tripartite division for all characters where this is feasible and then for supplementary keys to use intermediate classes. For the full description it is best to use in each case the terms which give the clearest picture of the characters of the particular variety, taking care that none of these terms conflict with those used in the primary classification.

\section{THE FRUIT}

The fruit of the vine is of the type called by botanists a "berry," which is defined as "a several-carpellate, several-seeded, fleshy fruit with a pericarp, entirely soft." This definition excludes the strawberry, blackberry, and raspberry, which are typical berries in the popular use of the term, but includes gooseberries, cranberries, and red currants. The berries are borne on a branching stem in a cluster of the form known botanically as a compound raceme, or panicle.

Color Classes.-The colors of ripe grapes vary with different varieties from an almost pure chlorophyll-green through yellow, pink, red, purple, to almost black.

The primary division adopted is into three general classes, white, red, and black. Probably no grape exists which can be accurately described by any of these terms, but they serve well to make a general grouping into grapes with light or little color, grapes with dark or much color, and grapes which are intermediate in this respect. This grouping, with the intermediate subclasses, is as follows:

\begin{tabular}{lll}
\multicolumn{1}{c}{ 1. WHITE } & 2. RED & \multicolumn{1}{c}{3 BLACK } \\
Green & Pink & Dull red \\
Yellowish green & Light red & Purple \\
Yellow & Bright red & Reddish black \\
Golden-yellow & Brick-red & Bluish black
\end{tabular}

These terms do not exhaust the color possibilities. The presence of 
more or less bloom on the skin may modify any of them, and lead to the qualification of "gray" or "grizzly" - for example, Gray Riesling, Grizzly Frontignan, Chauché Gris. Grapes may be parti-colored, as with very ripe grapes bronzed on the sunny side, or may be striped like Zabalkanski; or yellowish grapes may become pinkish when overripe, like Semillon.

Color of Wine Grapes.-An account of the value and utility of grape varieties used for manufacturing purposes requires special consideration of the color.

The color of a table grape is the impression we receive from a surface view of the unbroken fruit. It is the effect of the coloring matter in the skin modified by the overlying bloom. Since these two factors have mutually opposing effects on the intensity of the color and modifying effects on its quality, the apparent color is an unreliable measure of the amount and character of the pigmentation of the whole grape.

The color of grapes to be used for juice, wine, or other manufacturing purposes is characterized and measured by the kind and amount of color that can be extracted from the whole grape by maceration, heating, fermentation, or any similar manufacturing process. It differs among varieties in hue (quality), in brightness (quantity), and in stability (durability).

The Salleron colorimeter ${ }^{11}$ is a convenient means of measuring the color. The grapes are crushed thoroughly and heated to $80^{\circ} \mathrm{C}\left(175^{\circ} \mathrm{F}\right)$ with frequent stirring, and then allowed to cool. The colored juice is then extracted by pressing and filtered for the test. Ten tints are recognized, VR (violet red), 1VR, 2VR, 3VR, 4VR, 5VR, R (red), 1R, 2R, 3R. These are represented by disks of satin, prepared by the Gobelins Factory. The colored juice is compared with these disks.

The color of the new wine or extracted juice of fresh, sound grapes, except for a few varieties, such as Grignolino, lies in the violet-red range of this series, usually near the top. With time and oxidation, the color declines toward the red range. The change of color through the series consists of slight additions of yellow.

The intensity is determined by the depth of colored juice necessary to equal the intensity of the standard disks and is expressed by a number representing this depth. The more intense the color, therefore, the smaller the number. To facilitate comparisons, Hilgard inverted this order so that the numbers of the Hilgard scale ${ }^{12}$ vary directly with the intensity

\footnotetext{
"Dujardin, J. Notice sur les instruments de précision appliqués à l'oenolgie. 5th ad. p. 555-62. Chez les Auteurs, 24 rue Pavée, Paris. 1923.

${ }^{12}$ Bioletti, Frederic T. A new method of making dry red wine. California Agr. Exp. Sta. Bul. 177:8-11. 1906.
} 
of color. The 100 of Hilgard's scale corresponds to the 40 of Salleron's and represents the color intensity of a dark-red wine. The Hilgard number is obtained by dividing 4,000 by the Salleron number.

For the purposes of the winemaker, the intensity of the color is of the most importance, for it affects most notably the character of the wine. A suitable classification of intensity using the Hilgard scale is that shown in table 2.

The locality has a notable effect on the amount of coloring matter. In the hot arid regions of the interior valleys, the color is low ; in the warm,

TABLE 2

COLOR OF THE JUICE OR WiNe OF RED GRAPES

\begin{tabular}{|c|c|c|c|}
\hline Class & Color index, limits & Description & Color intensity \\
\hline 1 & $0-14$ & Very light & Less than one-quarter of the required amount \\
\hline 2 & $15-29$ & Light & About half of the required amount \\
\hline 3 & $30-49$ & Medium & $\begin{array}{l}\text { About the amount of color usually required for wine or } \\
\text { juice }\end{array}$ \\
\hline 4 & $50-89$ & Heavy & About twice the required amount \\
\hline 5 & $90-149$ & Very heavy & About three times the required amount \\
\hline 6 & $>150$ & Excessive & Coloring wines \\
\hline
\end{tabular}

semiarid southerly coast counties, it is somewhat higher; in the foothills of the Sierra at 2,000 feet elevation, it is still higher; while in the cooler northerly grape-growing counties nearer the coast but sheltered from the ocean fogs, the color intensities reach their maximum. In areas of still lower temperature, there is not sufficient heat for the grapes to attain full maturity, and the color intensities remain low. When the same varieties are compared and the means are reduced to percentages, the average variation due to locality in these regions is :

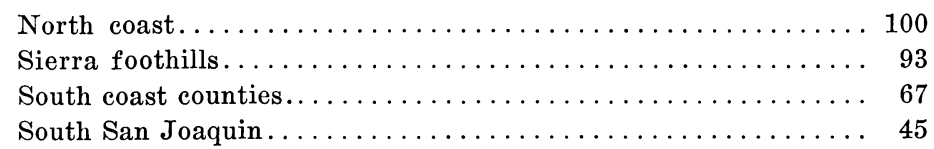

Form of Berry.-The normal or usual form of most wild grapes is spherical or slightly oval. Most cultivated wine grapes show little variation from this form. Table grapes, however, have been highly selected in this respect and vary from the form of a ball to that of a pickle, with many variations and irregularities between these extremes.

Few grapes have a perfect geometrical form, but geometrical forms are the most convenient means of representing groups, as they suggest well the real forms. As in the case of colors, it seems best to use common words which cover a certain range of ideas for the general groups and 
more precise terms for the subgroups and descriptions. The classification suggested is as follows :

Round:

A. Spherical-Gros Colman, Chasselas

$B$. Oblate-White Corinth, Palomino

Oval, short:

C. Ellipsoidal-Madeleine Celine, Malaga

D. Cylindroidal-Dizmar, Ohanez

$E$. Ovoid-Emperor, Diamond Jubillee

$F$. Obovoid-Muscat of Alexandria, Purple Damascus

Oval, Long:

G. Ellipsoidal-Citronelle

$H$. Cylindroidal-Khandahar, Monukka

I. Ovoid-Zabalkanski, Burgrave

$J$. Obovoid-Hunisa, Alloued Zeine

Irregular :

$K$. Truncate-Ohanez, Flame Tokay

L. Pointed-Alulu

$M$. Fusiform-Olivette blanche

$N$. Falcoid-Cornichon

o. Falcoid elongated-Pizzutello

The photographs of berries grown in the Davis variety collection shown in figure 3 are examples of real forms approximating the diagrammatic forms of figure 2, and the letters on both correspond with the list above.

The descriptive terms given above are intended for the characteristic form of the variety, but owing to the large fluctuations of form with the same variety and in the same cluster, it is not always easy to determine this form. For example, the most common form of the berry of the Sultanina in California is short ovoid. The form of the best-developed berries, however, is often short or medium-long cylindroidal. This form appears, however, only in clusters where the berries are loose and on well-nourished vines. In most cases, the berries are so numerous and so crowded in the cluster that they do not attain their symmetrical form, but are distorted. This difficulty occurs frequently with nearly all varieties of peculiar or unusual form-for example, the Flame Tokay, the Rish Baba, and the Ohanez.

Where the form is extreme, there is always much variation in the berries, even on the same cluster, due to differences in degree of development. Figure 4 is a photograph of eleven berries from the same cluster of Pizzutello and shows berries that would be called variously falcoid (more or less elongated), ellipsoidal (elongated or short), obovoid, and fusiform. Yet a glance at a well-developed cluster from which these ber- 
ries were taken (see fig. $3, O$ ) will indicate the elongated falcoid (fig. $2, O)$ as the characteristic and usual form. This form is associated with a single seed, as is illustrated by the sections of the berries at the right of the top row of figure 4 . When the berry contains two seeds, as in the berries of the second row, it becomes fusiform. This may perhaps be considered a better-developed berry, but it is rare in this variety and

Sizes

Mean dia. in centimeters

Mean weight in grams

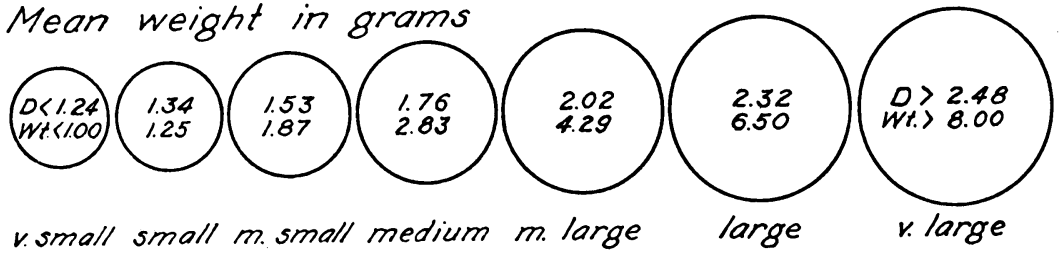

Forms
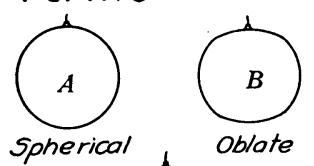

oblate
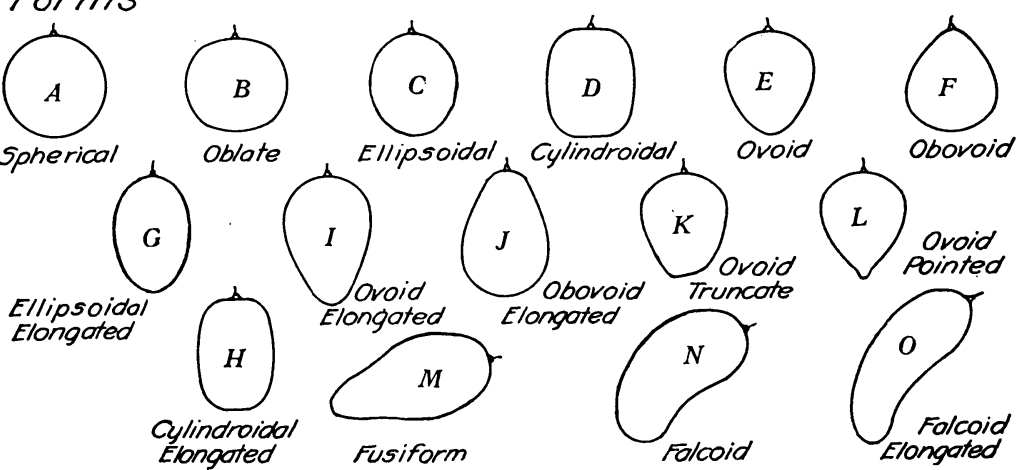

Cylindroidal

Obovoid

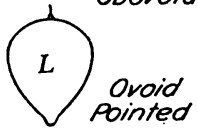

Fig. 2.-Sizes $(\times 0.8)$ and forms $(\times 0.6)$ of grape berries-diagrammatic. Compare lettered section with correspondingly lettered berries in figure 3 .

therefore not characteristic. The bottom row shows elongated ellipsoidal imperfect berries which have produced no seed.

A similar case is shown in figure 5, which is a photograph of four berries of Olivette blanche before and after splitting longitudinally. The berry at the upper left-hand corner $(A)$ is fusiform and may be taken as characteristic since it is both the most usual and associated with the best-developed fruit. It contains four seeds. Berry $B$ contains only three seeds and tends to be falcoid by a smaller development of the side containing only one seed. Berry $C$, which contains only two seeds, becomes regular but changes to long ellipsoidal by a diminished development of both sides. Finally, berry $D$, with only one seed, is still less developed 


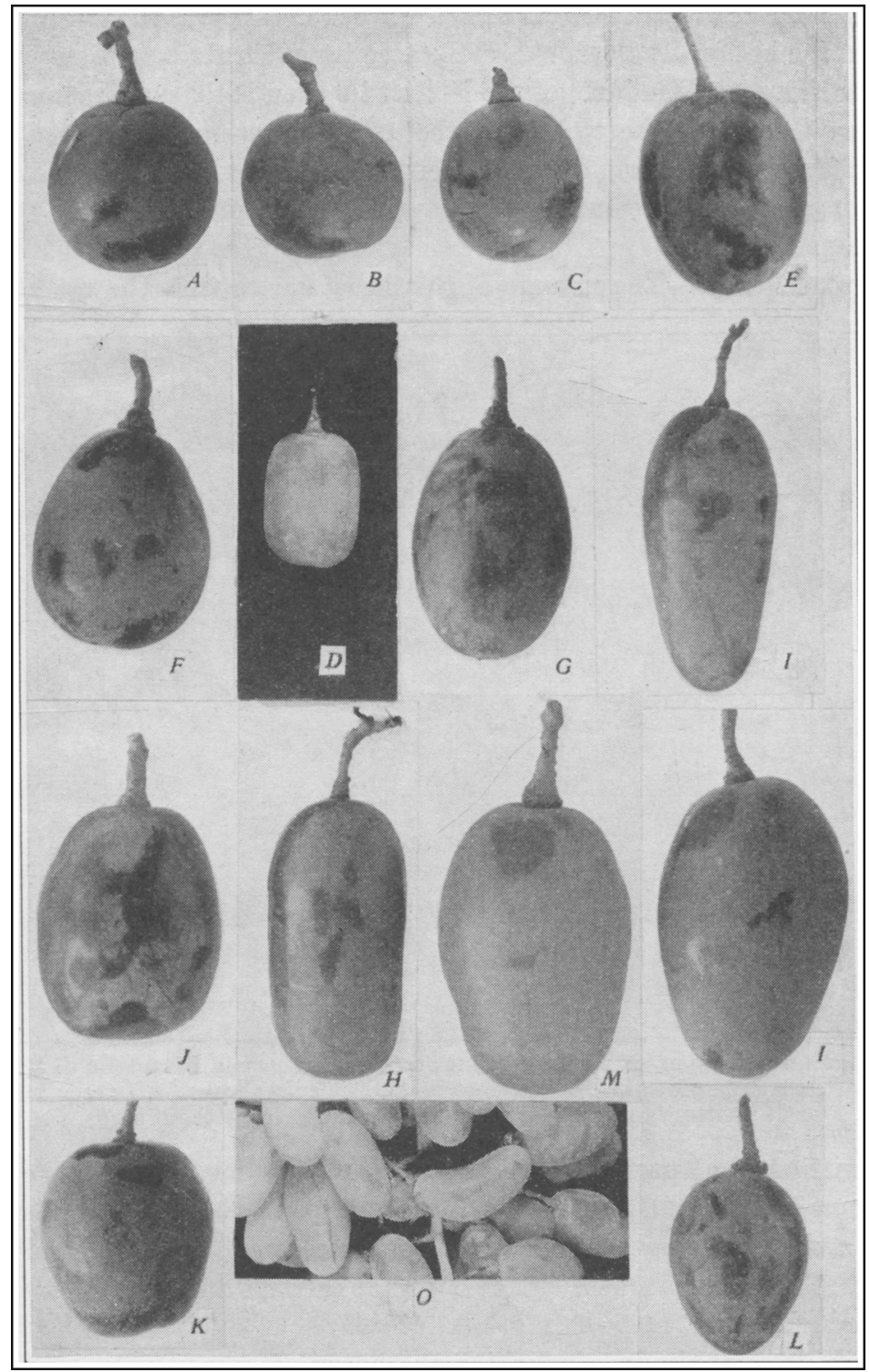

Fig. 3.-Berries represented by the idealized forms of figure 2. (Reductions various.) See classification on page 237 . 
and becomes elongated ovoid with a slight tendency to the falcoid form due to the better development of the side in which the seed lies.

The characteristic form of the Pizzutello then is that of the most-common well-developed berry but not that of the rarer best-developed berry. The characteristic form of the Olivette blanche is also the most-common well-developed berry, but this berry with the Olivette blanche is the best developed.

Size of Berry.-The volume of the berry varies with the variety and

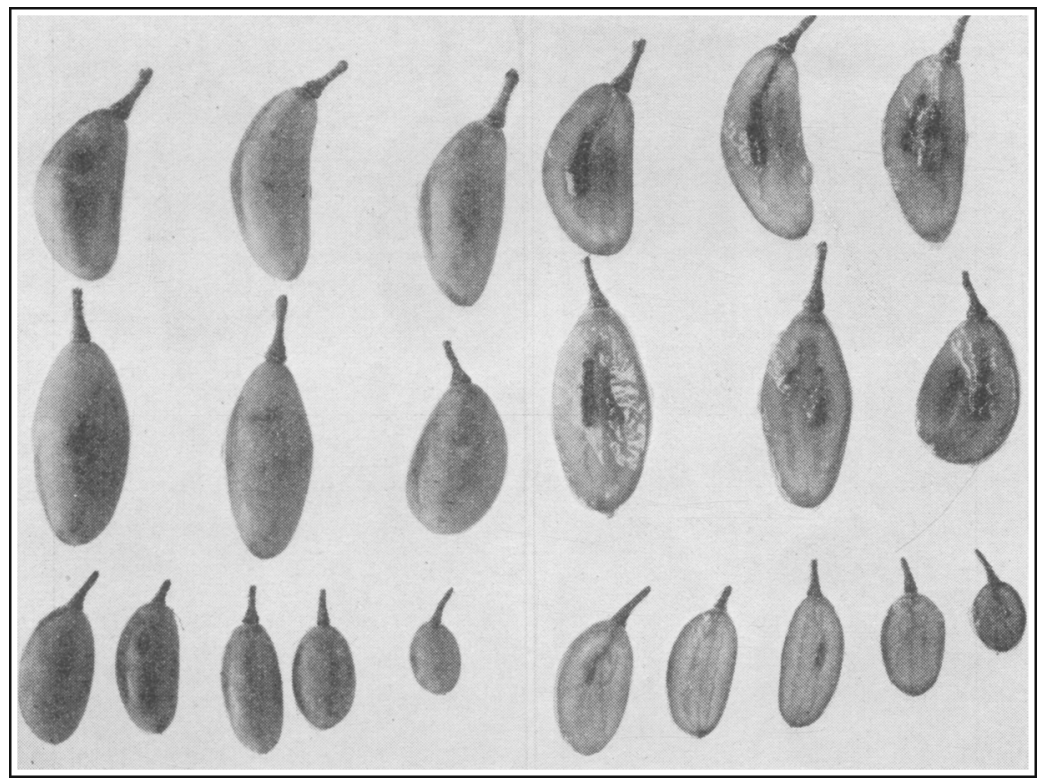

Fig. 4.-Effects of seed development on form of berry in Pizzutello di Roma: on left, whole berries; on right, the same berries split; top row, 1 seed; middle row, 2 seeds; bottom row, imperfectly developed berries without seeds. $(\times 0.5$.)

also with the cultural, climatic, and soil conditions. It varies between different berries on the same vine and in the same cluster. There is, however, a clearly recognized classification into small, medium, and large grapes. These terms must be understood as relative and with reference to local conditions.

There is a maximum size which the berry of any variety can attain under optimum conditions. This maximum is rarely attained and never by all the berries in a cluster. In stating the size of the berry of any variety some kind of average must be used. This may be the average size of the largest berries found on a good cluster or on a number of clusters grown under good conditions, or the average size of all the berries on a 
good cluster. The first average is perhaps the best for classification and the second for indicating the cultural value of the variety. The first is that adopted here for classification, the ten largest berries being taken from a cluster which shows a good normal development for the variety and for the region (Davis). A measure of the variability in size can be obtained from $W / w$, where $W=$ the mean weight of the ten largest berries and $w=$ the mean weight of all.

The size can be expressed in terms of diameter, of volume, or of weight.

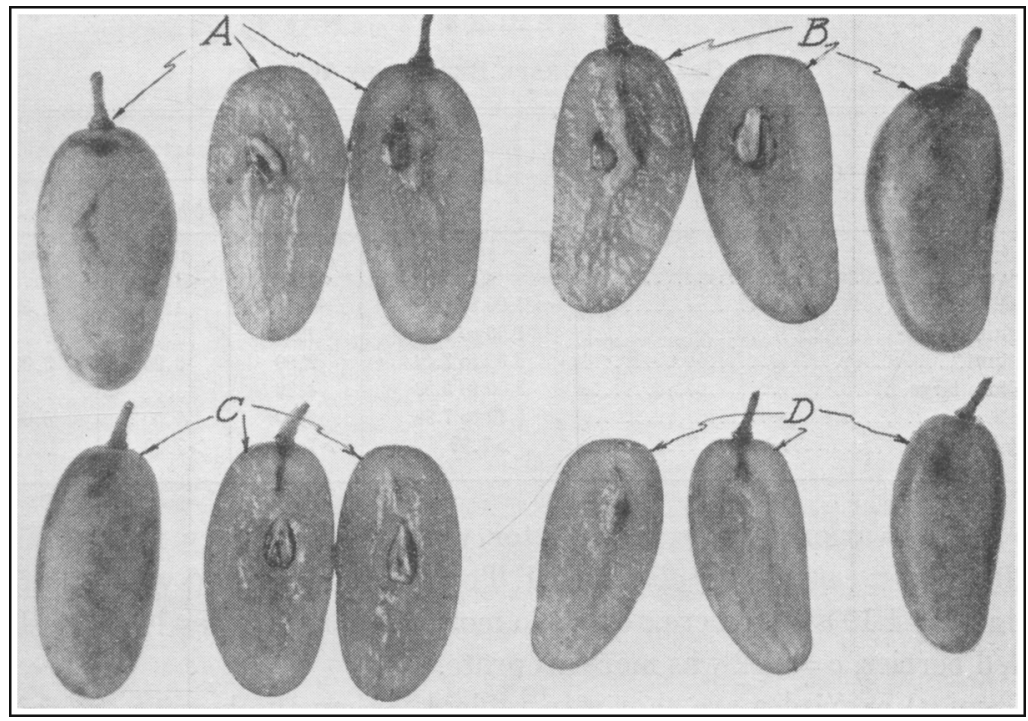

Fig. 5.-Variation of form due to number of seeds in Olivette blanche: $A$, 4 seeds ; $B, 3$ seeds; $C, 2$ seeds; $D, 1$ seed. ( $\times 0.6$.)

Weight gives the most accurate comparison and is the magnitude most easily determined. The determination of the volume is tedious and timeconsuming and would have no advantage over the weight. The transverse diameter or the mean of the transverse and longitudinal diameter is most generally used because it gives a clearer visual impression of the size. It is, however, misleading, owing to the variability of form. A spherical grape with a diameter of $20 \mathrm{~mm}$ would weigh about 4.2 grams, while an ovoid grape of the same transverse diameter might weigh 4.6 grams, an ellipsoidal grape 5.0 grams, and a cylindroidal grape 5.4 grams, if the longitudinal diameters of the last three were 24 millimeters.

Table 3 shows the classification adopted, and the upper row of figure 2 shows the relative size of the various classes.

The volume of a berry can be estimated, usually with the necessary de- 
gree of accuracy, from the two diameters..$^{13}$ If the transverse diameter is designated $2 a$ and the longitudinal diameter $2 b$, the most generally satisfactory results are given by the formula for a spheroid $4.19 a^{2} b$. For ovoid or obovoid berries with a distinctly attentuated end, the formula $4.19 a^{2}[1 / 2(a+b)]$ was found a little more accurate.

From this calculated volume the weight can be estimated by multiplying with a factor to allow for the specific gravity and the deviation of the berry from the exact geometric form. By trial with large numbers of

TABLE 3

Size Grades of Grape Berries by Weight

\begin{tabular}{|c|c|c|c|c|}
\hline \multirow{2}{*}{ Class } & \multirow{2}{*}{ Limits } & \multicolumn{3}{|c|}{ Approximate midvalues } \\
\hline & & 7 grades & 5 grades & 3 grades \\
\hline Very small. . & $\begin{array}{l}\text { grams } \\
<1.00\end{array}$ & $\underset{<1.00}{\operatorname{grams}}$ & $\underset{<1.00}{\operatorname{grams}}$ & grams \\
\hline Small............. & 1.00 to 1.49 & 1.25 & 1.50 & 1.50 \\
\hline Medium small... & 1.50 to 2.29 & 1.90 & & \\
\hline Medium.......... & 2.30 to 3.49 & 2.80 & 3.00 & 3.00 \\
\hline Medium large $\ldots \ldots \ldots \ldots \ldots \ldots \ldots \ldots \ldots \ldots \ldots$ & 3.50 to 5.29 & 4.30 & & \\
\hline 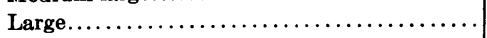 & 5.30 to 7.99 & 6.50 & 6.00 & 6.00 \\
\hline Very large $\ldots \ldots \ldots \ldots \ldots \ldots \ldots \ldots \ldots \ldots \ldots \ldots$ & $>7.99$ & $>7.99$ & $>7.99$ & $\ldots$ \\
\hline
\end{tabular}

berries of various forms, this factor was found to vary from 1.05 to 1.20, in most cases being close to 1.1. The formula adopted was therefore weight $=4.19 a^{2} b c$, where $c$ could in most cases be taken as 1.1. For elongated berries, $c=1.2$ was more accurate.

Typical examples are shown in table 4 . When the berries are fairly regular and not overripe (table 4, Nos. 1, 2,3), which is the general case, the value 1.1 for the factor $c$ gave an approximation quite sufficient for the purposes of size classification. When the berries vary in form (table 4 , No. 4), the value 1.2 gave a closer approximation. When the berries were overripe (Nos. 5 and 6 ), the value 1.2 was usually found best because of their higher specific gravity and perhaps also because of a slight systematic error in the diameter measurements, which were too low owing to the softened texture of the fruit.

Period of Ripening.- The date at which the grapes ripen depends on the variety, the climate, the condition of the vine, and the amount of crop.

${ }^{13}$ The method sometimes adopted of using the mean of the two diameters for size classification is misleading. It results in placing a spherical berry with a mean diameter of $\frac{(20+20)}{2}=20 \mathrm{~mm}$, and a volume of about $4.2 \mathrm{cc}$, in the same size class as an elongated berry with a mean diameter of $\frac{(28+12)}{2}=20 \mathrm{~mm}$, and a volume of only about $2.1 \mathrm{cc}$. 
It varies, therefore, not only with the nature of the variety, but with locality, season, and method of treatment. After making due allowance for these complicating factors, there remains, however, a tendency to ripen more or less early or late, which is a property of the variety.

Several ampelographers have proposed a classification according to the epoch or period of ripening. That of Pulliat ${ }^{14}$ has been the most generally used and seems the most convenient. He recognized five classes:

TABLE 4

Comparison of Actual Weight of Berry with Weight Calculated FROM DIAMETERS

\begin{tabular}{|c|c|c|c|c|c|c|c|}
\hline \multirow{2}{*}{ No. } & \multirow{2}{*}{ Variety } & \multirow{2}{*}{ Form } & \multirow{2}{*}{$\begin{array}{l}\text { Volume, } \\
\text { calcu- } \\
\text { lated* }\end{array}$} & \multirow{2}{*}{$\frac{\text { Wt. }}{\text { Vol. }}$} & \multirow{2}{*}{$\begin{array}{l}\text { Actual } \\
\text { weight }\end{array}$} & \multicolumn{2}{|c|}{$\begin{array}{l}\text { Calculated weight } \\
(W=V c)\end{array}$} \\
\hline & & & & & & $c=1.1$ & $c=1.2$ \\
\hline 1 & Chavushi..... & Cylindroid. . & $\begin{array}{l}c c \\
6.40\end{array}$ & 1.04 & $\begin{array}{l}\text { grams } \\
6.66\end{array}$ & $\begin{array}{r}\text { grams } \\
7.04 \dagger\end{array}$ & $\begin{array}{c}\text { grams } \\
7.68\end{array}$ \\
\hline 2 & Burgrave...... & Ovoid....... & 7.59 & 1.07 & 8.13 & 8.55 & 9.11 \\
\hline 3 & Rish Baba............ & Cylindroid........ & 5.51 & 1.13 & 6.23 & 6.06 & 6.61 \\
\hline 4 & Muscat gigas......... & Round (variable).. & 4.93 & 1.18 & 5.81 & 5.42 & 5.98 \\
\hline 5 & Diamond Jubilleeł. . . & Ellipsoid.......... & 7.33 & 1.17 & 8.61 & 8.06 & 8.80 \\
\hline \multirow[t]{2}{*}{6} & Gros Marocł.......... & Round............ & 5.32 & 1.19 & 6.34 & 5.85 & 6.38 \\
\hline & Means.......... & n.......... & 6.18 & 1.12 & 6.91 & 6.80 & 7.42 \\
\hline
\end{tabular}

* Calculated from the formula, $V=4.19 a^{2} b$, where $V=$ volume, $2 a=$ transverse diameter, and $2 b=$ longitudinal diameter.

$\dagger$ For each variety, weight is calculated with two values of $c$; the calculation that comes closest to the actual weight is italicized in each case.

$\ddagger$ Overripe.

I, II, III, and IV - each ripening 12 or 15 days after the preceding classand a fifth class which he called précoce, or very early.

Some have attempted to classify varieties in a similar way on the basis of the amount of heat necessary to bring the grapes to maturity. This avoids the uncertainty of dates, which differ greatly with region and location. The amount of heat is usually calculated by adding the mean temperature above $0^{\circ} \mathrm{C}$ of every day from the time of the starting of the buds to the full ripeness of the fruit. The necessary sum of temperature calculated in this way, according to Gasparin, ${ }^{15}$ ranges from $2,264^{\circ} \mathrm{C}$ $\left(4,075^{\circ} \mathrm{F}\right)$ for the earliest, to $5,000^{\circ} \mathrm{C}\left(9,000^{\circ} \mathrm{F}\right)$ for the latest varieties, while the intermediate classes are assigned intermediate sums in an irregular and apparently arbitrary way.

The temperature sum arrived at in this way is misleading because it assumes that all increments of temperature are of equal value for the

\footnotetext{
${ }^{14}$ Pulliat, V. Mille variétés de vignes-description et synonymies. 3rd ed. $414 \mathrm{p}$. Paris. 1888.

${ }^{15}$ Molon, G. Ampelografia. p. 1243. Milan, Italy. 1906.
} 
development of the vine. This leads to the fallacy that the temperature at Eureka, California, where no grapes will ripen, is more favorable than that of the Rheingau, where grapes are grown successfully. (See table 5.)

A better way is to reckon only the degrees of temperature above $10^{\circ} \mathrm{C}$ $\left(50^{\circ} \mathrm{F}\right)$, for this is about the point at which the vine becomes active. In this way we obtain a much more accurate comparison of the seasonal temperatures of different climates as to their effect on the development and ripening of grapes. The examples shown in table 5 illustrate this fact.

The temperature sums above $0^{\circ} \mathrm{C}\left(32^{\circ} \mathrm{F}\right)$ shown for both Eureka and Mainz are considerably higher than the minimum of Gasparin $\left(2,264^{\circ}\right.$

TABLE 5

Sfasonal Temperature Sums

\begin{tabular}{|c|c|c|c|c|}
\hline \multirow[t]{2}{*}{ Locality } & \multirow{2}{*}{$\begin{array}{c}\text { Season } \\
\text { months } \\
8.0\end{array}$} & $\begin{array}{c}\text { Temperature sums } \\
\text { above } \\
0^{\circ} \mathrm{C}=32^{\circ} \mathrm{F}\end{array}$ & \multicolumn{2}{|c|}{$\begin{array}{c}\text { Temperature sums } \\
\text { above } \\
10^{\circ} \mathrm{C}=50^{\circ} \mathrm{F}\end{array}$} \\
\hline & & ${ }_{2,849}^{\circ} \mathrm{C}={ }_{5,128}^{\circ}$ & ${ }^{\circ} \mathrm{C}=$ & $\begin{array}{l}{ }^{\circ} \mathrm{F} \\
808\end{array}$ \\
\hline Mainz, Germany... & 5.5 & $2,748 \quad 4,946$ & 1,098 & 1,976 \\
\hline Gironde, France... & 7.0 & 3,456 & 1,356 & 2,441 \\
\hline Boufarik, Algeria.. & 9.0 & 8,874 & 2,230 & 4,014 \\
\hline Fresno, California ..................... & 9.0 & $5,400 \quad 9,720$ & 2,700 & 4,860 \\
\hline Middle Egypt. ........................ & 12.0 & $7,140 \quad 12,852$ & 3,540 & 6,372 \\
\hline
\end{tabular}

C), but correspond rather closely with the minimum of Angot $\left(2,800^{\circ} \mathrm{C}\right.$, or $\left.5,040^{\circ} \mathrm{F}\right)$ and of Risler $\left(3,000^{\circ} \mathrm{C}\right.$, or $\left.5,400^{\circ} \mathrm{F}\right)$. That they are all unreliable in some cases is clear from the comparison of the records of Eureka and Mainz, which indicate that both localities should be able to ripen early grapes, though experience has shown that Eureka is unable to do so. The explanation is found in the difference in the length of the growing season and its effect on the sum of the temperatures above $10^{\circ} \mathrm{C}$ $\left(50^{\circ} \mathrm{F}\right)$. The temperature sum for Eureka is $\left(10^{\circ} \times 8 \times 30\right)+449^{\circ}$, that is, $2,400^{\circ} \mathrm{C}$ between $0^{\circ}$ and $10^{\circ}$ and $449^{\circ} \mathrm{C}$ above $10^{\circ}=2,849^{\circ} \mathrm{C}$, or $5,128^{\circ} \mathrm{F}$, above freezing; and the sum for Mainz is $\left(10^{\circ} \times 5.5 \times 30\right)+$ $1,098^{\circ}$, that is, $1,650^{\circ} \mathrm{C}$ between $0^{\circ}$ and $10^{\circ}$ and $1,098^{\circ} \mathrm{C}$ above $10^{\circ}=$ $2,748^{\circ} \mathrm{C}$, or $4,950^{\circ} \mathrm{F}$, above freezing.

Undoubtedly the sum of heat is an important factor in the time necessary to ripen grapes, but there are so many other factors that it is very difficult to give exact figures. It seems also, from observations made in the widely differing climates of the grape-growing regions of California, that the total sum necessary will vary with the magnitude of the daily means and with that of the spread between the daily maximum and minimum.

In the Imperial Valley and generally in southern California at low 
and moderate elevations, the mean temperature of the coldest month seldom falls to $10^{\circ} \mathrm{C}\left(50^{\circ} \mathrm{F}\right)$. According to the theory, the vines should be evergreen, which is not a fact. Moreover, the grapes in these regions should ripen from two to three weeks earlier than they actually do, if the theory applied there exactly. In the cooler grape-growing regions of California, however, the seasonal sums of temperature between the starting of the buds and the ripening of the grapes appear to agree well with the figures given for European vineyards.

On the basis of the above figures, it would appear that in general the hotter the climate the more total heat is necessary to ripen the grapes. ${ }^{10}$

TABLE 6

Approximate Mean Dates of Ripening of Varieties with Different Ripening Periods in the Various Regions, and the Temperature

Sums ABOve $10^{\circ} \mathrm{C}\left(50^{\circ} \mathrm{F}\right)$ NeCESSARY

\begin{tabular}{|c|c|c|c|c|c|c|}
\hline Varieties & $\begin{array}{l}\text { Temperature } \\
\text { sums above } \\
10^{\circ} \mathrm{C}=50^{\circ} \mathrm{F}\end{array}$ & $\underset{\text { Valley }}{\text { Imperial }}$ & $\begin{array}{l}\text { San Joaquin } \\
\text { Valley }\end{array}$ & $\begin{array}{c}\text { Sacramento } \\
\text { Valley }\end{array}$ & $\begin{array}{l}\text { Central } \\
\text { Valley }\end{array}$ & $\begin{array}{l}\text { North } \\
\text { coast }\end{array}$ \\
\hline Very early. & $\begin{array}{c}{ }^{\circ} \mathrm{C}={ }^{\circ} \mathrm{F} \\
1,111 \quad 2,000\end{array}$ & June 10 & July 15 & July 15 & August 15 & September 1 \\
\hline Early....... & $1,389 \quad 2,500$ & June 27 & August 7 & August 7 & September 3 & September 21 \\
\hline Midseason.. & $1,667 \quad 3,000$ & July 13 & September 4 & September 4 & September 21 & October 11 \\
\hline Late....... & $1,944 \quad 3,500$ & July 29 & October 2 & October 2 & October 10 & $?$ \\
\hline Very late... & $2,222 \quad 4,000$ & August 15 & October 31 & October 31 & $?$ & $?$ \\
\hline
\end{tabular}

In other words, as the temperature rises, though the ripening of the grapes is hastened, the acceleration is less than it would be if the same total of heat were sufficient.

On the basis of the dates of shipment of the various varieties grown in California and of the temperature records of the United States Weather Bureau, it seems that approximately $1,100^{\circ} \mathrm{C}\left(2,000^{\circ} \mathrm{F}\right)$ may be accepted as about the minimum sum of the daily mean temperature above $10^{\circ} \mathrm{C}\left(50^{\circ} \mathrm{F}\right)$ necessary for the ripening of the earliest varieties and approximately $2,200^{\circ} \mathrm{C}\left(4,000^{\circ} \mathrm{F}\right)$ as the sum necessary for the latest.

Assuming further that a temperature sum of $2,200^{\circ} \mathrm{C}$ above $10^{\circ}$ is necessary for the latest varieties, the ripening periods for the various regions may be arranged as shown in table 6 .

This table is merely tentative and approximate, and since it is based on the dates of shipping, it is subject to a systematic error due to the

\footnotetext{
${ }^{16}$ Studies of the factors influencing the maturing of grapes by this station have yielded results (unpublished) which indicate very definitely that the summation of heat-as day-degrees above $10^{\circ} \mathrm{C}\left(50^{\circ} \mathrm{F}\right)$-required to bring the fruit of a given variety from blooming to $18^{\circ}$ Balling is the same for all regions in which the fruit attains that degree of maturity. The discrepancy between these figures and those cited in the text is no doubt due in part to the earlier workers' use of the period leafing-out to harvest rather than blooming to harvest.
} 
tendency to ship all grapes except the latest before they reach full ripeness. If $20^{\circ}$ Balling be accepted as the condition of ripeness for table grapes and $22^{\circ}$ Balling for wine grapes, the dates would be retarded and the temperature sums above $10^{\circ} \mathrm{C}$ increased in most cases. In the three hotter regions all varieties of grapes have sufficient heat to ripen perfectly. In the north-coast region, late grapes such as Mataro and Burger ripen perfectly only in the most favorable seasons and situations, while still later grapes such as Ohanez seldom or never become edible. In the Central Valley region, late grapes are unsatisfactory and the very late, such as Rodites, seldom ripen perfectly.

Flavor.-A grouping according to flavor is of little use except to those who have a trained and discriminating sense of taste. Such marked flavors as those of the Muscats or of the labrusca varieties can be recognized by nearly every palate, but the delicate flavors which distinguish many, perhaps most, vinifera varieties can be recognized and clearly distinguished by comparatively few. They cannot be exactly measured nor very clearly described even by those who perceive them well. This limits their value in classification. Yet for those who do perceive them, they are perhaps the most certain signs by which many varieties ean be recognized.

In tasting a grape, we must distinguish clearly between two classes of sensation. These are tastes perceived in the mouth and throat, and aromas perceived in the nasal passages. Aromas are called "odors" when entering these passages through the nose, and "flavors" when entering through the mouth. Only the most marked of these aromas (Muscat and Concord) can be perceived as odors by smelling. The equally characteristic but less intense aromas (Cabernet, Semillon, Palomino, etc.) can be perceived only as flavors after they have entered the mouth.

Examples of tastes are sweetness, acidity, astringency, and bitterness. In these, grapes differ considerably quantitatively, but little qualitatively. They differ not only with variety but also with degree of maturity of the same variety and with the soil and climate where grown; and while of value in a full characterization of a grape, they are of little value in classification.

Flavors in grapes, on the other hand, differ both qualitatively and quantitatively, but owing to their elusive and almost indescribable nature, they are difficult to use as a basis upon which to establish groups. All vinifera grapes may be considered to have the flavor which is sometimes described as "grape" or vinous flavor, in which the varieties differ only in intensity. Special flavors in addition to this common flavor are numerous but usually without any very clear common quality by which 
they can be grouped. Most ampelographers make but two groups-that of grapes with "simple" or neutral flavor and those which are "aromatic." The first group includes the greater part of all varieties. Other classifiers introduce a third group, the "releve" or "sprightly," drawn from the confines of the neutral and the aromatic and including with the least noticeable of the aromatics any varieties among the neutrals which seem to have a trace of a special flavor. Others divide the aromatics into subgroups, with a muscat, a malvoisie, a cabernet, a spicy, a blackberry, or a strawberry flavor, and so forth. These groups are based on real or imaginary resemblances but in many cases are too indefinite and disputable to be of much general use in classification. For this reason the division by flavor has been placed last in table 1 (p. 232) to be used as a key by those who find it helpful and omitted by those to whom it conveys no useful ideas. The arrangement adopted, with examples, is as follows :

Neutral or simple-most varieties

Special or aromatic:

Muscat-Muscat of Alexandria, Muscat Frontignan, and many others

Cabernet-Cabernet Sauvignon, Cabernet Frane

Miscellaneous (pleasing)—Semillon, Colombard, Gewürz-Traminer, Riesling

Miscellaneous (less pleasing or displeasing)—Fresia, Zinfandel, Chaouch, Mataro, Burger

Pulp.-The greater part of the berry consists of large cells filled with juice. This is the pulp, or flesh, and constitutes from 85 to 90 per cent of the total weight, the rest being skin, from 6 to 10 per cent, and seeds, from 0 in the seedless grapes to 2 to 5 per cent in normal varieties.

The pulp is at first hard, green, and opaque, but softens in ripening, changes color, and becomes more or less translucent. In a few varietiesfor example, Vernaccia Sarda-the juice retains a green color, but in most it becomes yellowish and in a few pinkish or even red-for example, the Teinturiers and Bouschets. On overripeness, the pulp of most varieties becomes of a deeper yellow and that of many, even some white varieties-for example, Semillon-slightly pinkish. The texture or consistency of the ripe pulp varies with the variety in kind and degree, and ranges from hard (Ohanez) to soft (Damas rose), from crisp (Molinera) to mealy (Zabalkanski), and from sirupy (Furmint) to watery (Burger).

These variations depend on the character of the membranes of the pulp cells and on the concentration of the juice. The differences are marked and typical only in the thoroughly ripe berries. These differences in the character of the pulp may be summarized as follows :

Color: green, white, yellow, golden, pink, red

Texture: hard, firm, soft, crisp, mealy, melting, sirupy, watery

Juice: very sweet, sweet, acid, very acid, astringent 
Skin.-The skin of the berry consists of cuticle, epidermis, and adhering cells of the hypodermis and pulp. The cuticle is a thin, continuous, translucent membrane covering the epidermis, a layer of a single row of flattened cells which overlie the hypodermis, a layer of two or more rows of somewhat larger cells.

The thickness of the skin and its consequent weight depend upon how many of these layers of cells adhere to the skin when removed. The relative weight of the skin will vary with this factor and with the size of the berry and will range from about 5 to about 12 per cent of the weight of the whole berry.

The physical characters of the skin, like those of the pulp, influence greatly not only the eating quality of the grape but even more its keeping and shipping qualities. A hard or mealy pulp and a thick, tough, astringent skin are undesirable in a table grape from the consumer's standpoint but may be very useful where the grape has to be packed, shipped, and stored for any purpose (Ohanez, Emperor, Zabalkanski, Alicante Bouschet). Grapes which have the opposite characters are much to be preferred for eating, but their market is limited by difficulties of handling (Muscat of Alexandria, Black Hamburg, Rish Baba). The most useful grapes are usually those which possess a set of characters that is the best compromise for some particular purpose, the finer qualities being stressed for nearby markets and for consumers who will pay the high price necessary to return the extra cost of handling the more delicate varieties.

The bloom found on the skin of all varieties is a covering of fine, granular, irregular, waxy, velvety-white flakes varying in size and abundance. The bloom modifies the color of the grapes and if undisturbed adds much to their beauty. It is very easily removed, however, by the slightest touch, and great care in handling is necessary to preserve it. It is supposed to have some value in protecting the grapes from fungus diseases by causing rain and moisture to run off the skin. The quantity of bloom varies greatly with different varieties. In some, like the Meunier (= Miller), it looks almost like a dusting of flour. In others, such as the Perruno and the Palomino, it is almost absent, and the spreading, anastomosing vascular fibers between the epidermis and the pulp show clearly as a network through the transparent skin. This appearance is a useful distinguishing mark; for with most other varieties the fibers are seen clearly only after the bloom has been rubbed off.

The skin of many grapes shows more or less numerous lenticels, which appear as small, dark dots, or points. These are often conspicuous on white varieties, and their abundance is characteristic of some. 
The principal characters of the skin and torus (see below) are :

Skin: tender, tough; thin, thick ; bland, astringent

Bloom: heavy, moderate, light

Lenticels: absent, few, numerous

Torus: small, large; smooth, rough

Torus.-The end of the pedicel is a thickened, rounded, papillate body known as the "torus." This is the receptacle of the floral organs, to which the berry remains attached after the accessory flower parts have fallen. The size of the torus and the prominence and number of the papillae vary with different varieties.

Brush.-From the pedicel, the bundle of conducting vascular strands passes through the torus to the berry, where it divides and spreads to all parts. If a berry is pulled from its pedicel, more or less of this vascular bundle remains attached to the torus. The size and color of this attached part, called the "brush," vary with the variety.

Adherence of the Berry and Method of Detachment.-The degree and nature of the adherence of the berry to its support is of particular importance, especially for grapes which have to be packed, shipped, or stored. In some cases the berries break off very easily so that many of them become detached during the various handling operations such as picking, trimming, packing, and shipping. This is a great defect in a table grape. In others the adherence is very strong and any ordinary handling will loosen few or none.

The way in which berries become detached is of equal importance. The berry may become detached by the breaking of the pedicel or by the pulling out of the brush (see fig. 6 ). The breaking of the pedicel takes place particularly with varieties where it is slender and not very fibrous. As the skin is not broken, the berry neither molds nor ferments and little harm is done except the loss of berries or the disfiguring of the clusters where many berries fall. On the other hand, where the break occurs by the pulling out of the brush, the skin is broken and the pulp exposed to the germs of decay. This decay will then in time spread to the unbroken berries and soon the whole cluster is spoiled. The rapidity and amount of decay depend upon the character of the pulp and upon how much the skin is broken. If the pulp is juicy (fig. 6 , berries $a, b, d$ ), a drop of liquid exudes and forms a favorable medium for the growth of molds and yeasts ; and if the skin is badly broken (fig. 6 , berries $a, b$ ), the broken berry and adjoining sound berries are quickly destroyed. If on the contrary, the pulp is mealy (fig. 6, berries $c, e$ ), no juice exudes and, especially if the grapes are very sweet, the surface of the wound may become dry and prevent decay. 
The ease with which the berries become detached and the way in which they separate are varietal characters and depend on the characteristics of various parts of the berry, pulp, brush, skin, torus, and pedicel. They are also influenced by the degree of ripeness. Very ripe berries tend to become detached more easily but with less injury to the skin or exudation of juice. The berries of varieties with a thick pedicel and large, fibrous brush may adhere more strongly but the injury is greater when

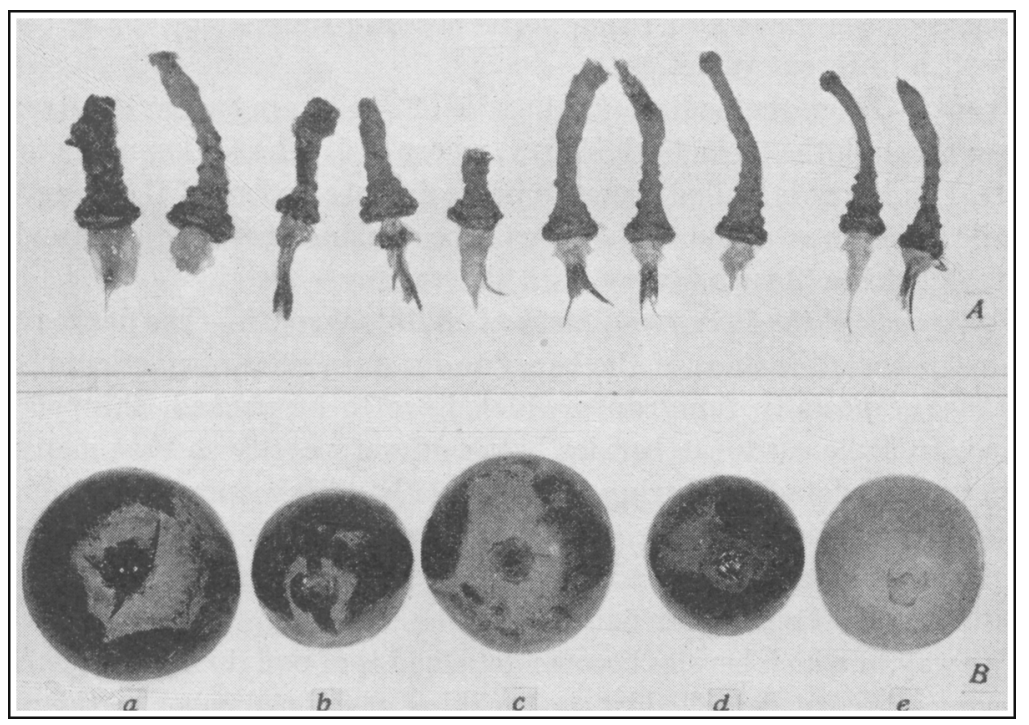

Fig. 6.-Detachment of berries: $A$, pedicel, torus, brush; $B$, effect of detachment of brush. ( $\times 1.5$.)

they do become detached (fig. $6, A$, pedicel at left). In handling or packing heavy, very compact clusters, a break between the skin and the brush is often caused without detaching the berry and may lead to decay in a cluster that appears uninjured. The Ohanez, or grape of Almeria, which is noted for its excellent keeping qualities, has a thin pedicel, but the latter is firmly attached to its brush, which is small and parts from the berry with little damage to the skin and without exudation of juice.

On the basis of the strength of adherence and the method of detachment, the following classes may be established:

Adherence: very strong, strong, medium, weak, very weak

Method of detachment:

1. By breaking of the pedicel

2. By extraction of the brush with more or less injury to the skin and with more or less exudation of juice 
The adherence is stronger with berries of firm pulp, thick tough skin, well-developed brush, and thick, fibrous pedicel.

Detachment Index.-Attempts have been made to correlate the force needed to detach a berry from its pedicel with the keeping and shipping qualities of the grape. The force needed to detach a berry is shown for several varieties in table 7 . The mean pull needed for 20 berries of each variety ranged from $591 \pm 52(\sigma=108.3 \pm 11.6)$ for Angelino (Flame

TABLE 7

Pull Necessary to Detach Berry from Pedicel; Means of 20 Berries; Davis, 1932

\begin{tabular}{|c|c|c|c|c|c|}
\hline Variety & Mean & $\begin{array}{l}\text { Standard } \\
\text { deviation }\end{array}$ & Variety & Mean & $\begin{array}{l}\text { Standard } \\
\text { deviation }\end{array}$ \\
\hline Angelino .......... & $\begin{array}{l}\text { grams } \\
591 \pm 52\end{array}$ & $\begin{array}{c}\text { grams } \\
108.3 \pm 11.6\end{array}$ & Palomino. & $\begin{array}{l}\text { grams } \\
298 \pm 26\end{array}$ & $\begin{array}{c}\text { grams } \\
54.2 \pm 5.8\end{array}$ \\
\hline Alphonse Lavallée..... & $491 \pm 40$ & $84.4 \pm 9.0$ & Trivoti.......... & $296 \pm 31$ & $65.2 \pm 7.0$ \\
\hline Danugue............. & $421 \pm 39$ & $81.1 \pm 8.6$ & Alloued Zeine.......... & $295 \pm 35$ & $73.7 \pm 7.9$ \\
\hline Teneron de Cadenet.... & $408 \pm 24$ & $49.6 \pm 5.3$ & Black Ferrara......... & $284 \pm 28$ & $58.6 \pm 6.2$ \\
\hline Ohanez............. & $404 \pm 30$ & $63.0 \pm 6.7$ & Malaga ............ & $281 \pm 9$ & $18.9 \pm 2.0$ \\
\hline Ahmeur bou Ahmeur.. & $395 \pm 43$ & $89.9 \pm 9.6$ & Siderites......... & $270 \pm 18$ & $39.0 \pm 4.2$ \\
\hline Burgrave............ & $360 \pm 33$ & $69.0 \pm 7.4$ & Coudsi......... & $262 \pm 22$ & $46.4 \pm 4.9$ \\
\hline Prince of Wales.......... & $354 \pm 36$ & $75.5 \pm 8.1$ & Damascus........... & $261 \pm 14$ & $28.6 \pm 3.1$ \\
\hline Pis de Chêvre Blanc.... & $348 \pm 39$ & $80.9 \pm 8.6$ & Alicante Bouschet.... & $260 \pm 14$ & $31.0 \pm 3.3$ \\
\hline Pizzutello. . . . . . . . . & $340 \pm 45$ & $94.0 \pm 10.0$ & Rish Baba............. & $240 \pm 21$ & $43.3 \pm 4.6$ \\
\hline Molinera......... & $339 \pm 26$ & $54.9 \pm 5.9$ & Chaouch........ & $235 \pm 28$ & $57.8 \pm 6.2$ \\
\hline Gros Colman.... & $337 \pm 27$ & $56.4 \pm 6.0$ & Moscatello fino... & $231 \pm 18$ & $27.8 \pm 4.0$ \\
\hline Khandahar.... & $336 \pm 33$ & $69.7 \pm 7.4$ & Sultanina gigas.... & $230 \pm 17$ & $35.0 \pm 3.7$ \\
\hline Dattier......... & $331 \pm 27$ & $55.6 \pm 5.9$ & Monica......... & $219 \pm 11$ & $23.1 \pm 2.5$ \\
\hline Muscat Blowers........ & $313 \pm 27$ & $55.5 \pm 5.9$ & Citronelle......... & $218 \pm 32$ & $68.0 \pm 7.3$ \\
\hline Kurtelaska........... & $312 \pm 27$ & $56.7 \pm 6.0$ & Trentham Black...... & $204 \pm 15$ & $30.5 \pm 3.3$ \\
\hline Korinthi blanc... & $307 \pm 22$ & $46.7 \pm 5.0$ & Chasselas Dupont..... & $203 \pm 17$ & $35.6 \pm 3.8$ \\
\hline Cornichon $\ldots \ldots \ldots \ldots \ldots$ & $300 \pm 42$ & $90.6 \pm 9.7$ & Augibi.............. & $199 \pm 12$ & $25.9 \pm 2.8$ \\
\hline
\end{tabular}

Tokay) to $199 \pm 12(\sigma=25.9 \pm 2.8)$ for Augibi. Table 7 indicates some correlation with shipping quality; for nearly all the varieties which required a pull of over 250 grams are good to fair shippers and nearly all below this figure are poor. A suggested classification by detachment index is given in table 8, which also indicates the distribution of the thirtysix varieties tested at Davis (table 7 ) in such a classification.

Characters of the Seed.-The normal or perfect number of seeds in a grape is 4 , but the usual number 2 or 3 , though berries with 1 or 4 are common. Rarely, the abnormal numbers of 5,6 , or even more, may occur. Imperfectly developed berries of any variety may be seedless. In a few varieties-the so-called "seedless" grapes-the berries are usually all seedless. The average size of the seeds varies in a similar way. Varieties may therefore be classified according to the average number of seeds, which varies from nearly 4 to nearly 0 , and according to the average 
weight of a seed, which varies in vinifera through a range of about 1 gram to 5 grams per 100 seeds. Number, and to a less extent size, are influenced by cultural and growing conditions and have their full descriptive value only when conditions are alike and favorable and a considerable number of berries are examined.

The general form of the seed in vinifera varieties is pyriform-cordate. The features which present characters of value for classification are shown in figure 7.

The principal descriptive features of the seed shown in figure 7 are: (1) the body, which may be more or less rounded or elongated longitudi-

TABLE 8

Classification of Table-Grape Varieties by Detachment Index

\begin{tabular}{|c|c|c|c|c|}
\hline \multirow{2}{*}{ Grade } & \multirow{2}{*}{ Midvalue } & \multirow{2}{*}{ Limits } & \multicolumn{2}{|c|}{ Example, Davis } \\
\hline & & & Means & $\begin{array}{c}\text { Number of } \\
\text { varieties }\end{array}$ \\
\hline Very small.. & grams & $\begin{array}{l}\text { grams } \\
<150\end{array}$ & grams & 0 \\
\hline Small....... & 200 & $150-249$ & 220 & 9 \\
\hline Medium.... & 325 & $250-399$ & 313 & 22 \\
\hline Large......... & 500 & $400-599$ & 463 & 5 \\
\hline Very large.. & $\ldots$ & $>599$ & $\ldots$ & 0 \\
\hline
\end{tabular}

nally, and more or less flattened or triangular in horizontal cross section; (2) the beak, which may be straight or incurved, rough, wrinkled, or smooth, and varies in length, thickness, and the sharpness of the angle at the hilum; and (3) the carina (keel) which may be sharp or rounded and more or less prominent. The other features shown in the figure are either difficult to distinguish in the dry, mature seed or vary little with the variety.

The chalaza occupies a position near the middle and widest part of the body on the dorsal side and in vinifera is farther from the hilum than in labrusca and other species on account of the greater length of the beak, which in vinifera is usually about one-third of the length of the whole seed. The raphe, a slender conducting strand of vascular bundles, extends from the hilum along a sulcus, or groove, on the ridge of the keel and over through the notch to the dorsal side, where it ends with the chalaza. The raphe is small and usually indistinguishable on the dry seed, but the sulcus is usually made plain by a small hand magnifier.

Number of Seeds.-The average number of seeds per 100 berries in forty-five varieties tested was 215 -which agrees rather closely with the medium class of table 9-and varied from 125 in Henab to 360 in Muscat 
of Alexandria. This covers about the usual range. These counts do not include the small "shot" or seedless berries, which occur with nearly all varieties and are particularly common with some, such as the Muscat of Alexandria. The "seedless" varieties are not represented. A convenient
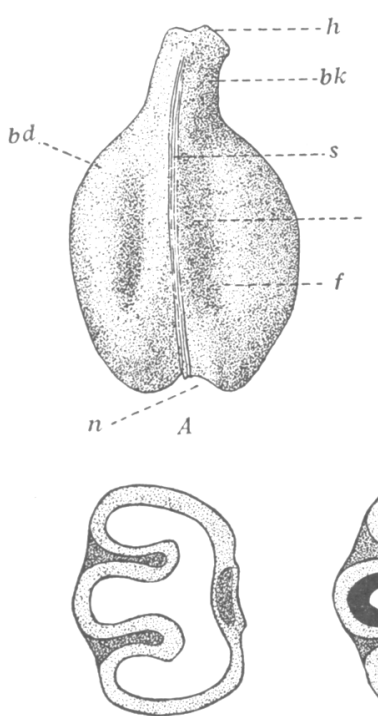

D

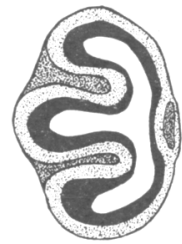

E

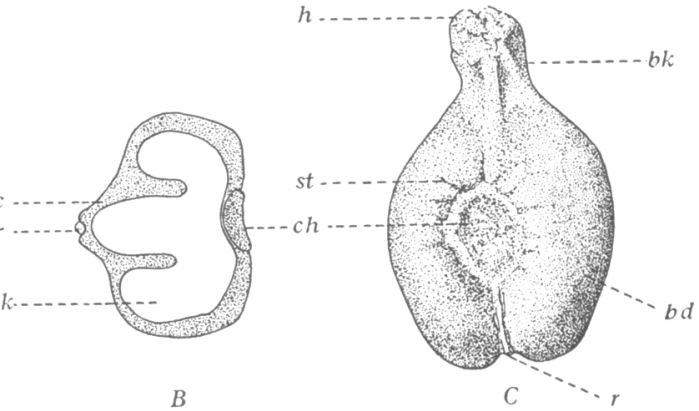

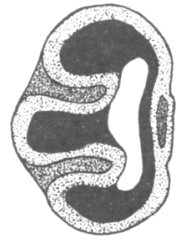

F

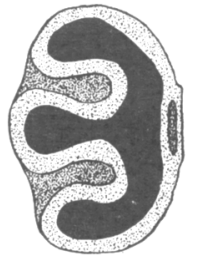

G

Fig. 7.-Structure of grape seeds $(\times 5): A-C$, typical fresh seed, perfect kernel- $A$, ventral surface; $B$, section; $C$, dorsal surface. $b d$, Body; $b k$, beak; $c$, carina (keel) ; $c h$, chalaza ; $f$, fossette ; $h$, hilum; $k$, kernel ; $n$, notch ; $r$, raphe; $s$, sulcus ; st, striation.

$D-G$, Seed of Alloued Zeine, dried-D, perfect kernel; $E, F$, imperfect kernels; $G$, kernel lacking.

classification according to number of seeds in 100 normal berries, based on the varieties in the Davis collection, is shown in table 9.

The average number of seeds gives no indication of their distribution among different berries. Table 10 shows this distribution among 100 berries of each of five varieties - four with a large number and one (Ohanez) with a medium. This shows clearly that to characterize the grape of a certain variety as having 2 seeds or 3 seeds is misleading. Each of the four varieties in the table has berries with at least three different numbers of seeds; and one, the Ohanez, which has the smallest average number, has the largest variation and is the only one which has 5-seeded berries. As a rule, the mean number of seeds indicates the mode. The mean for Ohanez was 228 , which puts it in the medium class of table 9 , with a mode of 2 seeds to the berry. In the same way, the means for the other four varieties place them in the class of large number of seeds and 
indicate that the mode is 3-which is true except for the Malaga, where the number of berries with 2 seeds is equal to the number with 3 .

Seedless Grapes.-No cultivated variety of grape is known which is absolutely free from seeds, perfect or abortive. The so-called "seedless

TABLE 9

Classification of Grape Varieties by Number of Seeds IN 100 BERRIES

\begin{tabular}{|c|c|c|c|}
\hline Class & Midvalue & Limits & $\begin{array}{l}\text { Distribution of } 45 \\
\text { varieties at Davis, } \\
\text { per cent }\end{array}$ \\
\hline Very few........ & 125 & $100-149$ & 11 \\
\hline Few............. & 175 & $150-199$ & 31 \\
\hline Medium......... & 225 & $200-249$ & 27 \\
\hline $\operatorname{Many} . \ldots \ldots \ldots$ & 275 & $250-299$ & 27 \\
\hline Very many................... & $\ldots$ & $>299$ & 4 \\
\hline
\end{tabular}

grapes" are varieties of which the berries are nearly always without seeds or in which the berries in most eases contain only imperfect small soft suggestions of seeds which usually pass unnoticed. There are various kinds or degrees of seedlessness.

The Sultanina (Thompson Seedless in California) is the most nearly TABLE 10

Distribution of Seeds in 100 Berries; Crop of 1929, Davis, California

\begin{tabular}{|c|c|c|c|c|c|c|c|}
\hline Variety & $\begin{array}{l}\text { Number } \\
\text { of berries }\end{array}$ & $\left|\begin{array}{c}\text { Seeds } \\
\text { per berry }\end{array}\right|$ & $\begin{array}{l}\text { Total } \\
\text { seeds }\end{array}$ & Variety & $\begin{array}{l}\text { Number } \\
\text { of berries }\end{array}$ & $\begin{array}{c}\text { Seeds } \\
\text { per berry }\end{array}$ & $\begin{array}{l}\text { Total } \\
\text { seeds }\end{array}$ \\
\hline \multirow{10}{*}{ Alphonse Lavallée... } & 7 & 1 & 7 & \multirow{7}{*}{ Ohanez. } & 8 & 1 & 8 \\
\hline & 30 & 2 & 60 & & 68 & 2 & 136 \\
\hline & 38 & 3 & 114 & & 16 & 3 & 48 \\
\hline & 17 & 4 & 68 & & 4 & 4 & 16 \\
\hline & 6 & 5 & 30 & & 4 & 5 & 20 \\
\hline & 2 & 6 & 12 & & - & & - \\
\hline & - & & - & & 100 & $M 2.28$ & 228 \\
\hline & 100 & $M 2.91$ & 291 & & & & \\
\hline & & & & \multirow{5}{*}{ Tokay $\ldots \ldots \ldots \ldots$} & 32 & 2 & 64 \\
\hline & 16 & 1 & 16 & & 64 & 3 & 192 \\
\hline \multirow{3}{*}{ Emperor.............. } & 24 & 2 & 48 & & 4 & 4 & 16 \\
\hline & 44 & 3 & 132 & & - & & - \\
\hline & 16 & 4 & 64 & & 100 & $M 2.72$ & 272 \\
\hline \multirow{8}{*}{ Malaga...... } & 100 & $M 2.60$ & 260 & \multirow{8}{*}{ All five varieties.... } & 31 & 1 & 31 \\
\hline & & & & & 198 & 2 & 396 \\
\hline & 44 & 2 & 88 & & 206 & 3 & 618 \\
\hline & 44 & 3 & 132 & & 53 & 4 & 212 \\
\hline & 12 & 4 & 48 & & 10 & 5 & 50 \\
\hline & - & & - & & 2 & 6 & 12 \\
\hline & $(100$ & $M 2.68$ & 268 & & - & & - \\
\hline & & & & & 500 & $M 2.64$ & 1,319 \\
\hline
\end{tabular}


perfect in this respect, but in rare instances a few berries are said to appear with seeds which though small are plainly hard seeds. The roundberried Sultana (Seedless Sultana in California) is similar, but hard seeds occur more frequently. In one case a vine of this variety in the

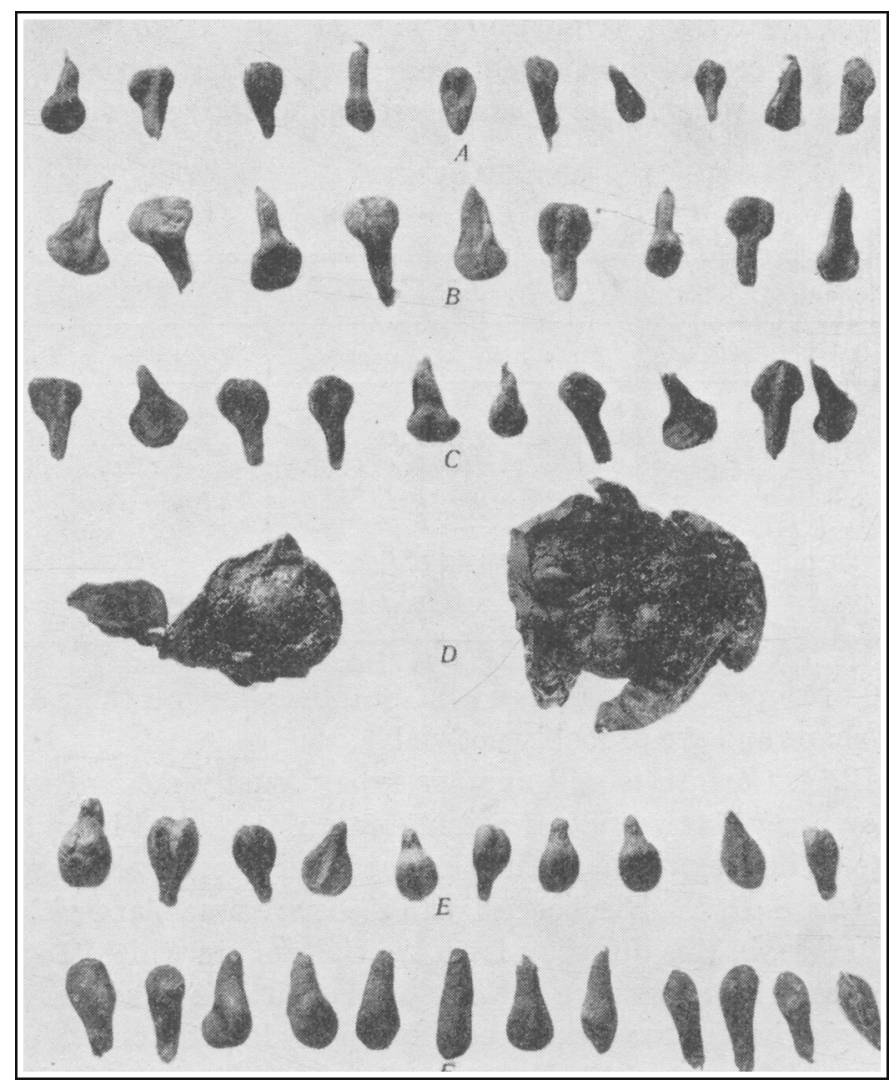

Fig. 8.-Imperfect seed of "seedless" varieties $(X 2) ; A$, Sultana (Round-berried Sultanina), Cupertino, $1890 ; B$, same variety, Davis, $1929 ; C$, same variety, Davis, $1915 ; D, E$, Black Corinth, Davis, 1930, perfect seed (rare); $F$, Monukka, Davis, 1930.

Davis collection produced a cluster of 492 berries, which contained 620 hard seeds, or 126 seeds to 100 berries (fig. 8, $A, B, C$ ). These seeds were small and of abnormal shape but hard and woody and would much depreciate the value of the grapes for raisins.

The Monukka, a black "seedless" grape, is of another type. A vestige of a seed occurs in nearly every berry but is generally so small and soft 
that it is hardly noticeable in the fresh grape and even in the dried grape does not injure the value of the raisin. Occasionally, and in some seasons frequently, the seeds develop further and though still small are hard enough to be objectional in a supposedly seedless raisin (fig. $8, F$ ).

All the seeds produced by these types are probably nonviable. Even the largest are of light weight and abnormal shape. Usually from 70 per cent to 95 per cent of the dry mature seeds of normal varieties will sink when placed in water. This is considered as indicative of viability. Only

TABLE 11

Forms of Vinifera SEeds

\begin{tabular}{|c|c|c|c|c|c|}
\hline \multicolumn{2}{|c|}{ Body } & \multicolumn{2}{|c|}{ Beak } & \multicolumn{2}{|c|}{ Keel } \\
\hline Description & Example, fig. 9 & Description & Example, fig. 9 & Description & Example, fig. 9 \\
\hline $\begin{array}{l}\text { Rounded....... } \\
\text { Cuneate....... } \\
\text { Oblong........ } \\
\text { Elongate...... } \\
\text { Flattened.... }\end{array}$ & $\begin{array}{l}B, C \\
A \\
F \\
I \\
H\end{array}$ & 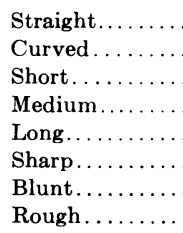 & $\begin{array}{l}A, F, I, \text { etc. } \\
B, C \\
B, C, D, G, H \\
A, E, F \\
I \\
A, E \\
B, C, D, F \\
B, C, F\end{array}$ & $\begin{array}{l}\text { Prominent...... } \\
\text { Flattened........ } \\
\text { Sharp........... } \\
\text { Rounded....... }\end{array}$ & $\begin{array}{l}E, F, I \\
H \\
A \\
C\end{array}$ \\
\hline
\end{tabular}

from 10 to 15 per cent of the seeds of Sultana sink and these are not of normal shape and are probably not viable.

The Black Corinth is still another type. Usually most of its berries show no perceptible vestige of a seed, but an occasional berry, perhaps 2 or 3 to a cluster, will have fully formed, hard seeds which germinate readily (fig. $8, D, E$ ). The berries with seeds are much larger than those without seeds, in this differing from the Sultana, in which the presence of a hard seed influences the size of the berry little if at all, as compared with berries having vestigial seeds. Rarely a Black Corinth cluster is found in which most of the berries contain seeds and the fruit is all of full size. A few small abortive seeds are also found in the Black Corinth.

In this connection the Khalili is of interest. This variety has seeds which are apparently normal, but in a test of several hundred planted, only about 15 germinated and of these only 1 lived more than a few months. Its seeds are very light—out of 200 dry seeds not one would sink in water.

The seeds of Carignane, Mourastel, and Alloued Zeine are similar to those of Khalili in that few of them sink when placed in water. Most of the seeds which float are hollow and contain no kernel. In some cases (Alloued Zeine, fig. 7, $D-G$ ), these hollow seeds are as large, and to judge 


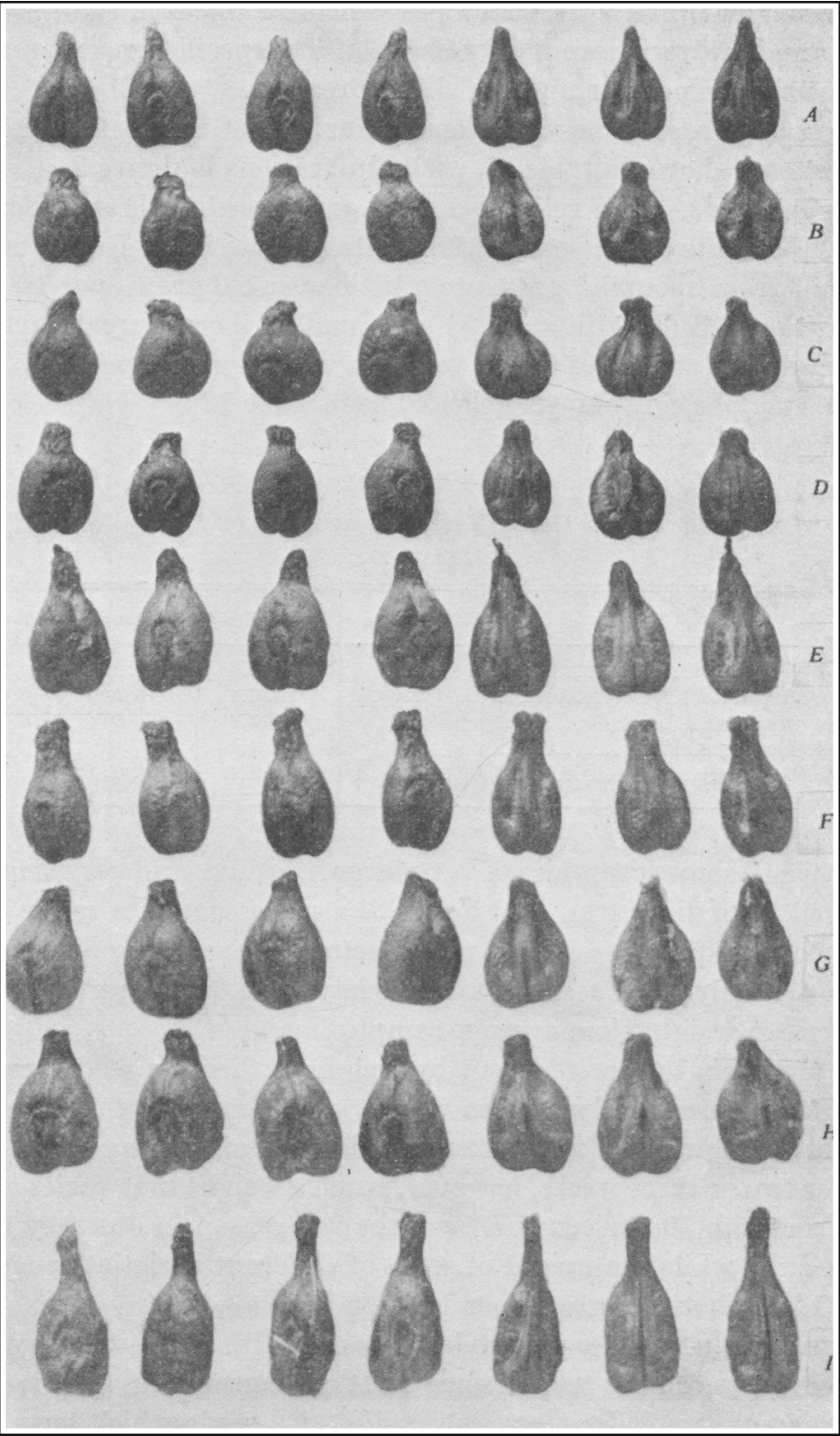

Fig. 9.-Forms of seeds $(\times 2): A$, Carignane; $B$, Grenache; $C$, Johannisberger Riesling; $D$, Zinfandel ; $E$, Emperor ; $F$, Gros Maroc ; $G$, Prince of Wales; $H$, Hunisa ; $I$, Pizzutello di Roma. 
from their outward appearance, as well developed as the good seeds. They are, however, mere hollow shells of low specific gravity and when dry, crush into powder under a slight pressure.

Form of Seeds.-The variations of form most useful for descriptive purposes are shown in table 11, with illustrations in figure 9.

Size of Seeds.-The relative size of grape seeds is best indicated by weight. Weights of the seeds of 68 vinifera varieties at Davis indicate a range of from about 1.5 grams to a little over 5.0 grams per 100 . Seeds lighter than 1.5 (Khalili $=1.25$ ) are usually all or in great part imperfect. The mean weight of the 68 varieties was 3.4 grams per 100. The size of seeds may be conveniently classed as in table 12 .

TABLE 12

Classification of Grape Varieties by Sizes of SEeds-Weight IN GRAMS PER 100

\begin{tabular}{|c|c|c|c|}
\hline Class & Midvalue & Limits & Example, fig. 9 \\
\hline Very small....... & $\ldots$ & $<1.5$ & $\ldots \ldots$ \\
\hline Small ................... & 2.0 & $1.5-2.4$ & $A, B$ \\
\hline Medium $\ldots \ldots \ldots \ldots \ldots \ldots \ldots$ & 3.0 & $2.5-3.4$ & $C, \bar{D}$ \\
\hline Large $\ldots \ldots \ldots \ldots \ldots \ldots \ldots$ & 4.0 & $3.5-4.4$ & $F$ \\
\hline Very large $\ldots \ldots \ldots \ldots \ldots \ldots \ldots$ & $\ldots$ & $>4.4$ & $E, G, H$ \\
\hline
\end{tabular}

Figure 10 shows examples of very large, medium, and very small seeds enlarged four diameters, and figure 9, a more complete range of sizes enlarged two diameters. They are selected by excluding all misshapen and abnormally small seeds of each variety and have therefore a slightly larger mean weight than average samples.

An objection to measurement by weight is that the seeds are hygroscopic and consequently vary in weight somewhat with the humidity of the air and their age. Fresh mature seeds after air-drying in the laboratory for two or three weeks, however, reach a weight that varies at Davis only from 7 to 10 per cent between the wet season in January and the dry in July, while the weight of seeds of different varieties ranges from about 1.5 to about 5.0 grams per 100 .

Some ampelographies use the length and width of the seed as classifying characters. This is troublesome and time-consuming and gives a less exact idea of size differences, especially with seeds which have an unusually long beak like the Pizzutello or a very short beak like the Grenache and Dronkane or are much flattened like the Hunisa. With most varieties, however, the weight of normal seeds can be estimated rather closely from the length and width. A comparison of the actual weight 
with the estimated weight computed from the length and width indicates with seeds of usual form, the relative specific gravity, which has a bearing on their viability.

Table 13 gives weights and measurements of some typical seeds. Col-

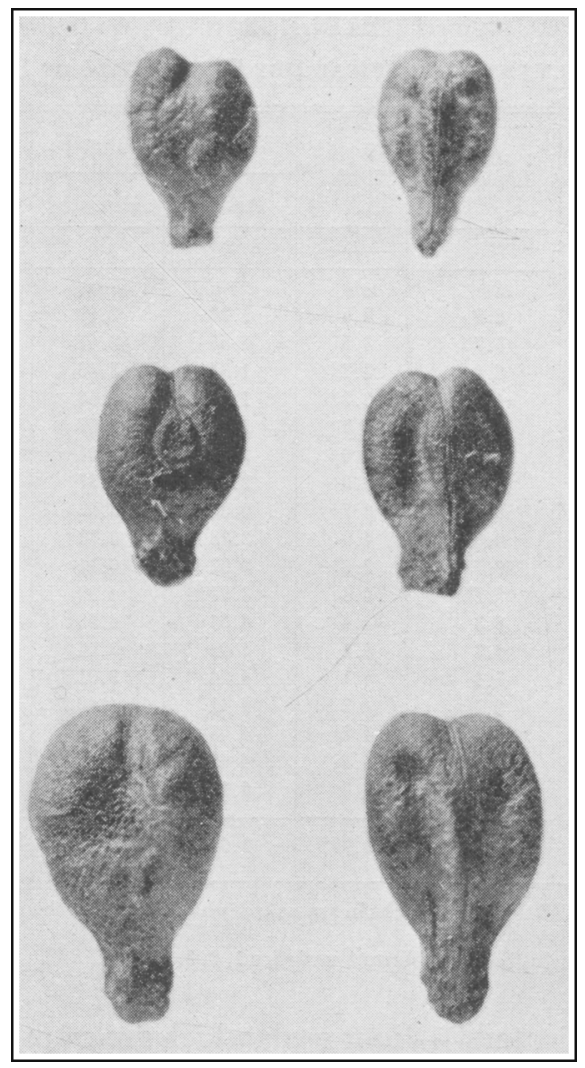

Fig. 10.-Range of size of grape seeds : small, medium, large. $(X 4$.

umn 4 gives an approximate weight computed by the formula, 0.03 $(L \times W)^{3 / 2}$. This is an empirical formula based on a comparison of the length and width with the weight of a large number of varieties. Column 5 shows how near the computed weight is to the actual weight found. The deviations are due to differences of form and specific gravity, which with most varieties fall within rather narrow limits. Where the deviation is large, it is due either to considerable variation from the usual form, as in Pizzutello (fig. 9, $I$ ), or to imperfect development, as 
in Mourastel, Khalili, and Carignane. The cause of the deviation in these last three is their low specific gravity, indicated in table 13, column 6 , by the low percentage of seeds which sank when placed in water.

The factor $K(0.03)$ used in table 13 applies only to perfect seeds. It

TABLE 13

Weights and Measurements of Typical Dry Grape Seeds of 18 Varieties, Davis

\begin{tabular}{|c|c|c|c|c|c|c|}
\hline \multirow{3}{*}{ Variety } & \multirow{2}{*}{$\begin{array}{c}L, \\
\text { Length }\end{array}$} & \multirow{2}{*}{$\begin{array}{l}W, \\
\text { Width }\end{array}$} & \multicolumn{2}{|c|}{ Weight per 100 seeds } & \multirow{2}{*}{$\begin{array}{l}\text { Col. } 3 \text { as a } \\
\text { percentage } \\
\text { of col. } 4\end{array}$} & \multirow{2}{*}{$\begin{array}{l}\text { Percentage } \\
\text { of seeds } \\
\text { that sank } \\
\text { in water }\end{array}$} \\
\hline & & & Actual & Calculated ${ }^{*}$ & & \\
\hline & 1 & 2 & 3 & 4 & 5 & 6 \\
\hline 1. Mourastel... & $\begin{array}{r}m m \\
6.0\end{array}$ & $\begin{array}{r}m m \\
3.5\end{array}$ & $\begin{array}{c}\text { grams } \\
1.28\end{array}$ & $\begin{array}{c}\text { grams } \\
2.89\end{array}$ & $\begin{array}{c}\text { per cent } \\
44\end{array}$ & $\begin{array}{c}\text { per cent } \\
17\end{array}$ \\
\hline 2. Khalili................ & 5.7 & 3.5 & 1.55 & 2.67 & 58 & 2 \\
\hline 3. Carignane...$\ldots \ldots \ldots \ldots$ & 6.4 & 3.7 & 1.67 & 3.46 & 48 & 37 \\
\hline 4. Grenache............. & 4.9 & 3.2 & 1.96 & 1.86 & 105 & 74 \\
\hline 5. Beclan . . . . . . . . . & 5.1 & 3.3 & 2.14 & 2.07 & 103 & 84 \\
\hline 6. Zinfandel.............. & 5.5 & 3.6 & 2.49 & 2.64 & 94 & 67 \\
\hline 7. Johannisberger Riesling & 5.4 & 3.6 & 2.53 & 2.57 & 98 & 58 \\
\hline 8. Cabernet Sauvignon.... & 6.6 & 3.7 & 2.89 & 3.62 & 80 & 91 \\
\hline 9. Petit Bouschet......... & 6.0 & 4.0 & 3.38 & 3.53 & 96 & 71 \\
\hline 10. Pizzutello............. & 9.7 & 3.6 & 3.92 & 6.19 & 63 & 77 \\
\hline 11. Zabalkanski.... & 6.7 & 4.4 & 3.99 & 4.80 & 83 & 15 \\
\hline 12. Rambola......... & 6.3 & 4.4 & 4.03 & 4.38 & 92 & 89 \\
\hline 13. Duriff .......... & 6.3 & 4.1 & 4.09 & 3.94 & 104 & 84 \\
\hline 14. Emperor......... & 7.4 & 4.1 & 4.24 & 5.01 & 85 & 100 \\
\hline 15. Prince of Wales.. & 6.7 & 4.2 & 4.41 & 4.48 & 98 & 80 \\
\hline 16. Hunisa.............. & 7.4 & 4.2 & 4.65 & 5.20 & 89 & 82 \\
\hline 17. Trevoti.............. & 6.9 & 4.5 & 4.65 & 5.19 & 90 & 93 \\
\hline 18. Dronkane............. & 7.2 & 4.6 & 6.11 & 5.72 & 107 & 79 \\
\hline Means.............. & $6.31 \dagger$ & $3.99 \dagger$ & $3.68 \dagger$ & $3.93 \dagger$ & $\ldots$ & $\ldots$ \\
\hline
\end{tabular}

* Calculated weight $=K(L \times W)^{3 / 2}=$ weight in grams computed from length and width in mm. $K=0.03$ and applies only to seeds which sink.

$\dagger$ Mean of 14 varieties excluding the aberrant varieties 1, 2, 3, and 10.

does not apply to "floaters"-light seeds which are empty or contain only imperfect kernels.

The seeds which sink have large well-developed kernels. Those which float are either empty or have small kernels varying from a trace to almost full size (fig. 7, p. 253). Most of the seeds which sink are viable, but nearly all of those which float cannot germinate. The floaters are usually lighter and smaller than those which sink. In some cases, floaters occur which are nearly or quite as large as the sinkers ; they are, however, of lighter specific gravity owing to imperfect kernels and hollow spaces.

The percentage of floaters varies greatly not only with the variety but also with conditions which influence the vigor of the vine, such as seasonal temperature and soil moisture, diseases and pests, and the amount 
of crop. How much each of these factors influences the percentage in a particular case it is impossible to say, but under similar conditions there is a considerable variation in the number, size, and weight of the seeds of different varieties.

Characters of the Cluster.-The fruit of Vitis vinifera grows in a cluster (compound raceme or panicle), which in cultivated varieties varies

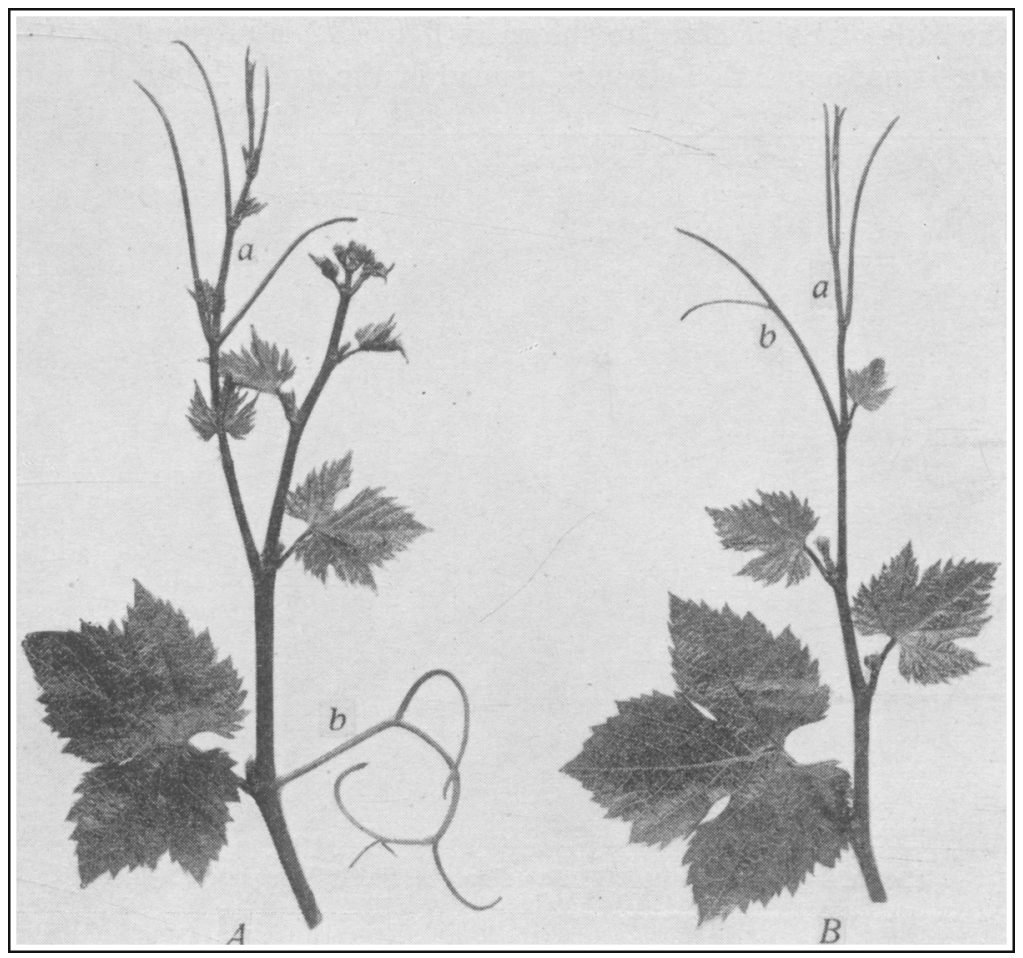

Fig. 11.-Abnormal shoots and tendrils on Grec Rouge variety: $A$, $a$, tendril bearing leaves; $b$, normal tendril ; $B, a$, shoot bearing tendrils instead of leaves; $b$, normal tendril.

greatly in weight, number of berries, form, and compactness. The cluster has the same origin as the tendril and occurs in a corresponding position on the cane. Each is a modified shoot or branch. A cluster may be considered as a much-developed tendril that branches repeatedly and bears grapes. Abnormal cases are found in which a tendril bears a few small grapes, and the first branch of a cluster often retains its tendril character and bears no grapes. That the tendril and therefore the cluster originates from an abortive or modified shoot is shown by cases in which 
a tendril branches repeatedly and bears leaves (fig. 11, $A$, at $a$ ) or in which the growing tip of a shoot develops into a tendril (fig. 11, $B$, at $a$ ).

The clusters grow in the same position as the tendrils, which is at the side of a node opposite to a leaf. They occur usually as a pair at two adjacent nodes between two smooth nodes bearing neither tendril nor cluster. Sometimes there is only 1 cluster and very rarely 3 , 4 , or 5 on a cane.

The cane of Saint Macaire shown in figure 12 is unusual in two respects. It not only has 5 clusters instead of the usual 2 , but the middle

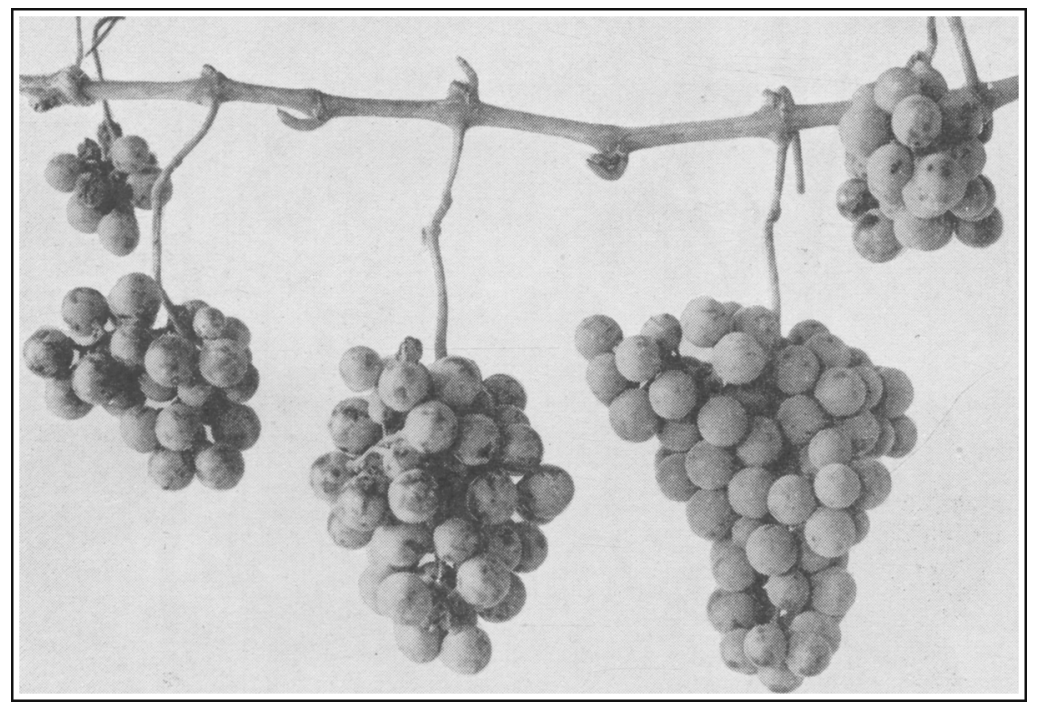

Fig. 12.-Lateral cane with five clusters, Saint Macaire. $(\times 0.5$.

one is situated between two smooth nodes, contrary to the usual sequence of two tendril or cluster nodes followed by a single smooth node.

The cane shown in figure 13 shows also 5 clusters, but this is not an exception to the rule because only the 3 large ones are borne on the main cane. The 2 small clusters are borne on small lateral canes growing, as is normal, out of the leaf side of the main cane. These second-crop clusters are common on many varieties. On some varieties, such as the Black Morocco, the laterals may branch and these secondary laterals may branch again. Each member of this series may then bear grapes and thus yield second, third, and even fourth crops, each a few weeks later than the one which precedes it. Only in the hottest climates with an extremely long growing season do the third or fourth crops ripen. This happens 
sometimes in the Coachella Valley of California, where the Black Morocco is popularly known as the "everbearing" grape, and in Italy, where it is called "Trevoti."

Form of Cluster.- The cluster is more irregular than the berry and less easily described in terms of geometrical forms. Figure 14 and the bottom row of figure 15 show typical variations in form. The cluster con-

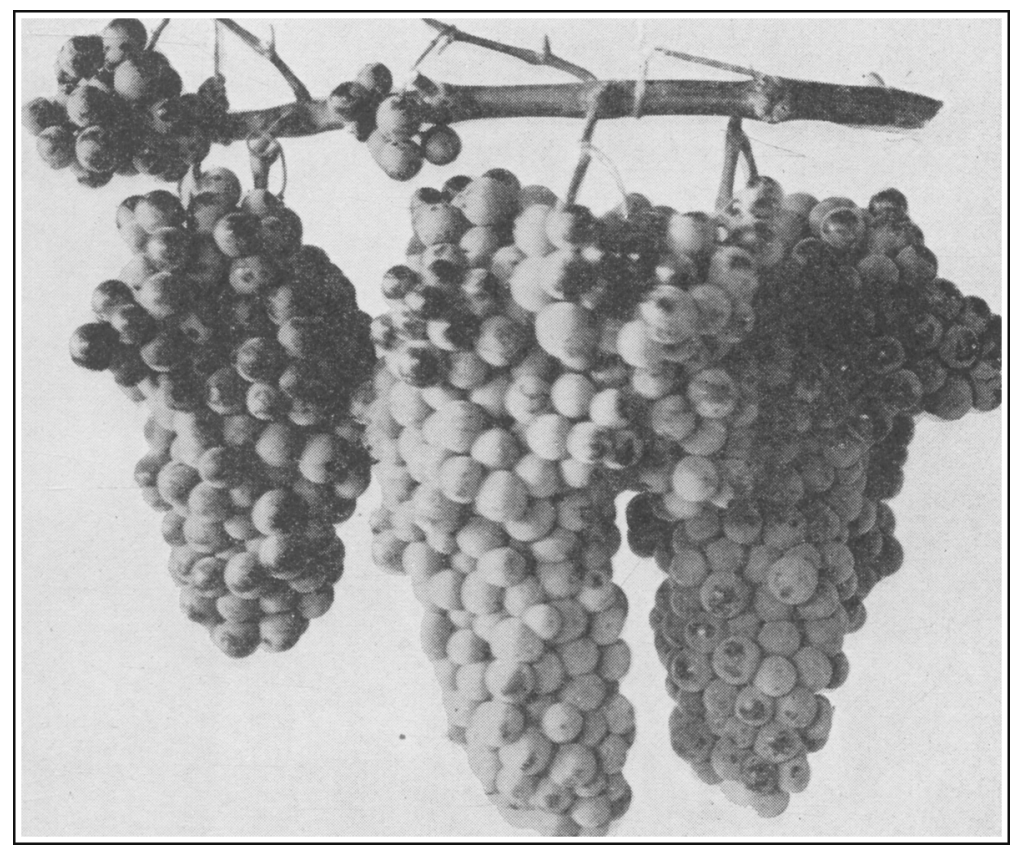

Fig. 13.-Cane with three first-crop and two second-crop clusters, Alicante Bouschet. $(\times 0.4$. $)$

sists of a main part, to which is attached one or more excrescences or appendages called "shoulders" or "wings." These appendages modify the general form of the cluster, which is determined by the main part.

The commonest form is conical, varying from short conical(fig. 14, $A, B$ ) through intermediate (fig. 14, $C, E$ ) to long conical (fig. 14, $D, F$ ). This form may be modified by one or more closely adhering shoulders (fig. 14 -right side $E$, left side $C, F$ ) or by loosely attached wings. (fig. 14 -right side $C, F$ ). When the cluster tapers little or not at all, it is called cylindrical (fig. 14, $G, H, I$ ) and may be modified by shoulders (fig. 14, $H$ ) or wings (fig. 14, $I$ ). The principal shoulder or wing represents the first division of the rachis, and when large and free, a double cluster results (fig. $15, I, J$ ). 
Compactness.-The degree of compactness with which the berries are arranged in the normal cluster depends on the size and number of berries and on the length of the stem and its branches and of the pedicels. Various degrees are shown in figure 15, upper two rows. An extreme degree of compactness is shown by $A$ of this figure and an extreme degree of

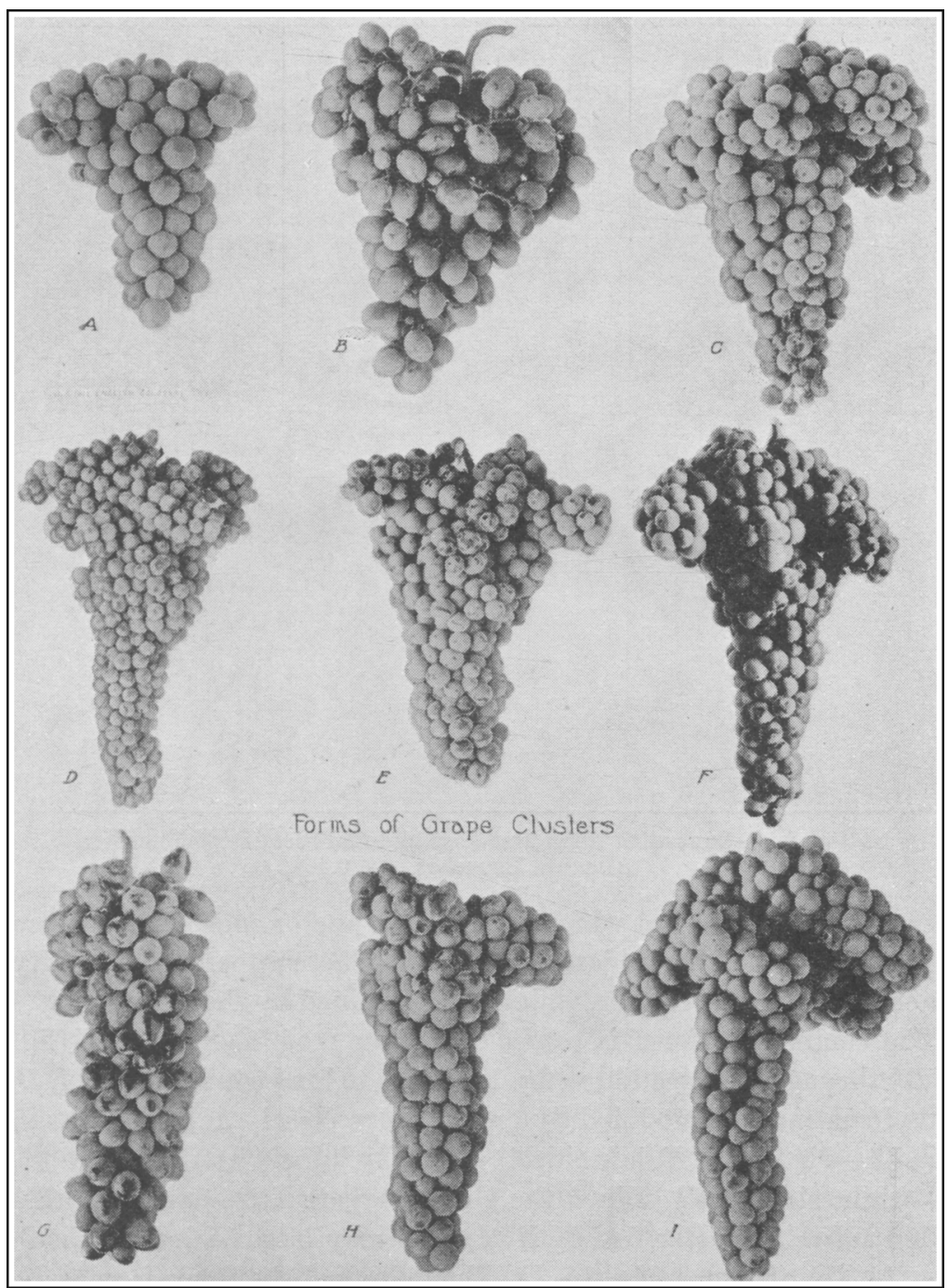

Fig. 14.-Forms of clusters: $A, B$, short conical; $C, E$, conical ; $D, F$, long conical ; $G, H, I$, cylindrical ; $C, E, H$, shouldered; $F, I$, winged. ( $\times 0.2$, approx.) 
looseness by $E$. The degrees usually recognized are : very compact ( $A$ of fig. 15$)$; moderately compact $(B)$; well filled $(C)$; loose $(D)$; and very loose $(E)$. The degree of looseness may be increased abnormally by a

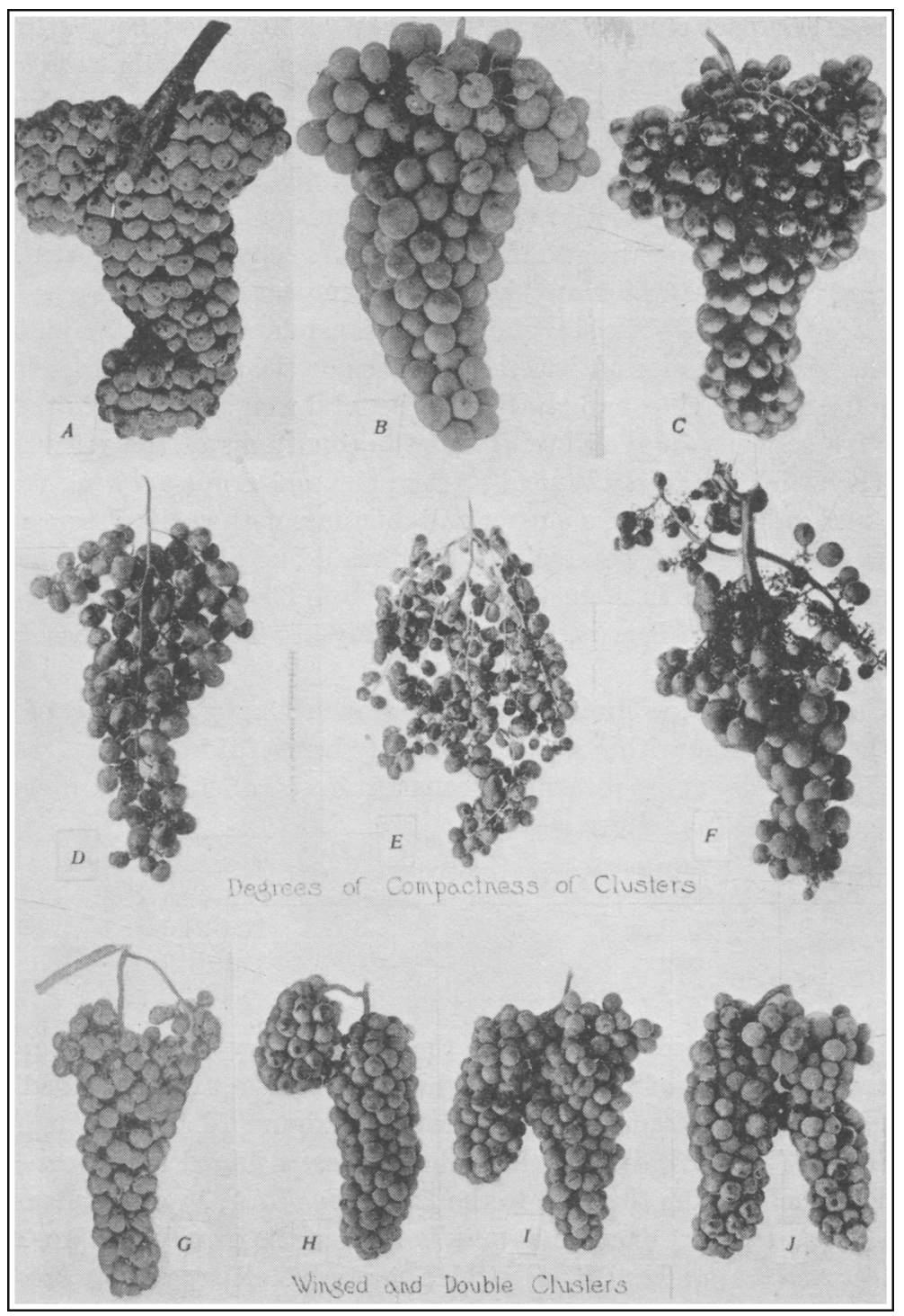

Fig. 15.-Degrees of compactness and doubling: $A$, very compact; $B$, compact; $C$, well-filled; $D$, loose ; $E$, very loose; $F$, coulured; $G-J$, series from small wing to double cluster. ( $\times 0.12$ to 0.20 .) 
failure of some of the flowers to set (fig. 15, $F$ ) (coulure) or of the berries to grow to full size (millerand, shot berries) (fig. 15, $E$ ). The degrees of compactness shown by $B, C$, and $D$ of figure 15 are the most desirable, especially for table or other grapes which have to be packed, shipped, or stored. Compact clusters are difficult to pack firmly without injury to the berries, and if very compact, the berries seem sometimes to be pulled partially loose from the pedicel during growth. Such berries offer a starting place for molds, which quickly invade the whole cluster. This and a thin skin explain the susceptibility to black mold (Aspergillus) of Zinfandel and similar varieties with compact clusters. Loose and well-filled clusters are more pleasing to the eye and more convenient for eating and drying than those which are either very compact or very loose.

Size of Cluster.-The size of a cluster depends on the size and number of the berries it contains, and these in turn on the variety, environment, condition of the vine, and relation of the total weight of crop to the productive capacity of the vine. Under the conditions of the vineyard at Davis, which are fairly typical of the principal grape-growing regions of California, the size of a cluster will fluctuate with variety from a very large one of about 6 pounds to a very small one of $1 / 4$ pound, and the number of berries in a cluster, from 1,000 to 50. Lighter clusters, or a smaller number of berries, are found rarely in vinifera varieties except with second crop.

This character has limited value for ampelography, however, because of the wide range within a variety. It may be useful in extreme cases or with varieties that are reasonably constant in size of cluster. A suggested classification is as follows:

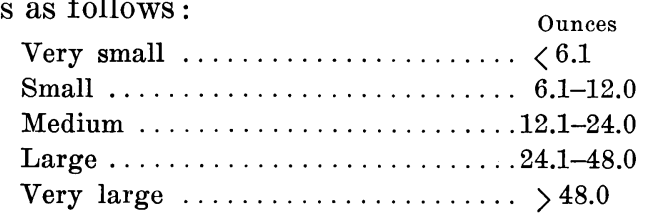

Stems.-The size and form of the cluster vary with the character of the framework of stems upon which the berries are suspended. The structure of this framework is indicated in figure 16. It consists of the peduncle $(A, a ; C, a)$, by which the cluster is joined to the cane and which reaches from the cane to the first branch $(A, b)$ of the stem; the rachis $(A, c ; C, c)$ or main "trunk" of the stem, from which are given off the main branches $(B, d)$, which may give off secondary branches $(B, e ; C, e)$; and finally the pedicels $(A, f ; C, f)$, to the ends of which are attached the berries.

The stems vary in length, thickness, texture, degree of branching, and 
color. Figures 16 and 17 illustrate some typical forms. The stem of Henab (fig. 17, $A$ ) is unusually slender, and with few and short secondary branches. Such stems facilitate packing, since they allow the cluster to be fitted into the container easily-unless, as is often the case, the stems

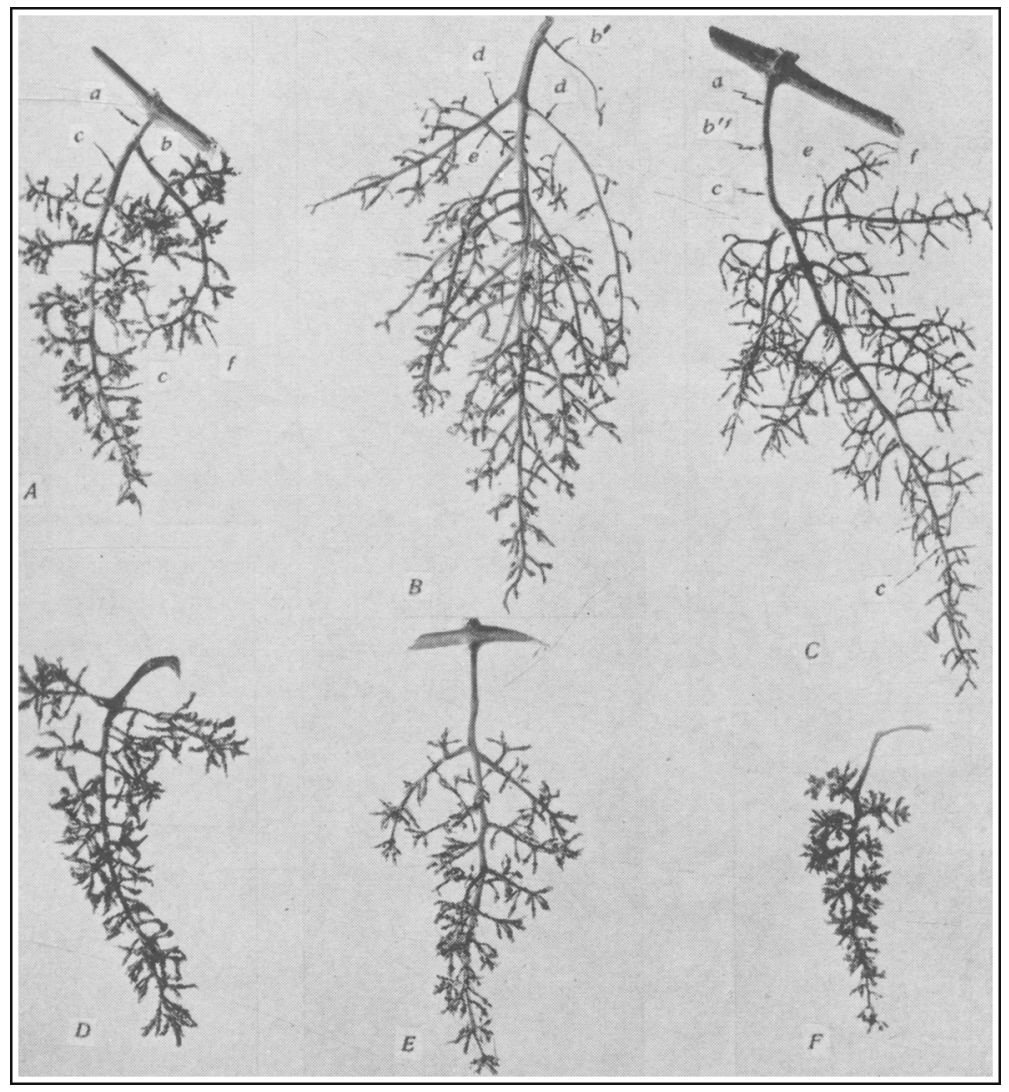

Fig. 16.-Structure of stems: $A$, Gros Colman; $B$, Hunisa; $C$, Danugue; $D$, Madresfield Court; $E$, Tokay; $F$, Beclan. $a$, Peduncle; $b$, first branch, sometimes retaining tendril character $\left(b^{\prime}\right)$ or abortive $\left(b^{\prime \prime}\right)$; $c$, rachis; $d$, main branch; $e$, secondary branch; $f$, pedicel. $(\times 0.3$.)

are brittle and the berries loosely attached. The stem of Muscat gigas (fig. 17, C) is at the other extreme. It is extraordinarily thick in all its parts. Such a stem makes packing very difficult, especially if the stems are succulent and brittle, as is usually the case. The cluster cannot be fitted into the container and a slight pressure will break the stem and dislodge berries. 


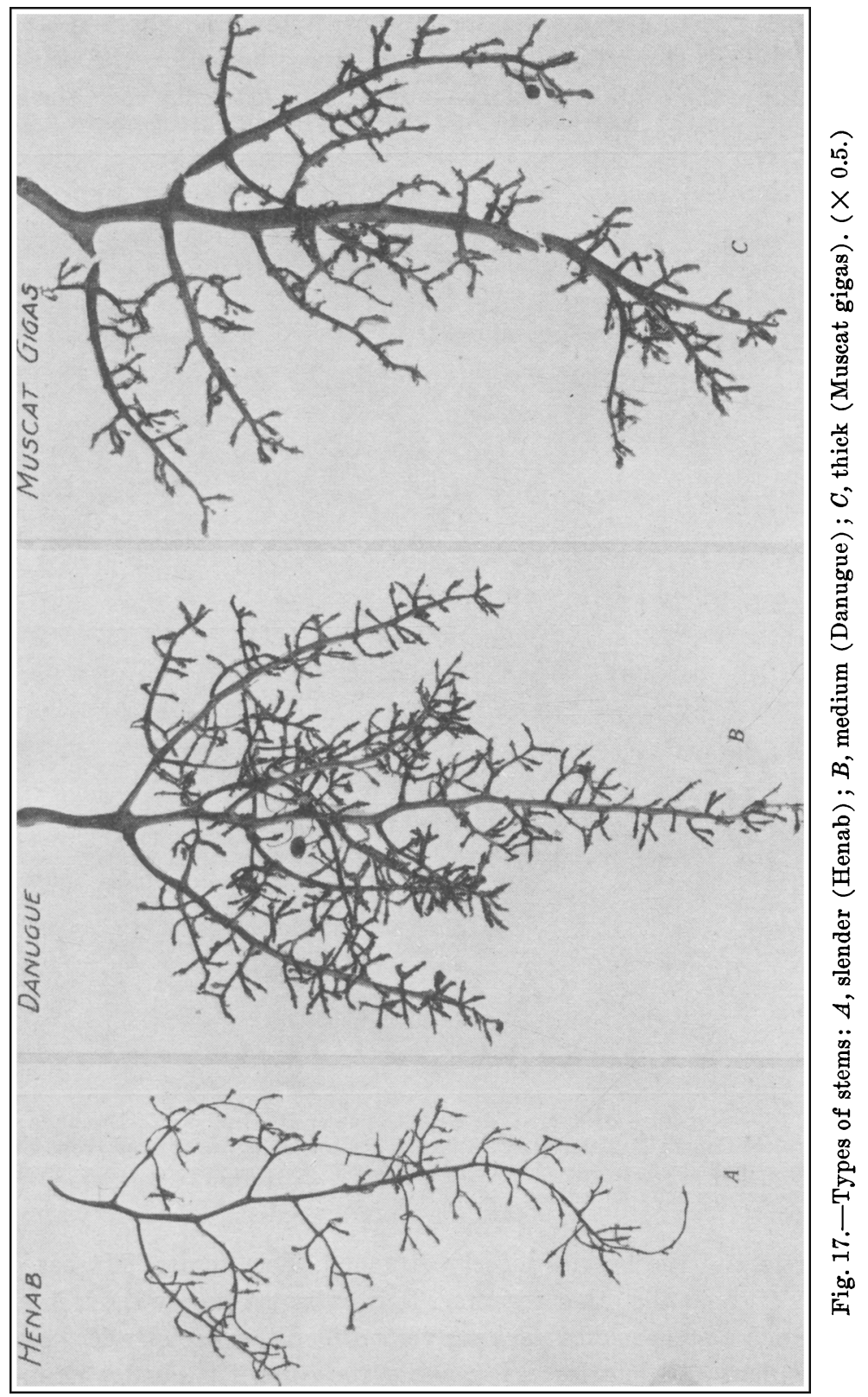


The stem of Danugue (fig. 17, B) is intermediate and is well supplied with main and secondary branches. Such a stem is excellent for packing if it has the other desirable qualities. It should be sufficiently fibrous to hold the berries well and to withstand handling without breaking. It should not remain green and herbaceous after the grapes are ripe and ready to harvest.

The peduncle should be long and firm to serve as a handle by which the clusters can be gathered and packed without danger of breaking. If it is too short or too thick and woody (fig. 16, D), the cluster is difficult to pick without injury, at least to the extent of cutting or loosening some berries or spoiling the bloom.

Often the first branch of the rachis retains its tendril character (fig. $\left.16, B, b^{\prime}\right)$ or bears only a few berries, and still more often this branch is abortive or dries up before the grapes develop (fig. 16, $C, b^{\prime \prime}$ ). This is an advantage, for the combined length of the peduncle and of the first joint of the rachis is sufficient for easy and careful handling of the cluster. With varieties in which the first branch of the rachis sets a large number of berries and thus forms a heavy compact shoulder (fig. 15, $A$ ), the cluster can be improved by removing this branch before the berries develop. Short branches and absence of secondary branches make compact clusters, difficult to pack (fig. 16, $D, F^{\prime}$ ). The various characters of the stem that are available for classification purposes are:

Size: short, long; slender, medium, thick

Texture: brittle, tough, herbaceous, woody

Branches: few, many; short, long

Color

The weight of stems varies from about 5 per cent of the weight of the cluster to about 1 per cent, but this character is inconvenient to use for classification and seldom valuable.

\section{THE LEAF}

The principal leaf characters of value in description are those of form, size, dentation, color, surface, contour, indument, texture, and petiole. These may be classified as follows :

Form, general:

Outline — cordate-orbicular, cordate-pentagonal

Ratio of width to length $(W / L)$ - very narrow, narrow, medium, wide, very wide

Lobes, number-none, three, five, more than five, lacinate

Sinuses:

Depth-none, shallow, medium, deep, very deep

Width—closed, perforate, narrow, medium, wide 


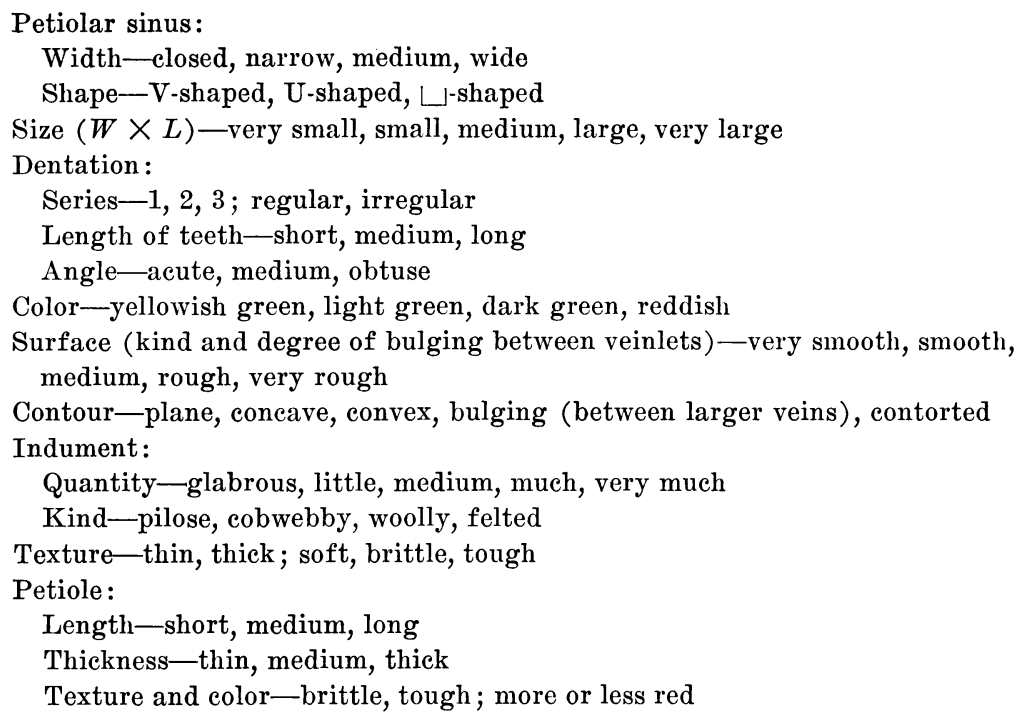

The forms of vine leaves are very diverse and complicated and offer valuable characters for classification and description. The most important are those of lobing and dentation.

Outline.-The general outline in all vinifera varieties is cordate. This cordate form may be modified so that at one extreme it is orbicular (fig. $18, E$ ) and at the other pentagonal (fig. 18, $H$ ). The asymetry or uneven growth of the two sides of the leaf, which is noticeable in some species, is usually slight in vinifera leaves and is of little value for description.

Descriptions of vine leaves often make reference to the relation of length to breadth. Such references are difficult to interpret unless the terms "length" and "breadth" are defined. The definitions adopted here are given in the section, "Method of Measuring Size" (p. 282). With these definitions, relative size can be expressed by $W \times L$ and a factor of the form by the ratio $W / L$. In leaf measurements of several hundred varieties of vinifera vines at Davis, the latter ratio has been found always greater than 1. A few leaves (for example, Feher Szagos) seem to the eye longer than wide, but this impression is contradicted by measurement. (See fig. 18,D.) The statement that the vine leaf of a certain variety is longer than wide is probably an error unless other definitions of length and width are used. If the length is taken as the distance from the apex to the farthest extension of the lower lateral lobes, the length is often slightly greater than the width, but the difference is usually slight either way, as is evidenced by the nearly circular outline of most vine leaves. The greater differences between varieties and the greater 
ease and definiteness of measurement with the method used here increases the descriptive value of the ratio $W / L$.

The ratios of width to length found in leaves of vinifera varieties at Davis have been from a little over 1.0 to a little over 1.5. The classifica-

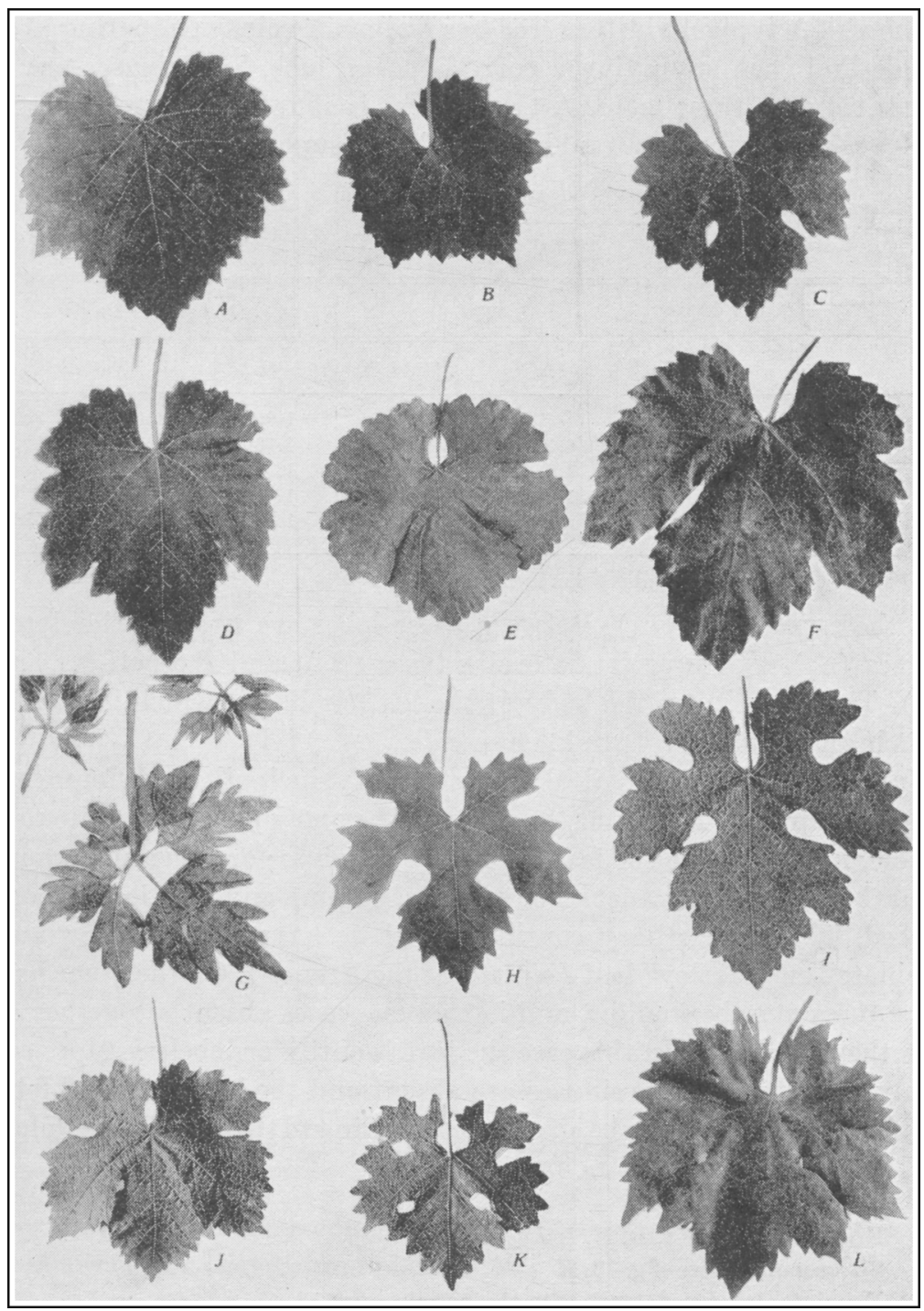

Fig. 18.-Types of leaves: $A$, Limberger; $B$, Chardonay ; $C$, Affenthaler ; $D$, Feher Szagos; $E$, Sylvaner ; $F$, Mills ; $G$, Chasselas cioutât ; $H$, Neiretto grosso ; $I$, Burger; $J$, Muscat of Alexandria ; $K$, Cabernet Sauvignon; $L$, Bellino. 
tion adopted is illustrated in table 14. The lowest value found in vinifera varieties was that of the Feher Szagos, which varies from 1.1 to 1.2 (fig. $18, D$ ), and the highest that of Muscat of Alexandria, 1.57 (fig. 18, $J$ ). The relatively narrow range of $W / L$ between varieties limits the use of this measurement in separating varieties.

Lobes.-A typical vinifera leaf has five main veins originating at the petiole and each supplying a corresponding lobe. The sinuses are the spaces between these lobes. A typical leaf is shown in figure 19. It has five lobes : two inferior lateral lobes $\left(L_{1}\right)$, two superior lateral lobes $\left(L_{2}\right)$,

TABLE 14

Ratio of Width to LeNGTH of Grape Leaves

\begin{tabular}{|c|c|c|c|c|}
\hline \multirow{2}{*}{ Class } & \multicolumn{2}{|c|}{$W / L$} & \multicolumn{2}{|c|}{ Examples-Davis } \\
\hline & Limits & Midvalue & $W / L$ & Variety \\
\hline Very narrow.. & $<1.15$ & 1.1 & 1.05 & Brockton* \\
\hline Narrow......... & $1.15-1.24$ & 1.2 & 1.18 & Feher Szagos \\
\hline Medium.... & $1.25-1.34$ & 1.3 & 1.30 & Grec rouge \\
\hline Wide....... & $1.35-1.44$ & 1.4 & 1.40 & Petit Bouschet \\
\hline Very wide. & $>1.44$ & 1.5 & 1.57 & Muscat of Alexandria \\
\hline
\end{tabular}

* Brockton is an American variety, not a vinifera.

and the apical lobe $\left(L_{\mathrm{a}}\right)$. Between these lobes are two inferior lateral sinuses $\left(S_{1}\right)$, two superior lateral sinuses $\left(S_{2}\right)$, and the petiolar sinus $\left(S_{\mathrm{p}}\right)$. This constitutes the body of the leaf, or blade, which is attached to its branch by the leaf stalk, or petiole.

Variations from this typical form are due principally to differences in number, depth, and shape of the sinuses. They may penetrate quite to the petiole, in which case the leaf becomes 5-foliolate; or other sinuses may occur between the branches of the main vein, and the leaf becomes 7-lobed. This process may continue until we have what is known as a "lacinate" or "parsley" leaf (cioutât of the French). On the other hand, the sinuses may be shallow, and in extreme cases absent altogether and with them the lobes. In this case the leaf is entire or lobeless. More commonly the lower lateral sinuses are absent and the leaf is then 3-lobed. Vinifera leaves may thus be classified according to their lobing as follows:

Entire, without lobes-fig. 18, $A, B$

Three-lobed-fig. 18, $C$

Five-lobed-fig. 18, $D, H, I, J$

Six or more lobes-fig. $18, K$

Foliolate, lobes penetrating to the petiole-fig. 18, $G$

The Chasselas cioutât occasionally found mixed in plantings of Chasselas doré is the best-known example of foliolate vine leaves. Figure 18, $K$ 
shows an approach to seven sinuses. In some varieties this approach to seven lobes is frequent. Examples are Cabernet Sauvignon, Burgrave, Neiretto grosso, Damas rose, and Sultana. Abnormally deep or numerous sinuses often occur on suckers, water-sprouts, and individual vines.

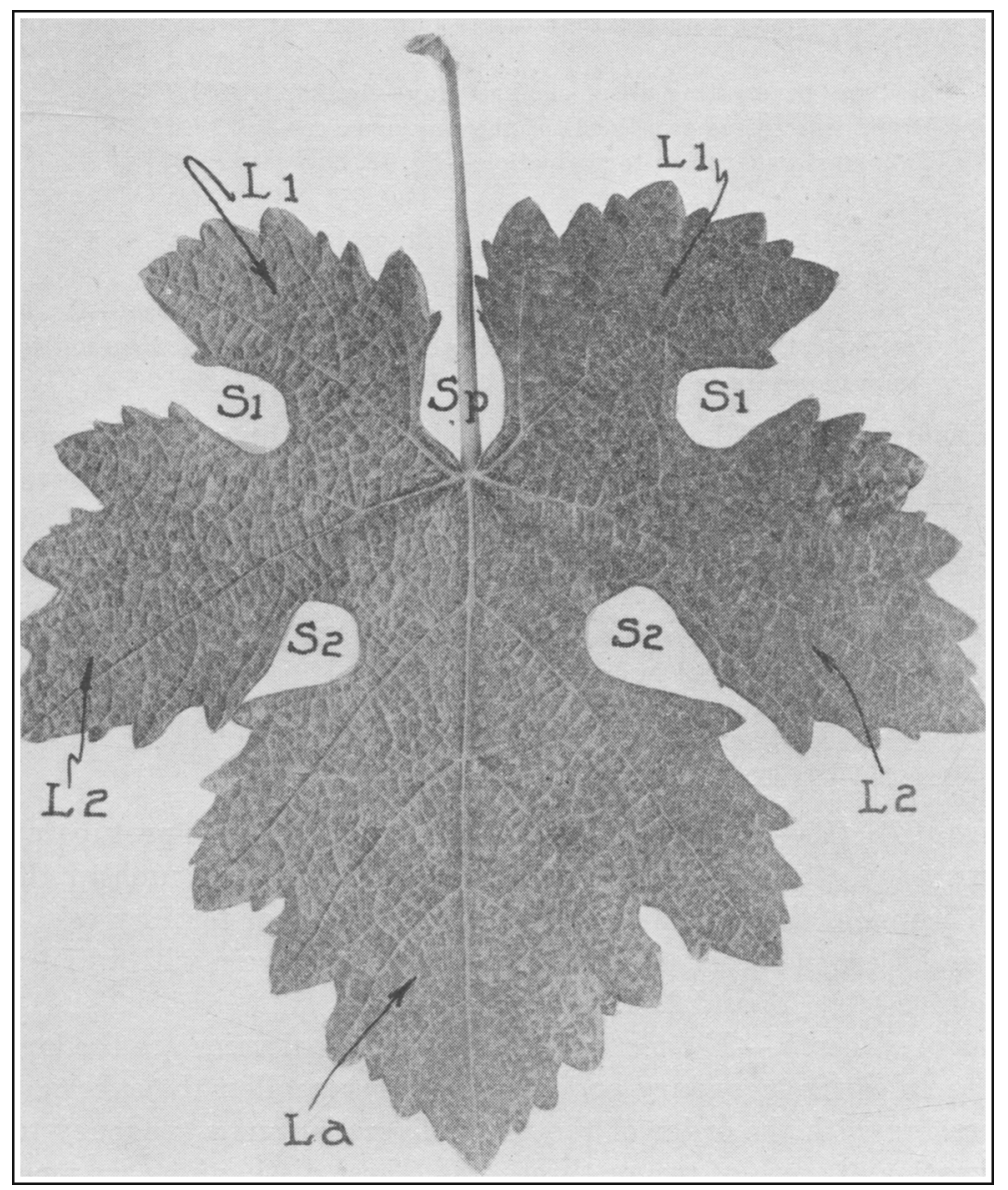

Fig. 19.-A typical vinifera leaf: $L_{1}$, inferior lateral lobes; $L_{2}$, superior lateral lobes; $L_{\mathrm{a}}$, apical lobe; $S_{1}$, inferior lateral sinuses; $S_{2}$, superior lateral sinuses; $S_{\mathrm{p}}$, petiolar sinus.

Very deep sinuses are common on seedlings, especially during the first few years before they begin to bear.

The lobes vary in shape, but it is most convenient to consider the shape of the sinuses, which is a necessary consequence of the shape of the lobes. Sinuses.-There are normally five sinuses-two upper, two lower, and 
the petiolar sinus. The last has peculiarities of its own and is considered by itself. The sinuses vary in number, depth, and form (fig. 18). They may be classified according to depth and form as follows :

Depth:

None except the petiolar sinus-fig. 18, $A, B$

Shallow, penetrating less than one-third of the way to the petiole-fig. 18, $D, E$

Medium, penetrating about one-half way-fig. $18, J, K$

Deep, penetrating two-thirds of the way or more-fig. $18, H, I$

Foliolate, penetrating to the petiole-fig. 18, $G$

Form:

Narrow, the lobes near together but not touching-fig. 18, $C, D, F$

Wide, the lobes wide apart-fig. 18, $H, I$

Closed, the lobes overlapping so that the sinus is not apparent-fig. $18, L$

Perforate, the lobes overlapping only above and not near the base so that the sinus appears as a hole through the leaf-fig. $18, K$; fig. $20, A$

Petiolar Sinus.-The characters considered in the petiolar sinus are its width and its shape, and the angle at its base. The following terms may be used in classifying this sinus :

Closed, lobes overlapping-fig. 20, I

Narrow, width less than depth-fig. $19, S_{\mathrm{p}}$

Medium, width about equal to depth-fig. 20, $B, E$

Wide, width greater than depth-fig. 20, $A, D$

Angle at base acute-fig. 20, $G$

Base rounded-fig. 20, $D, E, C$

Base flat-fig. 20, $A, B$

Size of Teeth.-The margin of the leaf is furnished with protuberances known as "teeth." These teeth differ in size, form, and number. Each tooth occurs at the terminus of a main, secondary, or tertiary vein, and its size differs in accordance with the order of the vein with which it is associated (figs. 19 and 21).

Series of Teeth.-The teeth of the five principal veins are the largest and those of the secondary and tertiary veins smaller, the average size decreasing with the order of the veins. There is thus a tendency to an alternation of teeth of two or three sizes. These distinctions are more or less marked with different varieties. At one extreme there may be little difference in the size of the teeth of the veins of different orders. In this case the teeth are said to be regular, or in one series. This case occurs in vinifera $X$ labrusca hybrids but is rare in pure vinifera. At the other extreme may be found five large teeth corresponding to the five main veins ; a larger number, about 15 to 25 , of moderately large teeth corresponding to the secondary veins occurring between the very large teeth; and a somewhat larger number, 20 to 50, of small teeth corresponding to 
the tertiary veins, occurring between the moderately large teeth (fig. 18, $H, L$, and fig. 22). The teeth are then said to be irregular, or in three series. Cases of three series are commoner than those of one. The distribution of teeth in a typical leaf with three series is shown in figure 23

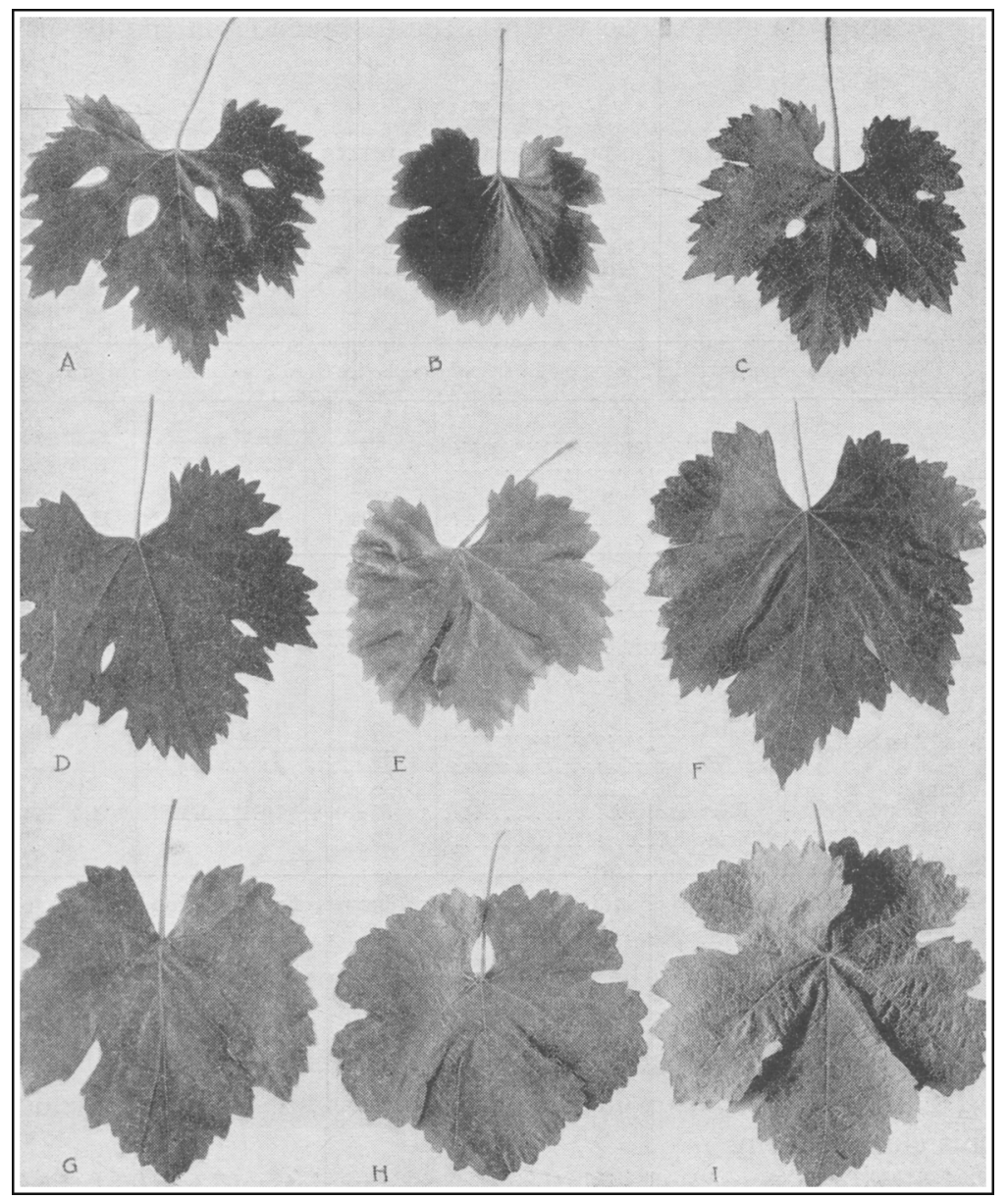

Fig. 20.-Types of petiolar sinuses: $A$, square base, wide; $B$, square base; $C$, rounded; $D$, U-shaped, wide; $E$, U-shaped ; $F, \mathrm{U}$-V-shaped ; $G$, V-shaped ; $H$, overlapping; $I$, closed.

(p. 283) and in table 19. A common case is where the difference of size between the teeth of the main veins and of their main branches is not great. In this case there is a fairly regular alternation of large and small teeth, and they are said to be in two series (fig. 18, $I, K$ ). 
Acuity of Teeth.-The teeth are roughly triangular and appear narrow or wide, pointed or rounded, according to their apical angles and the curves of their sides. These angles can be measured directly with a protractor or determined by the ratio between the length and the width of the tooth. The length is the distance from the apex to the base, along a line bisecting the angle. The width is the distance from the lower end

TABLE 15

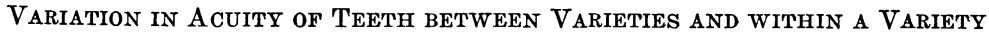

\begin{tabular}{|c|c|c|c|c|}
\hline \multirow{2}{*}{ Group or variety } & \multirow{2}{*}{ Series } & \multirow{2}{*}{$\begin{array}{c}\text { Number } \\
\text { of } \\
\text { teeth }\end{array}$} & \multicolumn{2}{|c|}{ Acuity of teeth } \\
\hline & & & $\begin{array}{c}\text { Mean or } \\
\text { weighted mean }\end{array}$ & $\begin{array}{l}\text { Standard } \\
\text { deviation }\end{array}$ \\
\hline
\end{tabular}

Variation between varieties; based on 5 teeth of each series from 1 leaf of each variety

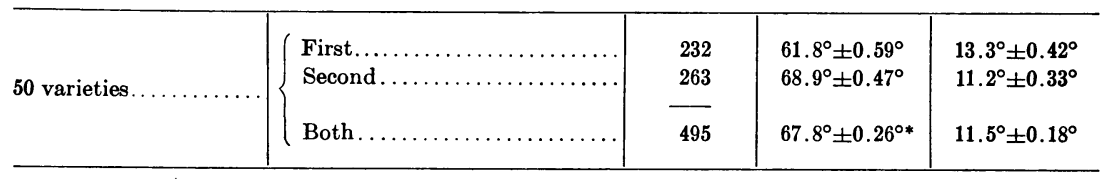

Variation within a variety; based on 5 teeth of each series on 1 leaf from each of 10 vines

\begin{tabular}{|c|c|c|c|c|}
\hline Hunisa.... & 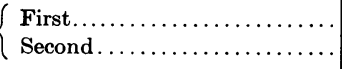 & $\left.\begin{array}{l}50 \\
50\end{array}\right\}$ & $77.3^{\circ} \pm 0.42^{\circ *}$ & $4.4^{\circ} \pm 0.30^{\circ}$ \\
\hline Muscat of Alexandria... & $\left\{\begin{array}{l}\text { First } \ldots \ldots \ldots \ldots \ldots \ldots \ldots \ldots \ldots \ldots \ldots \ldots \\
\text { Second } \ldots \ldots \ldots \ldots \ldots \ldots \ldots\end{array}\right.$ & $\left.\begin{array}{l}50 \\
50\end{array}\right\}$ & $63.5^{\circ} \pm 0.74^{\circ *}$ & $7.7^{\circ} \pm 0.57^{\circ}$ \\
\hline Damas rose. & $\left(\begin{array}{l}\text { First } \ldots \ldots \ldots \ldots \ldots \ldots \ldots \ldots \ldots \ldots \ldots \ldots \ldots \ldots \ldots \\
\text { Second } \ldots \ldots \ldots \ldots \ldots \ldots \ldots\end{array}\right.$ & $\left.\begin{array}{l}50 \\
50\end{array}\right\}$ & $79.1^{\circ} \pm 0.43^{\circ *}$ & $4.5^{\circ} \pm 0.30^{\circ}$ \\
\hline
\end{tabular}

* Mean for both series weighted according to the ratio $5: 27$ between first and second series.

of the shorter side to the other side along a line perpendicular to the line bisecting the angle.

The larger teeth influence the aspect of the leaf much more than the smaller, and for this reason only the first and second series are considered in this classification.

To indicate the range of variation between varieties, 5 teeth of the first series and 5 of the second were measured on a typical leaf of each of fifty varieties, with the results given in table 15 .

The average ratio of the first series of teeth to the second series was 5 to 27 , so that the measurement of both series together or of one average first-series tooth with 5 or 6 average second-series would give a close approximation to the correct figure for the whole leaf.

To indicate the variation within a variety, 5 teeth of the first series and 
5 of the second were measured on a typical leaf from 10 vines of each of three varieties; the results are reported in the second part of table 15.

The apical angle as determined by measurements of fifty varieties ranges from something under $40^{\circ}$ to something over $100^{\circ}$. It varies with the series and size of the teeth and with the variety. The 5 large teeth of the first series are the most acute and the small teeth of the third series
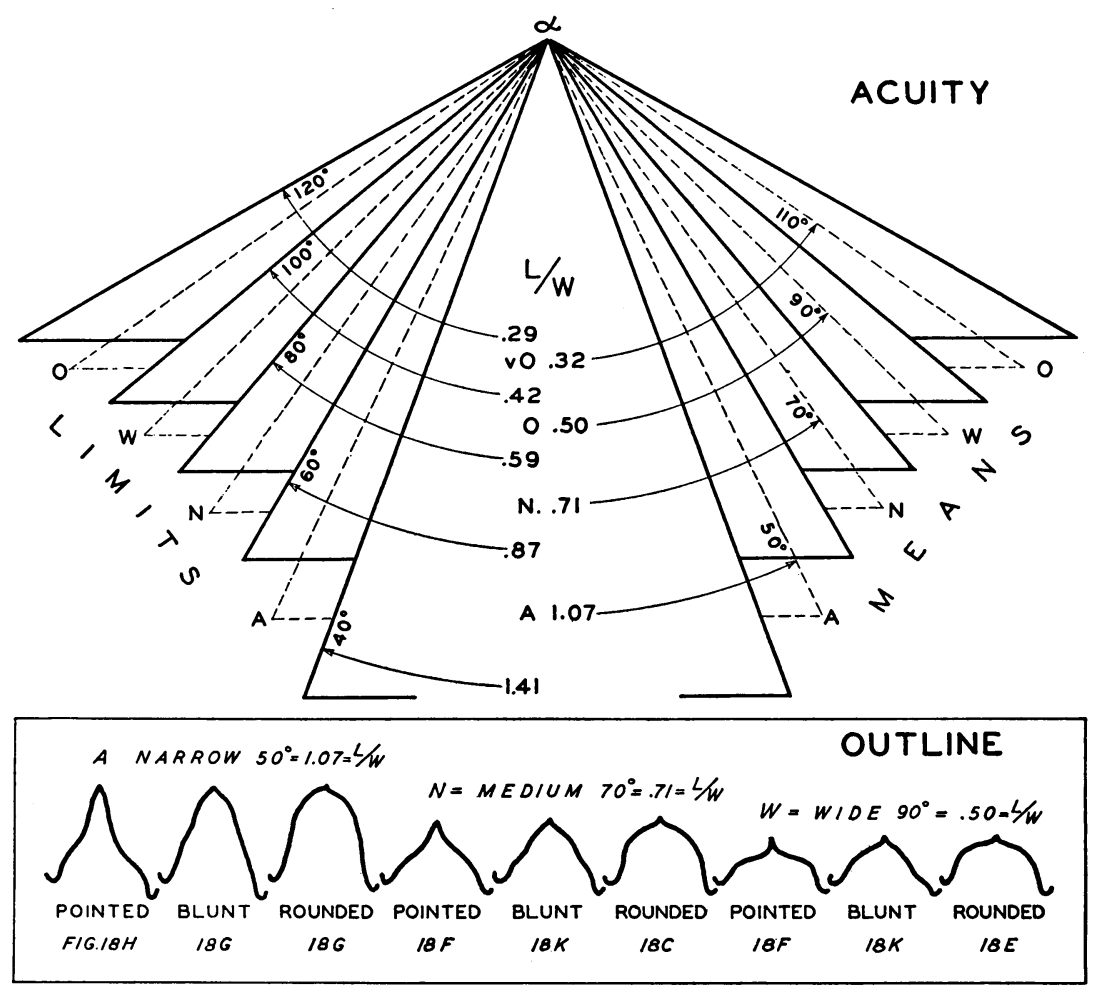

Fig. 21.-Vine-leaf dentation; above, means and limits of angle classes; below, outline classes. $v O$, Very obtuse; $O$, obtuse; $W$, wide; $N$, medium; $A$, narrow. For examples of teeth of these classes, see figure 18 as indicated.

the most obtuse. The angles of the second-series teeth approach those of the first. The angles of the third-series are of little use in classifying because they affect but slightly the apparent general acuity of the teeth and are difficult to measure. The average sharpness of angle of the two large series is quickly recognized and can be used as a basis of classification. The classification according to apical angle is given in table 17 and diagrammatically, together with the relation of angle to the ratio of length divided by width, in figure 21 . 
Number of Teeth.-The total number of teeth to a leaf, including all series, is fairly constant within certain limits on a normal leaf from about the sixth to the eighth joint of the cane. This is indicated by the results of countings of several leaves of each of three varieties (see table 16). Each leaf of a variety was taken from a different vine.

To determine the range of a number of teeth in a large number of varieties, counts were made of a single leaf of each of 48 varieties. Table 16 reports the data obtained.

From these two experiments, it appears that the number of teeth to a

TABLE 16

VARIATION IN NUMBER OF TEETH BETWEEN 48 VARIETIES AND WITHIN A VARIETY, DAVIS

\begin{tabular}{|c|c|c|c|c|}
\hline \multirow{2}{*}{ Group or variety } & \multirow{2}{*}{$\begin{array}{c}\text { Number } \\
\text { of } \\
\text { leaves }\end{array}$} & \multicolumn{3}{|c|}{ Number of teeth per leaf } \\
\hline & & Mean & $\begin{array}{l}\text { Standard } \\
\text { deviation }\end{array}$ & Range \\
\hline 48 varieties.... & 48 & $65.0 \pm 1.29$ & $13.3 \pm 0.92$ & $98-41$ \\
\hline Hunisa....................... & 9 & $60.7 \pm 1.32$ & $5.9 \pm 0.94$ & $69-52$ \\
\hline Damas rose $\ldots \ldots \ldots \ldots \ldots \ldots \ldots \ldots \ldots$ & 10 & $76.9 \pm 1.69$ & $7.9 \pm 1.19$ & $90-66$ \\
\hline Muscat of Alexandria $\ldots \ldots \ldots \ldots \ldots \ldots \ldots$ & 8 & $97.8 \pm 1.79$ & $7.5 \pm 1.35$ & $103-91$ \\
\hline
\end{tabular}

leaf is fairly regular and can be used as a character to help in the classification of varieties. See table 17.

Apex.-The curves of the sides of the teeth vary (fig. 21), as does the apical angle. Three general forms can be distinguished-pointed, blunt, and rounded.

Note-taking.-Time and space can be economized by using the summary of table 17, taking the characters in the order given. For many purposes measurements are not needed. The approximation of a careful estimate is often sufficient, especially if the judgment is controlled by an occasional measurement. The number of classes given with each character can be easily distinguished with a little practice. A simple system of symbols or abbreviations can be devised for notes. In cases of doubt a plus or minus sign after the symbol is useful.

Petiole.-The petioles (leaf stalks) vary in length, thickness, texture, color, and the angle they make with the blade.

The length is expressed by its relation to the length of the midvein. It varies considerably with the position of the leaf. Leaves growing rapidly and in the shade tend to have longer petioles, while leaves growing in full sunlight usually have shorter ones. The average length, with leaves on canes of medium vigor growing in the normal position-that is, near the 
TABLE 17

Classes of Leaf Dentation

\begin{tabular}{|c|c|c|c|c|}
\hline Class & \multicolumn{2}{|c|}{ Midvalue } & Limits & Examples \\
\hline \multicolumn{5}{|c|}{ Series } \\
\hline 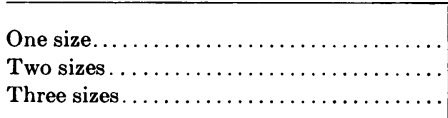 & \multicolumn{2}{|c|}{$\begin{array}{l}\cdots \cdots \\
\cdots \cdots \\
\cdots \cdots \cdots\end{array}$} & $\begin{array}{l}\cdots \cdots \\
\cdots \cdots \\
\cdots \cdots\end{array}$ & $\begin{array}{l}\text { Burger, Cabernet Sauvignon } \\
\text { Neiretto grosso, Bellino }\end{array}$ \\
\hline \multicolumn{5}{|c|}{ Size of teeth } \\
\hline 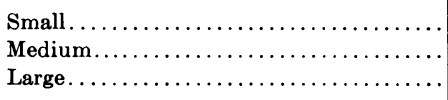 & \multicolumn{2}{|c|}{$\begin{array}{l}\cdots \cdots \cdots \\
\cdots \cdots \cdots \\
\cdots \cdots \cdots\end{array}$} & $\begin{array}{l}\cdots \cdots \\
\cdots \cdots \\
\cdots \cdots\end{array}$ & $\begin{array}{l}\cdots \cdots \\
\cdots \cdots \\
\cdots \cdots\end{array}$ \\
\hline \multicolumn{5}{|c|}{ Acuity } \\
\hline 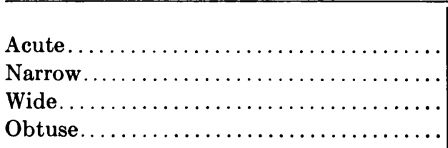 & $\begin{array}{l}L / W \\
1.07 \\
0.71 \\
0.51 \\
0.32\end{array}$ & $\begin{array}{c}\text { Angle } \\
50^{\circ} \\
70^{\circ} \\
90^{\circ} \\
110^{\circ}\end{array}$ & $\begin{array}{r}\text { Angle } \\
<60^{\circ} \\
60^{\circ}-79^{\circ} \\
80^{\circ}-99^{\circ} \\
>99^{\circ}\end{array}$ & $\begin{array}{l}\text { Blaue Elbe, } 55^{\circ} \\
\text { White Corinth, } 71^{\circ} \\
\text { Muscadet, } 94^{\circ} \\
\text { Sylvaner, } 120^{\circ}\end{array}$ \\
\hline \multicolumn{5}{|c|}{ Number of teeth } \\
\hline 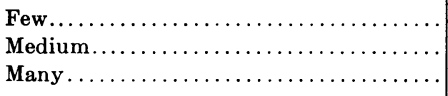 & \multicolumn{2}{|c|}{$\begin{array}{l}45 \\
65 \\
95\end{array}$} & $\begin{array}{c}<50 \\
50-79 \\
>79\end{array}$ & $\begin{array}{l}\text { Neiretto, } 42 \\
\text { Hunisa, } 62 \\
\text { Muscat of Alexandria, } 98\end{array}$ \\
\hline \multicolumn{5}{|c|}{ Apex } \\
\hline 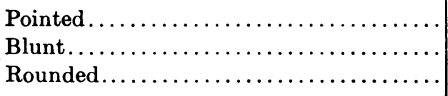 & \multicolumn{2}{|c|}{$\begin{array}{l}\cdots \cdots \cdots \\
\cdots \cdots \cdots \\
\cdots \cdots \cdots\end{array}$} & $\begin{array}{l}\cdots \cdots \\
\cdots \cdots \\
\cdots \cdots\end{array}$ & $\begin{array}{l}\text { Fig. } 18, H, F \\
\text { Fig. } 18, G, K \\
\text { Fig. } 18, G, C, E\end{array}$ \\
\hline
\end{tabular}

middle of the cane-is fairly constant. It varies from distinctly longer to distinctly shorter than the midvein. The thickness varies in a similar way. With practice one soon learns to distinguish between an average

TABLE 18

Size Classes of Leaves

\begin{tabular}{|c|c|c|c|c|c|c|}
\hline \multirow{2}{*}{ Class } & \multicolumn{2}{|c|}{$W \times L$} & \multicolumn{4}{|c|}{ Example (Davis) } \\
\hline & Midvalue & Limits & Variety & $L$ & $W$ & $W \times L$ \\
\hline Very small. . & $\begin{array}{l}\text { sq. } \mathrm{cm} \\
\ldots \ldots\end{array}$ & $\begin{array}{c}8 q . \mathrm{cm} \\
<75\end{array}$ & Bonarda & $\begin{array}{l}c m \\
7.3\end{array}$ & $\begin{array}{l}c m \\
6.3\end{array}$ & $\begin{array}{c}\text { sq. } \mathrm{cm} \\
46\end{array}$ \\
\hline Small............. & 100 & 75-149 & Beclan & 12.0 & 10.0 & 120 \\
\hline Medium................ & 200 & $150-299$ & Robin noir & 15.0 & 11.0 & 165 \\
\hline Large.................. & 400 & $300-600$ & Hunisa & 24.0 & 20.0 & 480 \\
\hline Very large $\ldots \ldots \ldots \ldots \ldots$ & $\ldots$ & $>600$ & Chaouch & 33.0 & 27.0 & 891 \\
\hline
\end{tabular}


thickness and the extremes of thickness and thinness. The terms used in description are as follows :

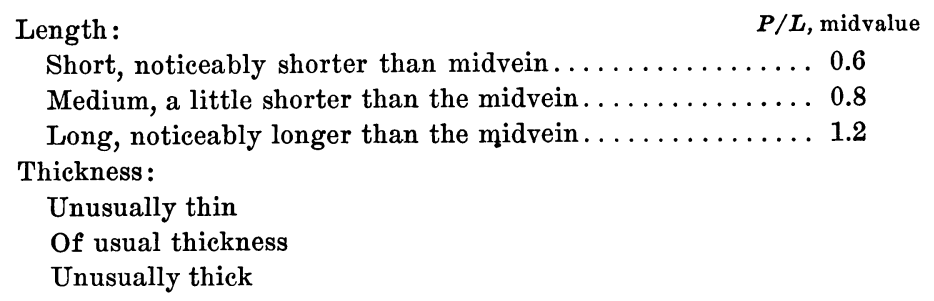

The other characters of the petiole are useful only in special cases. The texture may be unusually tough or unusually brittle. The color may be reddened more or less. This character, which the petiole shares with the veins, varies with age and exposure and is of value only in cases where it is absent from the mature leaves or where it appears on the young leaves or with unusual intensity on the old. The angle which the petiole makes with the blade varies from nearly $180^{\circ}$ (no angle) or extreme obtuseness, to an acute angle of as little as $45^{\circ}$. This angle is of importance in considering species, but is of little use in describing vinifera varieties. It varies almost from one extreme to the other on the same vine. Leaves tend to grow toward the light and if situated in the shade the obtuseness of the angle with the petiole will be greatly increased, while leaves growing in full sunlight tend to bend back toward the petiole and the angle becomes acute.

Leaf Size.-The leaf dimensions generally used are width and length, and from these the relative size or area can be indicated by the product $W \times L$ and the general form by the ratio $W / L$. Leaves from different parts of the shoot or cane differ in both of these respects, especially in size. The first leaf at the base of the cane is always smaller and less lobed, and the leaves generally increase in area with their distance from the base for several nodes. From the third or fourth node the size of the fully developed leaves on the same cane is usually fairly regular, but variations of vigor and rapidity of growth caused by changes in temperature and soil moisture during the elongation of the shoot may result in considerable variation. If care is taken to choose fully developed leaves beyond the sixth node on a cane which is growing with average vigor and normal exposure to light and air and with a normal crop, and which has not been pinched or topped, the measurements will usually be accordant and useful for comparing varieties growing under the same conditions of soil, water, climate, and training.

In order to obtain a measure independent of the environment and gov- 
erned only by the nature of the variety, Ravaz has proposed to express the relative size of the leaf by the ratio between the length of a normal leaf and the length of the internode where it occurs. This ratio, however, is not independent of all conditions; in fact, it is influenced more than

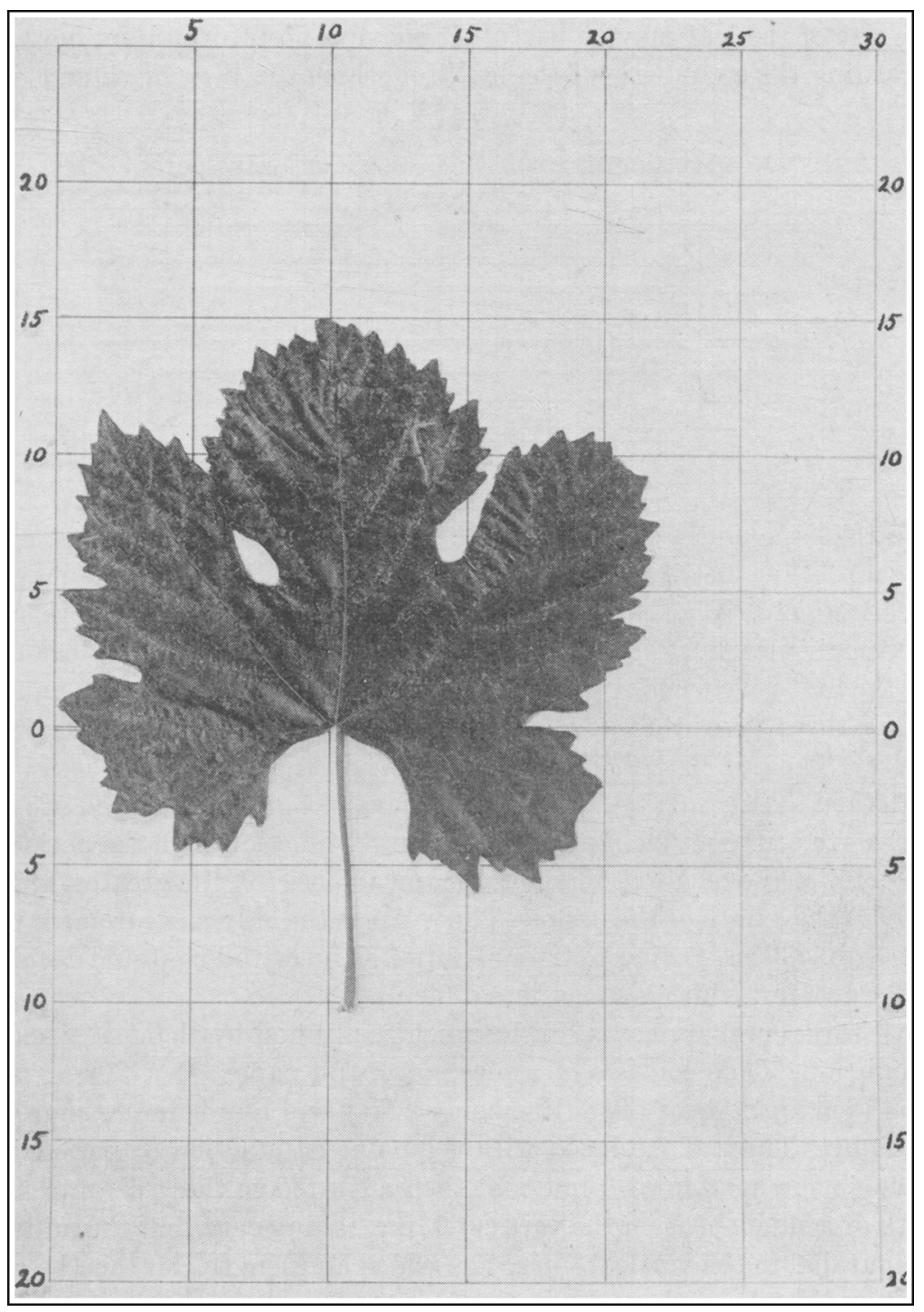

Fig. 22.-Leaf-measuring card $(\times 0.33): L=15 ; W=22 ; P=10.5$; $W \times L=330 ; W / L=1.47 ; P / L=0.70$. Ordinary millimeter graph paper is used, but in this photograph the finer lines are not visible. 
the actual size of the leaf by some. If the tip of a growing shoot is removed, as in pinching and topping, the leaves will become larger and the nodes near the point of injury will be shortened, with the result that the ratio of leaf length to node length will be greatly influenced. With care in avoiding abnormal cases, however, this method of indicating the relative size of the leaf may be useful. It conveys no information, however, regarding the actual size of the leaf, for which the $W \times L$ value is per-

TABLE 19

Number and Distribution of Teeth on Leaf Shown IN Figure 23

\begin{tabular}{|c|c|c|c|c|c|c|}
\hline \multirow{2}{*}{ Series } & \multicolumn{5}{|c|}{ Lobes (numbered counterclockwise) } & \multirow{2}{*}{ Total } \\
\hline & No. 1 & No. 2 & No. 3 & No. 4 & No. 5 & \\
\hline 1 & 1 & 1 & 1 & 1 & 1 & 5 \\
\hline 2 & 3 & 6 & 8 & 6 & 3 & 26 \\
\hline 3 & 6 & 8 & 10 & 7 & 5 & 36 \\
\hline Total & 10 & 15 & 19 & 14 & 9 & 67 \\
\hline
\end{tabular}

haps the best; and, as the latter value properly controlled gives as accurate a relative measure when comparing varieties in the same vineyard or collection, it is perhaps to be preferred for most purposes. Here, also, abnormal cases must be excluded. A graft on a large vigorous stock during the first year when it produces no crop may have leaves with an area two or three times that of normal leaves on a bearing vine of the same variety. The size classes adopted are shown in table 18.

Method of Measuring Size.-The dimensions of the leaf used are (a) the length of the midvein measured from its junction with the petiole to the point of the terminal tooth of the apical lobe, $(b)$ the greatest width, and $(c)$ the length of the petiole. The width is the only measurement that offers difficulties. Owing to irregularities of form and contour, deciding on the greatest width is sometimes difficult.

All three measurements can be much facilitated by the device shown in figure 22. This consists of a piece of graph paper $30 \times 50 \mathrm{~cm}$, with lines $1 \mathrm{~cm}$ apart, every fifth line being heavy and numbered as shown in the figure. The leaf is placed with the point of junction of petiole and blade on the horizontal 0 line and then adjusted so that the outermost tooth of a side lobe is on the vertical 0 line, taking care that the midvein lies parallel to the vertical lines. The width and length can then be read off immediately without hesitation.

Leaf Color.-The colors recognized in vine leaves are yellow (yellowish green), light green, dark green, and reddish, in each case sometimes 
bronzed more or less. The color varies somewhat with age, soil, and climate but is of value in distinguishing varieties which are much alike otherwise. Mixtures in vineyard and nursery can often be detected more easily

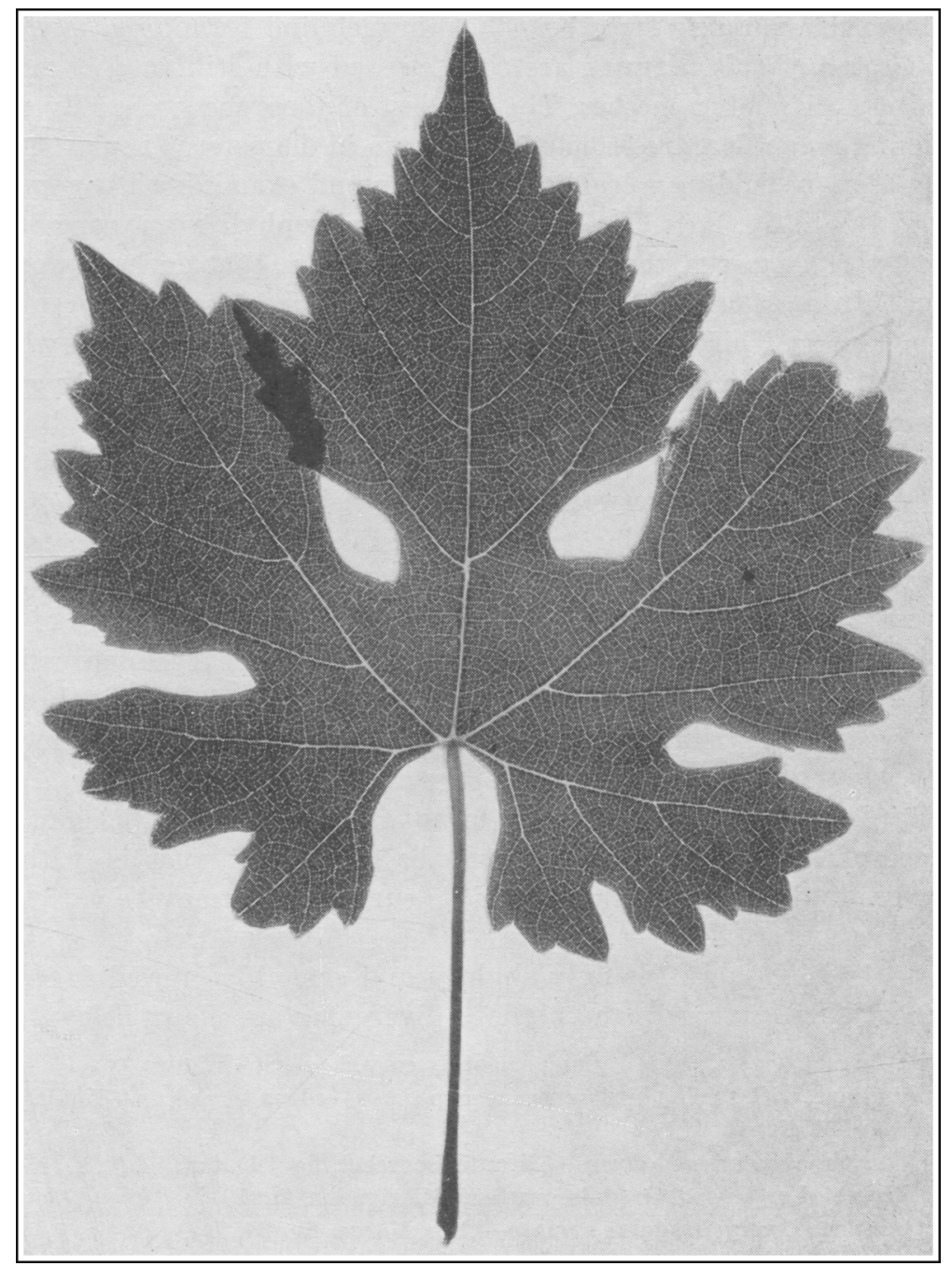

Fig. 23.-Veining and dentation of leaf, showing number and distribution of teeth. (See table 19.)

by differences in the color of the leaves than in any other way. The color to be noted is that of the upper side. That of the lower is modified by the indument. 
Leaf Surface.-The appearance of the leaves varies from more or less smooth to more or less rough, according to the variety. This appearance is due to the condition of the mesophyll between the veins. The five main veins send out branch veins on each side, and between these branches are smaller veins running from branch to branch and forming a network. The meshes of this network are then crossed with still smaller veins, forming still smaller meshes. The smallest of these meshes, easily seen without a magnifier, are from 0.5 to $1.0 \mathrm{~mm}$ in diameter. They are most easily seen by holding a leaf up to the sun and examining it by transmitted light (fig. 23). The surface of the mesophyll is in some cases almost perfectly even, that is, it lies in one plane so that the leaf appears smooth. In most cases it is more or less raised or bulging between the veins (fig. 19). This is most clearly seen on the underside of leaves which have little indument. Here the bulges are shown by corresponding depressions.

In the leaves of some varieties, these depressions are very shallow and correspond to the first network (fig. 23) of the large meshes; and as the surface in each of these larger meshes remains smooth and even, such leaves will appear fairly smooth (fig. 24, $A, C, F$ ). In other varieties, depressions occur also in the smaller meshes, and the roughness of the leaf increases in proportion to the number and depth of these depressions and their corresponding bulges on the upper side (fig. 24, $B, E$ ). Leaves may be classed as smooth and rough, but only the extremes, very smooth and very rough, have much practical descriptive value.

Leaf Contour.-By "contour" is meant the gross configuration of the surface of the leaf. A vine leaf may be nearly flat, that is, without wrinkles, folds, or marked curves in its surface, or it may be variously curved or contorted.

A leaf which is flat or only slightly and smoothly curved is called "plane." Various degrees and kinds of divergence are shown below :

Plane, flat or only slightly and smoothly curved-most varieties

Concave, with tendency to saucer or cup shape--edges turned up-Khalili, fig. 24, $C$

Convex, edges turned down-Alicante Bouschet, fig. 24, $A$

Wrinkled or bulged, irregular surface-Carignane, fig. 19

Contorted, very irregular surface-Gros Maroc, fig. 24, $B$

Most varieties would be characterized as "plane," so that this classification has much value only in special and extreme cases. (See fig. 24.)

Indument.-All vine leaves are more or less hairy, though in many cases nearly all the hairs fall off when the leaves are very young. There are two distinct forms-short, straight, upright hairs growing princi- 


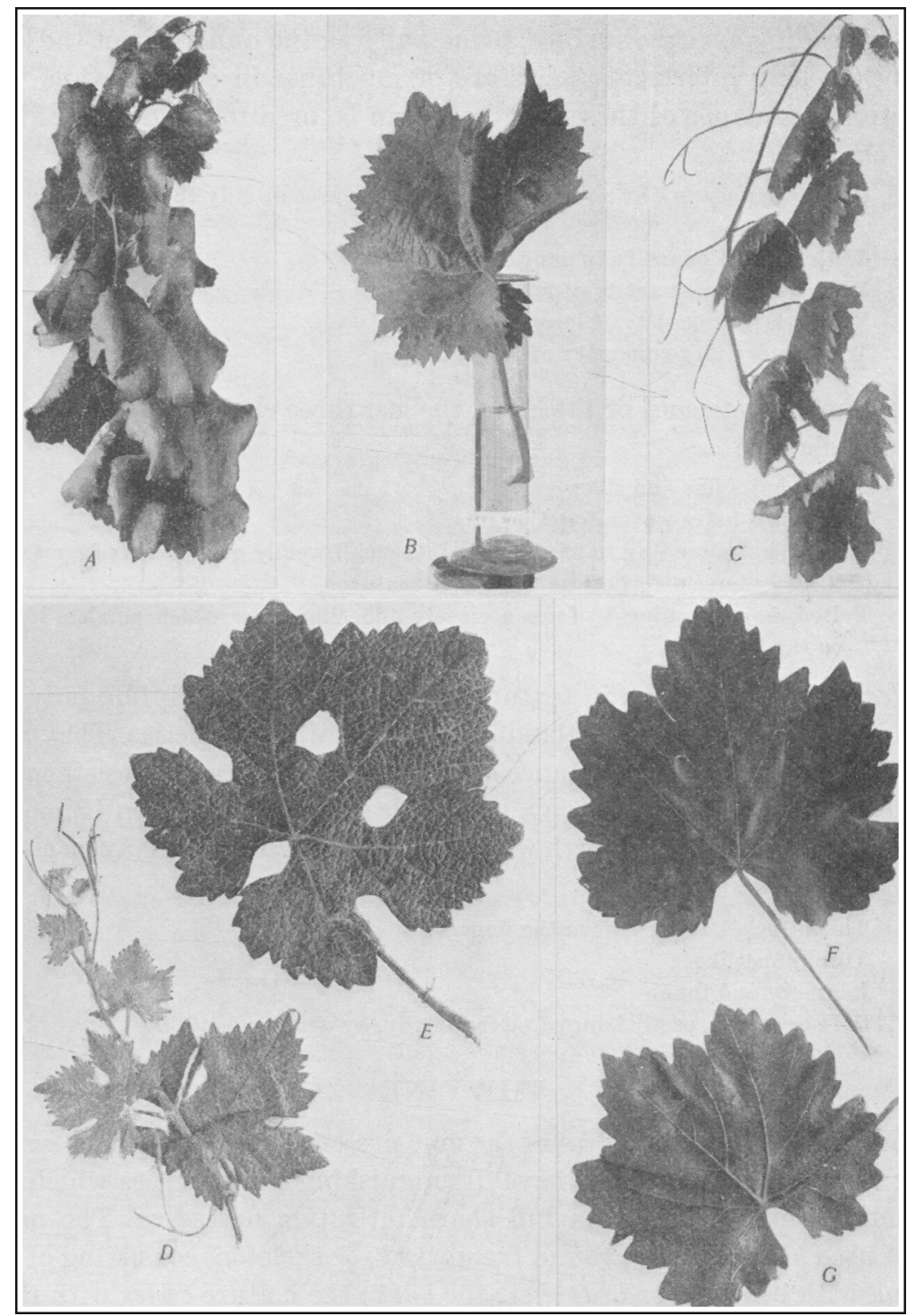

Fig. 24.-Contour, surface, texture, and indument of leaves $(\times 0.2): A$, convex, Alicante Bouschet; $B$, contorted, Gros Maroc; $C$, concave, Khalili ; $D, E$, surface rough, Meunier; $F$, upper surface smooth, Rish Baba; $G$, lower surface smooth, Rish Baba. 
pally near the angles of the veins; and long, interlacing hairs growing and spreading over the surface, principally on the underside of the leaf. Only the long interlacing hairs are of much use in classification. The relative abundance of these long hairs can be used to divide leaves into five classes:

Glabrous, very few or no hairs on expanded leaves or only the short upright hairs

With a small quantity of long hairs

With a medium quantity of long hairs

With a large quantity of long hairs

With a very large quantity of long hairs

On the arrangement of the hairs, the last three classes may be divided into subclasses :

Pilose, hairs fine and silky

Cobwebby, hairs woven together

Woolly, hairs tending to accumulate into small woolly groups or loose masses; these generally fall off as the leaves mature

Felted, hairs tending to form a closely adhering cover which persists longer on the leaves

Texture.-Variations in texture are of value in description only for special or extreme cases in classification of vinifera varieties. They may be of great practical importance on account of the greater resistance of some leaves to injury by strong, hot winds such as the Sirocco (Simoon) in North Africa and the north wind in California. Texture may be classified as follows :

Thick, feels bulky between the fingers

Thin, paperlike

Leathery and tough

Soft or brittle, easily injured mechanically, by wind or handling

\section{THE VINE}

Though the fruit and the leaf of the vine present the most useful descriptive characters, other parts have distinguishing peculiarities which are sometimes useful and for a full characterization necessary. The parts most used are the aboveground framework, or skeleton, consisting of the trunk with its arms, or branches; the bark; the mature canes with their buds; and the growing shoots and tips.

Size of Vine.-The size attained by a vine depends upon many factors besides that of variety-namely, age, environment, and the cultural methods to which it is subjected. To compare varieties in this respect, therefore, they must be subjected to identical and favorable conditions.

In this way it is possible to obtain ratios of size between vines, which 
can be used for the comparison of different varieties under other more or less favorable conditions. Comparisons of the relative sizes of vines pruned and trained in the same way can be most readily made from the circumference measurements of the trunk. Table 20 indicates the means and standard deviations obtained by dividing 97 varieties grown at Davis into three classes on the basis of circumference growth.

Although the figures of the table indicate a considerable difference in the rate of circumference increase for different groups of varieties, this measurement has value for purposes of distinguishing varieties only

TABLE 20

Mean Circumference Measurements of Slow-, Moderate-, AND FAST-GRowing VARIETIES AT Davis

(Figures for 97 varieties, ten- to eleven-year-old vines)

\begin{tabular}{|c|c|c|c|}
\hline Relative rate of growth & $\begin{array}{l}\text { Circum- } \\
\text { ference } \\
\text { class }\end{array}$ & $\begin{array}{l}\text { Mean } \\
\text { circum- } \\
\text { ference }\end{array}$ & $\begin{array}{l}\text { Standard } \\
\text { deviation }\end{array}$ \\
\hline Slow. . & $\begin{array}{l}c m \\
<18\end{array}$ & $\begin{array}{c}c m \\
16.08\end{array}$ & $\begin{array}{c}\mathrm{cm} \\
1.24\end{array}$ \\
\hline Moderate......... & $18-24.5$ & 20.98 & 1.80 \\
\hline 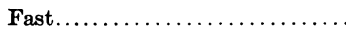 & $>24.5$ & 28.25 & 3.24 \\
\hline
\end{tabular}

under very limited conditions. Usually the slow- and fast-growing varieties can be separated on this basis, but a change in the soil, the rootstock, etc., could easily obscure differences in the rate of growth between slowand moderate- or moderate- and fast-growing varieties.

Bark.-The bark of vinifera vines is persistent. The new bark formed each year remains on the trunk for three, four, or more years, and forms an accumulation of annual layers. These layers finally become detached in the form of strings, ribbons, or patches of various lengths and widths. The appearance of these layers and the ways in which they become detached offer some distinctive characters useful in the determination of varieties.

With some varieties the accumulation of bark layers separates from the trunk in the form of long ribbons or straps (fig. 25, $B, D, E, F$ ). These ribbons are tough and fibrous and can be stripped off in pieces a foot or two long ; this leaves the clean, new, living bark of the last year exposed. Sometimes these ribbons are wide and remain whole with little or no splitting and resemble leather straps in texture, as in Burger, Madeleine Angevine, Furmint, Feher Szagos (fig. 25, $B, D$ ). Usually they split more or less, as in Panse de Roquevaire, Gros Colman, Rambola (fig. $25, E)$ or separate into narrow ribbons or coarse strings, as in Sultana, Sylvaner (fig. 25, $F$ ). 


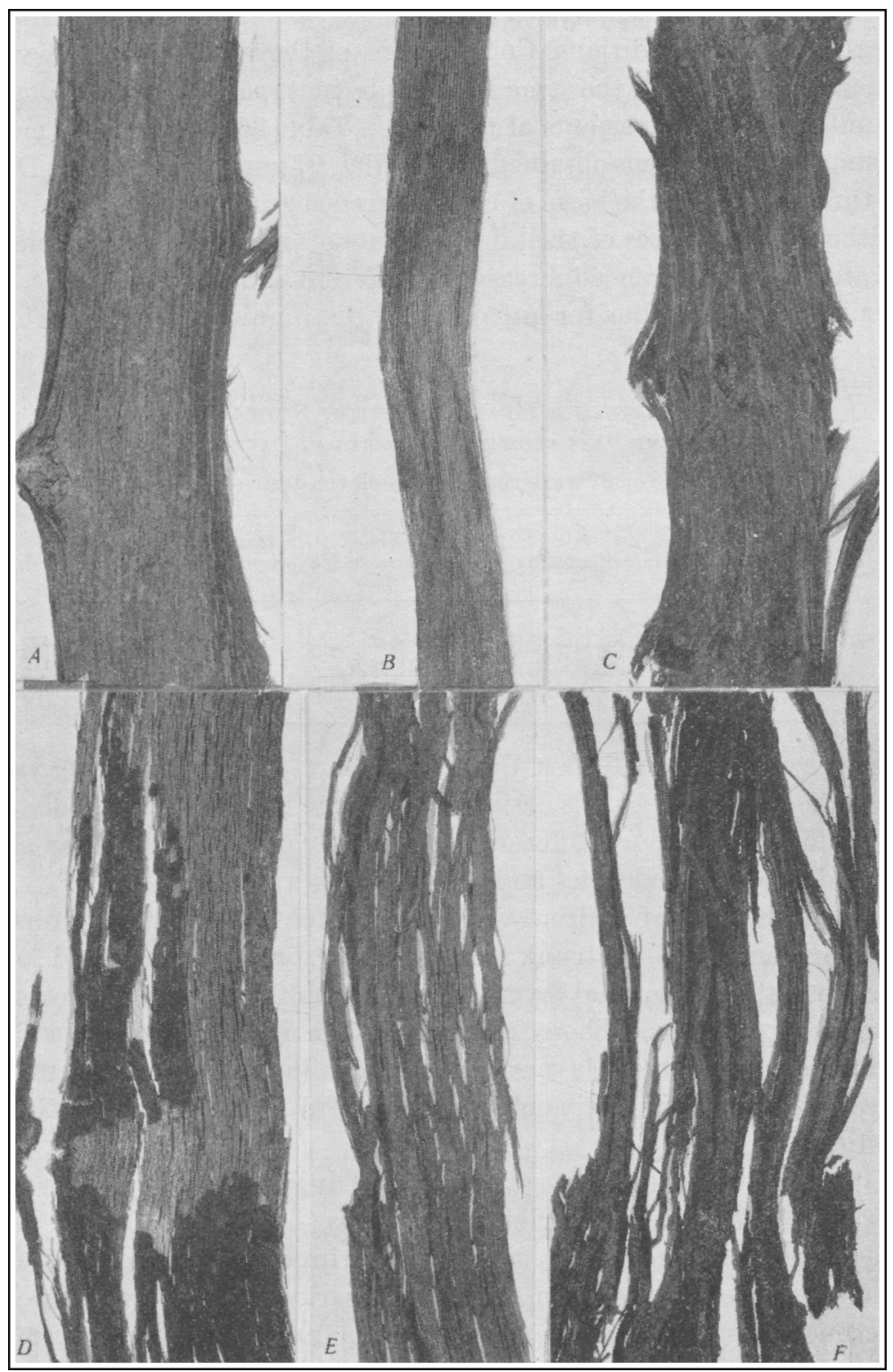

Fig. 25.-Types of bark: $A$, long, close, tough fibers; $B$, solid straps; $C$, short, brittle fibers; $D$, strap slightly fissured; $E$, strap much fissured; $F$, stringy. ( $A$ and $C$ on vine, others off.) 
With other varieties, the bark separates in short strings or patches which cannot be pulled off clean and to be removed must be scraped or rubbed with a steel glove or similar device (fig. 25, $C$ ). In rare cases the bark clings tight to the trunk for several or many years without splitting or cracking, as in Grosse blaue (fig. 25, $A$ ) ; and in others, more usual, it splits into solid ribbons before peeling off, as in Feher Szagos (fig. 25, $B$ ).

TABLE 21

Bark Characters: Percentage of Vines in the Various Classes

(Based on 140 varieties at Davis)

\begin{tabular}{|c|c|c|c|c|c|c|c|}
\hline \multicolumn{4}{|c|}{ Ribbons } & \multirow{2}{*}{\multicolumn{2}{|c|}{ Texture }} & \multirow{2}{*}{\multicolumn{2}{|c|}{ Color of underbark }} \\
\hline \multicolumn{2}{|c|}{ Length } & \multicolumn{2}{|c|}{ Width } & & & & \\
\hline Class & Per cent & Class & Per cent & Class & Per cent & Class & Per cent \\
\hline Very short & 1.5 & Very narrow & 0 & Very fine & 0 & Very light & 0 \\
\hline Short & 21.0 & Narrow & 20 & Fine & 21 & Light & 21 \\
\hline Medium & 20.0 & Medium & 37 & Medium & 34 & Medium & 60 \\
\hline Long & 56.0 & Wide & 40 & Coarse & 39 & Dark & 18 \\
\hline Very long & 1.5 & Very wide & 3 & Very coarse & 6 & Very dark & 1 \\
\hline
\end{tabular}

The principal characters of the bark of the trunk to be noticed are:

Texture: tough, brittle; fine, coarse

Ribbons: long, short; wide, narrow; entire or more or less fissured

Color of underbark : light, medium, dark, dun-brown, tinted

The color of the new bark when exposed by the removal of the accumulation of old barks varies with the variety, from a light grayish brown to a dark chocolate-brown. The brown is sometimes tinged with a shade of pink. After exposure the bark darkens, becoming mahogany-colored and sometimes nearly black (Muscat Blowers).

The distribution of the vines among the various grades of the bark characters is indicated by table 21, made up from observations on 140 varieties of Vitis vinifera at Davis.

\section{CANES AND BUDS}

The annual growth of the vine starts from a bud. The bud is usually one which was formed during the previous season, that is, it is situated on what is known as one-year-old wood. In some cases, especially with vigorous vines, it may be one situated on wood two years old or older, where it has remained dormant for one or more years. In the first case most of the buds are usually "fruitful," that is, they contain well-formed 
rudimentary flower clusters. In the other cases the flower clusters are usually present in restricted numbers or lacking. An example of the latter condition is to be found in the Sultanina.

Cane characters which distinguish varieties are those of color, size,

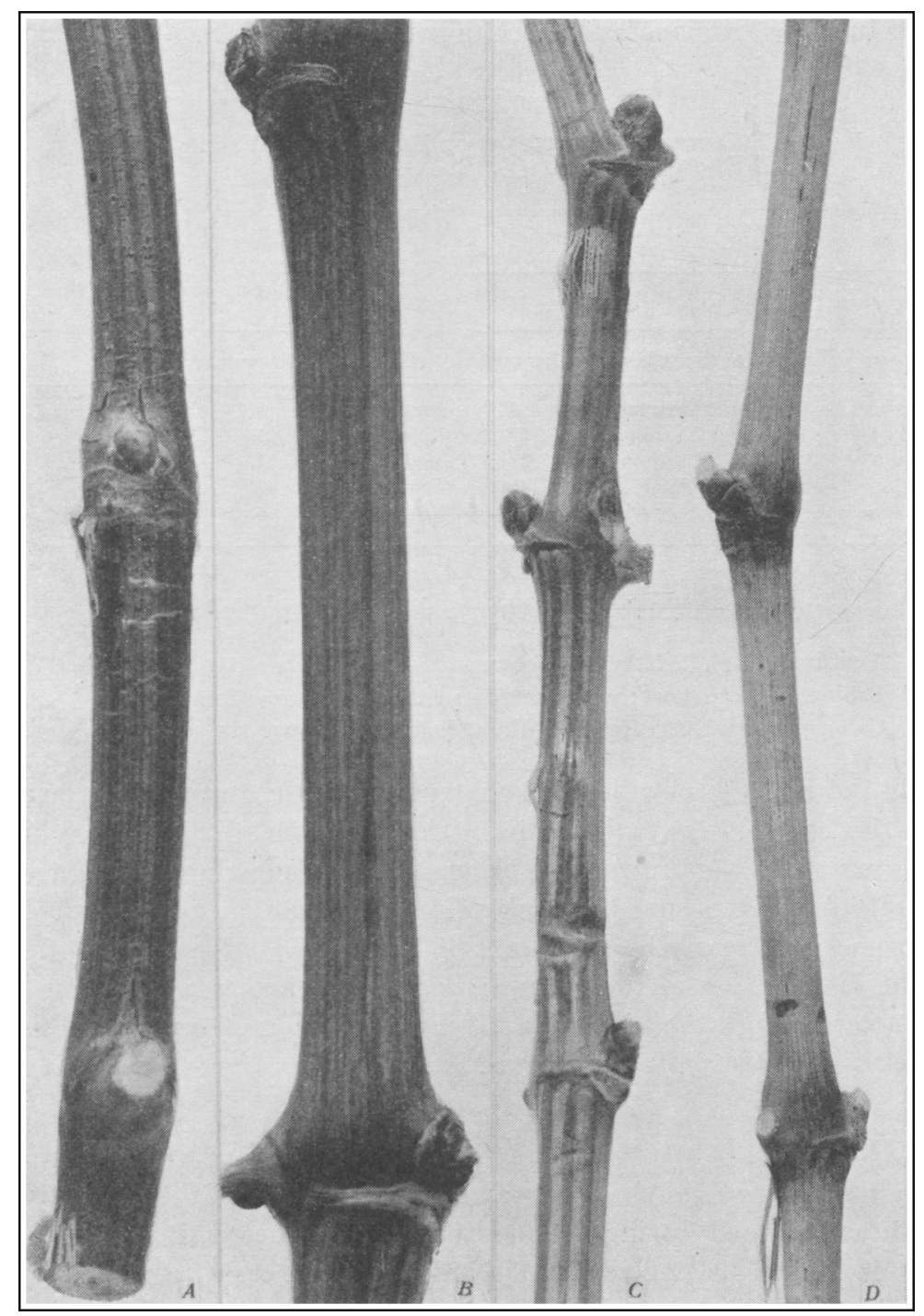

Fig. 26.-Coloration of vine canes: $A$, dark brown, no collar; $B$, medium brown, marked collar ; $C$, straw, faint collar; $D$, lilac, marked collar. 
form, and direction. The color is perhaps the most specific because the size and form are greatly influenced by nutrition, climate, and cultural operations.

Color of the Cane.-The color of the cane varies from dark brown to

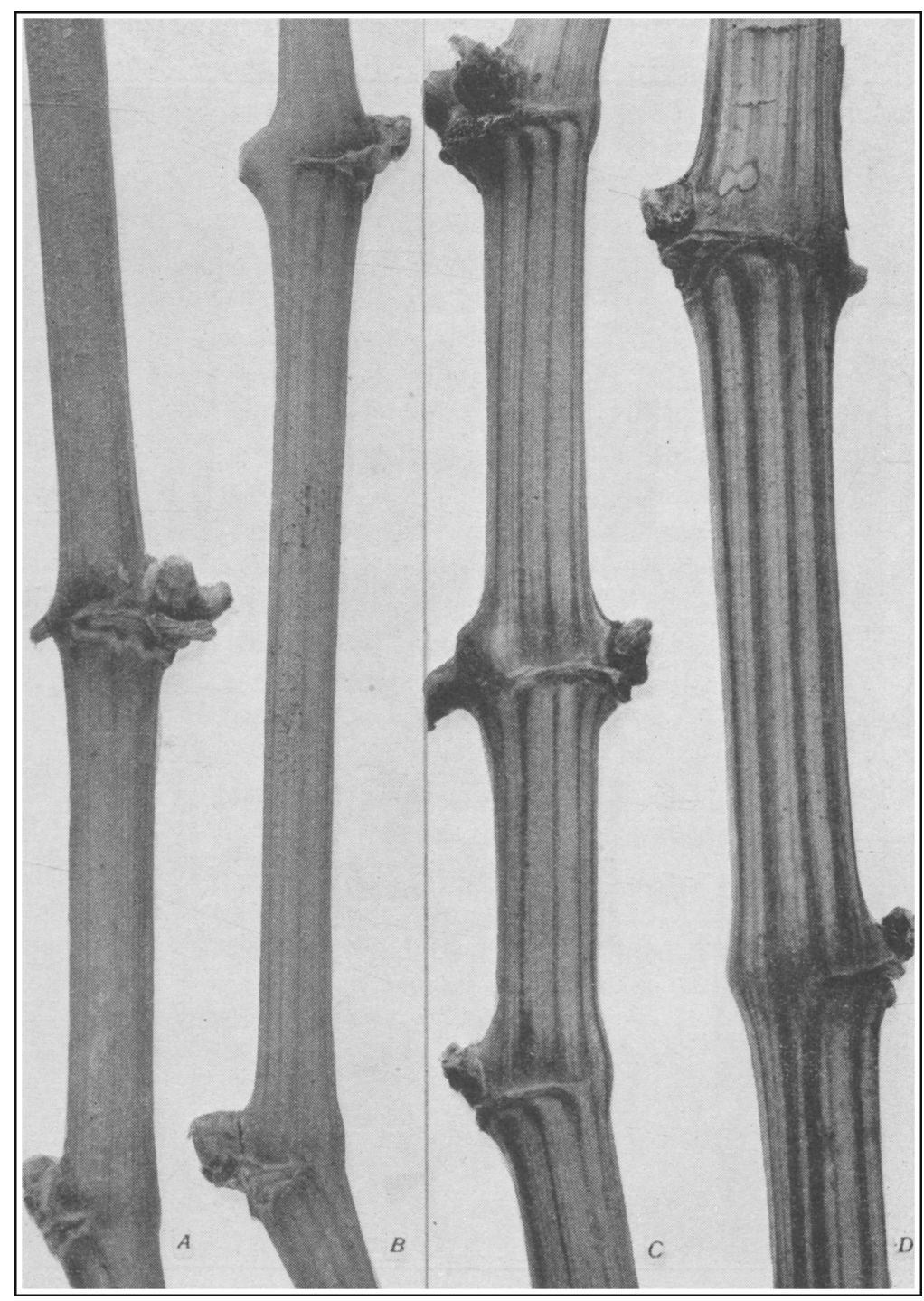

Fig. 27.-Striations on vine canes: $A$, none; $B$, faint; $C$, marked but narrow ; $D$, marked and broad. 
a light straw or grayish lilac. This applies to the ground color, which is the tint given to the bare canes when viewed from a distance. This color is very typical with a pure stand of a variety. It may be rendered less distinct by dark blotches left by oidium (fig. $28, A$ ) or by saprophytic fungi which discolor the canes in warm, moist weather. Some hint of the variation of this color is given by figure 26 , even though this is only a

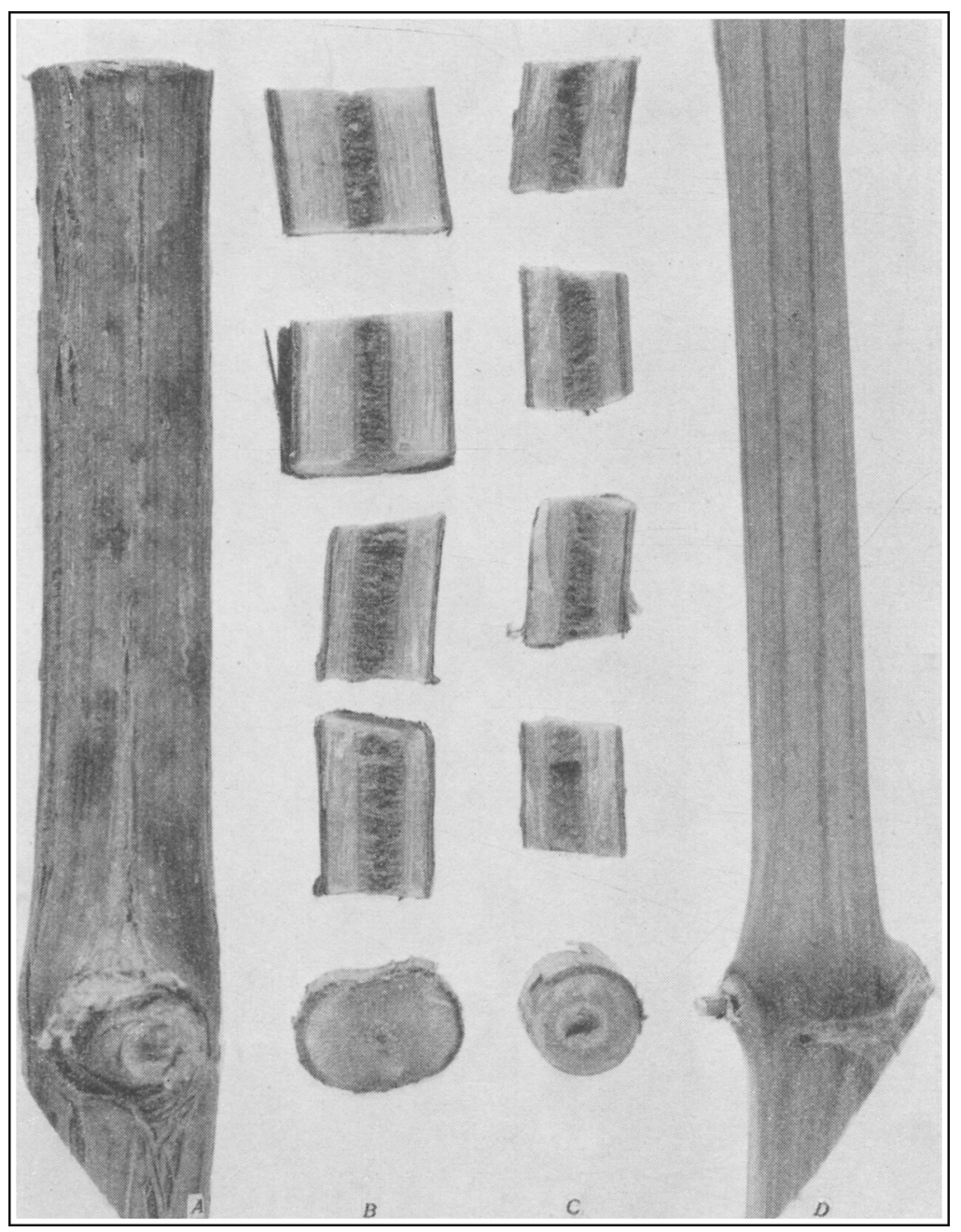

Fig. 28.-Flattening of very vigorous canes: $A, B$, very vigorous cane, flattened, diameter $2.0 \times 1.3$ centimeters; $C, D$, vigorous cane, round, diameter $1.2 \times 1.2$ centimeters. 
black and white photograph. The ground color is that which is shown by the larger part of the internode.

Nearly all canes have striations of a darker color, which when wide and numerous modify the ground color. Examples of these striations are shown in figure 27, varying from almost absent $(A)$ to a very marked and wide $(D)$.

The canes of most varieties have also a collar, or ring, at the node which is darker than the rest of the cane-more or less marked in some cases and barely visible in others. Examples are shown in figures 26 and 27.

Size of Cane.-The length and thickness of a cane will vary not only with the variety but also with more or less favorable growing conditions. Under like conditions, however, there is a very distinct difference due to the innate vigor or capacity for growth of the variety. The range in thickness due to variety is indicated in figures 26,27 , and 28 , and varies with healthy, normal vines from $1 / 4$ inch to $3 / 4$ inch at the middle of an internode taken from a little below the middle of the cane.

The length of the cane varies to a similar extent with variety from 3 or 4 feet to 15 feet or more under average conditions. The length of the cane depends, of course, on the number and length of the internodes. Measurements were made of the lower 5 to 10 internodes on typical canes of 310 varieties in the Davis collection in 1932. The longest internodes were, in virtually all cases, the fourth, fifth, sixth, and seventh; and the mean length of these four may be taken as representing a measure of the relative capacity for growth in length of the variety. The range of length of a fully developed internode may be taken as from 6 to 11 inches with a mean of 8.1 under the conditions of the Davis collection in 1932.

Form of the Cane.-The cross section of a vine cane is usually slightly elliptical but may range from nearly circular to a slightly flattened ellipse nearly twice as long as wide; see figure 28. The shorter diameter passes through the side on which the bud is situated. The extreme flattening of the cane is found on excessively vigorous and rapidly growing vines, usually near the middle of prostrate and sterile canes. 
